\title{
NUEVAS ESPECIES DE SIDA, SECCIÓN SIDA (MALVACEAE)
}

\author{
ANTONIO KRAPOVICKAS
}

\begin{abstract}
Summary: Krapovickas, A. 2014. New species of Sida, section Sida (Malvaceae). Bonplandia 23(2): 65-118.

The new species Sida ignaciana, S. Kelleri, S. Ioretana, S. palustris, S. ramoniana from Argentina; S. albinervia, S. carandana, S. cruziana, from Bolivia; S. abadiana, S. adrianopolitana, S. arcuata, S. bortolanensis, S. farroupilhensis, S. Heringeri, S. Kranzii, S. magnifolia, S. piraporana, S. Santosii, S. silvaniana from Brasil; S. tapiraguensis from Paraguay, and S. ambatense from NW Argentina and Bolivia, and S. Saraviae from NW Argentina to Peru are described.
\end{abstract}

Key words: Malvaceae, Sida, taxonomy.

Resumen: Krapovickas, A. 2014. Nuevas especies de Sida, sección Sida (Malvaceae). Bonplandia 23(2): 65-118.

Se describen las especies nuevas Sida ignaciana, S. Kelleri, S. loretana, S. palustris, S. ramoniana de Argentina; S. albinervia, S. carandana, S. cruziana de Bolivia; S. abadiana, S. adrianopolitana, S. arcuata, S. bortolanensis, S. farroupilhensis, S. Heringeri, S. Kranzii, S. magnifolia, S. piraporana, S. Santosii, S. silvaniana de Brasil; S. tapiraguensis de Paraguay; $S$. ambatense del NW de Argentina y Bolivia, y S. Saraviae del NW de Argentina hasta Perú.

Palabras clave: Malváceas, Sida, taxonomía.

\section{Introducción}

Recientemente (Krapovickas, 2007) se publicaron novedades sobre la sección Sida, con la intención de resolver la situación de algunas especies de la costa atlántica de Brasil. Ahora, al recibir una colección realizada por Héctor Keller en la provincia de Misiones, Argentina, especialmente en antiguos campos en el interior de la selva misionera y en pantanos, lugares poco visitados, se propuso estudiar todo el material indeterminado de nuestro herbario, cuyo análisis se había postergado a la espera de más ejemplares, pues de muchos de ellos disponía de uno solo.

\section{Sida L.}

Sida L., Sp. pl. 2; 683. 1753; Gen. pl. ed. V: 306. 1754.

Especie tipo: Sida alnifolia L., fue designada por Britton \& Brown (1913). Sin embargo, según el artículo 10.5, Ex. 7 del Código de Viena, esta es una elección del tipo según el Código Americano y debe ser reemplazada por la elección de Green (Prop. Brit. Bot.: 172. 1929) de Sida rhombifolia L. (Jarvis, 2007).

El género Sida ha sido dividido en varias secciones y grupos. Una detallada historia de la compleja nomenclatura de Sida L. fue realizada por Clement (1957).

\footnotetext{
${ }^{1}$ Instituto de Botánica del Nordeste IBONE (CONICET-UNNE, Facultad de Ciencias Agrarias), Sgto. Cabral 2131,
} C.C. 209 , (3400) Corrientes, Argentina. 
Schumann (1891) fue el primero en presentar un cuadro general al dividir al género Sida en siete secciones: Pseudomalachra K. Schum. (= sect. Malachroideae G. Don); Bastardiopsis K. Schum. [= gen. Bastardiopsis (K. Schum.) Hass1.]; Physalodes Griseb. (= genera Krapovickasia Fryxell y Rhynchosida Fryxell); Steninda Griseb.; Thirsinda K. Schum. (= gen. Sidastrum E. G. Baker); Malvinda Griseb. (= sect. Sida) y Pseudomalvastrum K. Schum. (= gen. Malvella Jaub. \& Spach).

Este sistema de Schumann fue seguido por Baker (1892), Rodrigo (1944), Kearney (1954, 1958) y Hutchinson (1967).

Baker (1892) acepta seis secciones:

I. Pseudomalvastrum A. Gray (= Malvella Jaub. \& Spach.),

II. Abutilastrum A. Gray (= Robinsonella Rose \& E. G. Baker),

III. Calyxhymenia A. Gray (= Krapovickasia Fryxell \& Rhynchosida Fryxell),

IV. Steninda Griseb.,

V. Pseudomalachra K. Schum. (= sect. Malachroideae G. Don),

VI. Malvinda Griseb. (=sect. Sida).

Monteiro (1936) acepta las secciones de Schumann (1891) y divide la sect. Malvinda en 11 grupos ( $\sin$ status taxonómico por falta de descripción latina): Oligandrae, Acutae (= sect. Disticophylla), Urentae (= sect. Nelavaga), Spinosae, Viarumae (= serie Viarumae), Glutinosae (= sect. Nelavaga), Decumbentae (= sect. Nelavaga), Serratae (= sect. Nelavaga), Subcuneatae, Cordifolia (= sect. Cordifoliae) y Rhombifoliae (= sect. Sida).

Monteiro (1942) acepta para Rio Grande do Sul las secciones Pseudomalvastrum, Pseudomalachra, Physalodes, Steninda, Thyrsinda, Malvinda y en ésta los grupos: Acutae, Spinosae, Urentae, Viarumae, Glutinosae, Decumbentae, Serratae, Cordifoliae y Rhombifoliae.

Monteiro (1949) divide la sect. Malvinda (= sect. Sida) en 4 subsecciones: I Oligandrae, II Distichaefolia, III Pentacocca y IV Polycocca, sin diagnosis latina. A la subsect.
Polycocca a su vez la divide en 7 grupos: 1 Subcuneatae, 2 Cordifoliae, 3 Angustissimae, 4 Acuminitae, 5 Potentilloides, 6 Rubifoliae y 7 Rhombifoliae, todos sin status taxonómico, por falta de descripción latina.

Fryxell (1985), al tratar las especies de Sida de Norte y Centro América, divide al género Sida en 11 secciones: Steninda Griseb., Oligandrae Clement, PseudoNapaeae A. Gray, Hookerianae Clement, Nelavaga Borss.Waalk. Spinosae Small, Muticae Presl, Cordifoliae (DC) Fryxell, Sida, Malachroideae G. Don y Ellipticifoliae Fryxell.

Numerosas especies fueron segregadas a otros géneros: Allosidastrum (Hochr.) Krapov., Fryxell \& Bates, Bastardiopsis (K. Schum.) Hassl., Billieturnera Fryxell, Dendrosida Fryxell, Krapovickasia Fryxell, Malvella Jaub. \& Spach, Meximalva Fryxell, Rhynchosida Fryxell y Sidastrum E. G. Baker. La separación de dichas especies ha dejado al género Sida menos heterogéneo, más natural y mejor caracterizado (Fryxell, 1985)

La sección Sida ha sido motivo de interpretaciones diversas, pero se considera apropiado el concepto de Fryxell (1985) al definir a Sida rhombifolia, es el más adecuado y merece ser seguido (Fuertes, 1995; Sivarajian \& Pradep, 1994).

La sección Sida se caracteriza por sus hojas cortamente pecioladas, romboideas, de base cuneada, por lo común trinervadas, con el margen entero hacia la base y hacia el ápice crenado-aserrado y el cáliz con 10 costillas prominentes, amarillentas en la base y con lóbulos plegados.

En la sección Sida se distinguen aquí 3 grupos que se diferencian por medio de la siguiente clave.

\section{Carpelos más de 6 (raro 5-7 en S. acrantha).}

2. Mericarpos múticos o con dos aristas simples. Serie Sida, pag. 79

$2^{\prime}$. Mericarpos con dos aristas bifurcadas. ..Serie Bifurcata, pag. 67

1'. Carpelos 5. Serie Viarumae, pag. 112 
Distribución geográfica de las especies de Sida, sect. Sida: Cosmopolita, S. rhombifolia; Colombia hasta Perú y Paraguay, S. setosa; Colombia hasta N de Bolivia, S. Poeppigiana; Perú hasta NW Argentina, S. Saraviae. Brasil, BA, S. abadiana, S. linearifolia, S. Santosii; BA a SP, S. acrantha; GO, S. silvaniana; GO, DF, $S$. magnifolia; MG, S. arcuata, S. bortolanensis, S. Heringeri, S. Leitaofilhoi, S. linearifolia, S. piraporana; MG a PR, AR (Misiones), $S$. Honoriana; MG a SC, S. lonchitis; MG, SP, RJ, BA, S. acrantha; PR, S. adrianopolitana, S. Kranzii; RS, S. farroupilhensis. Bolivia, La Paz a Tarija, S. Saraviae; Cochabamba, $S$. albinervia, S. Beckii; Sta. Cruz, S. carandana, S. cruziana, S. linearifolia. Paraguay, S. Glaziovii, S. Kelleri, S. linearifolia, S. rhombifolia, S. santaremensis, S. setosa, $S$. tapiraguensis, S.tuberculata var. pseudo- rhombifolia, S. viarum. Argentina, NW, S. ambatense, S. Saraviae; NE, S. ignaciana, $S$. Honoriana, S. Kelleri, S. loretana, S. palustris, S. ramoniana, $S$. tuberculata var. pseudorhombifolia, S. viarum; N, S. santaremensis; Centro y norte, $S$. rhombifolia.

\section{Series Bifurcata Krapov., ser. nov.}

Carpidia (5) 6-8, submutica, aristae bifurcatae.

Especie tipo: Sida piraporana Krapov.

Mericarpos (5) 6-8, submúticos, con dos aristas bifurcadas.

Las especies de la serie Bifurcata se pueden distinguir por medio de la siguiente clave.

\section{Clave para la identificación de las especies de la Serie Bifurcata}

1. Epifilo con pelos simples presentes. Hoja 2-4 cm long.

2. Ramas arqueadas. Flores en cabezuelas terminales. Estípulas con pelos simples en el margen. Uña de los pétalos pilosa. Tubo estaminal con pelos simples. Mericarpos 6. BR: MG. ... 2. S. arcuata Krapov.

2'. Ramas rectas.

3. Flores en glomérulos apicales. Hojas arqueadas. Mericarpos 5. BR: RO.

3. S. blepharoprion Ulbr.

3'. Flores solitarias a lo largo de las ramas. Hojas rectas. Estípulas con pelos estrellados.

4. Tubo estaminal con pelos glandulares. Planta erecta. Pedicelo 10-20 mm long. Uña de los pétalos pilosa. Mericarpos 9, con pelos en las aristas. BR: BA. ............. 1. S. abadiana Krapov.

4'. Tubo estaminal glabro. Ramas procumbentes. Pedicelo 5-10 mm long. Uña de los pétalos glabra. Mericarpos 9, glabros. PA: San Pedro.

8. S. tapiraguensis Krapov.

1'. Epifilo con pelos estrellados. Tubo estaminal glabro.

5. Flores solitarias o de a 2, pedicelo $5 \mathrm{~mm}$. Pétalos con la uña pilosa. Estípulas con pelos estrellados. Hoja hasta $4 \mathrm{~cm}$ long. Mericarpos 8. BR: MG. 6. S. piraporana Krapov.

5 '. Flores en glomérulos, pedicelos breves. Pétalos con la uña glabra. Estípulas con pelos simples en el margen. Hoja con pelos estrellados uniformes en ambas caras.

6. Estípulas con pelos estrellados en el haz. Flores en glomérulos apicales en ramitas axilares. Lóbulos del cáliz con pelos estrellados en el margen. Mericarpos 9, con pelos en el ápice. Hoja hasta $4 \mathrm{~cm}$ long. BR: BA. 7. S. Santosii Krapov.

6'. Estípulas con las caras glabras. Lóbulos del cáliz con pelos simples en el margen.

7. Pecíolo con un pequeño diente en la base. Hojas hasta $3 \mathrm{~cm}$ long. Flores axilares, solitarias y en glomérulos apicales. Mericarpos 7, glabros. BR: MG. 4. S. bortolanensis Krapov.

7'. Pecíolo con la base lisa. Hojas hasta $7 \mathrm{~cm}$ long. Flores en glomérulos axilares. Mericarpos 7, con pelos simples breves en el ápice. Bolivia. 5. S. cruziana Krapov. 


\section{Sida abadiana Krapov., sp. nov.} Fig. 1

Suffrutex $0,70 \mathrm{~m}$ altis, caulis laterales rectis. Foliis breviter petiolatis. Lamina rhomboidea, serrata, basin versus integra, supra pilis simplicibus. Floribus solitarii. Pedicellus 10$20 \mathrm{~mm}$ longus. Calyx $6 \mathrm{~mm}$ longus. Corolla cremea. Carpidiis 9, reticulatis, aristae breviae, bifurcatae.

Typus: Brasil. Bahia: Mun. Jandaíra, Rodovia

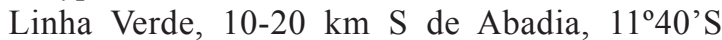
$37^{\circ} 30^{\prime} \mathrm{W}$, sublenhosa, $70 \mathrm{~cm}$, flor creme, orla da mata, 19-VIII-1995, G. Hatschbach, M. Hatschbach \& J. T. Motta 63162 (holotypus MBM, isotypus CTES).

Arbusto $70 \mathrm{~cm}$ alt., ramas rectas. Tallo cubierto de pelos estrellados. Estípulas filiformes, $6 \mathrm{~mm}$ long. Hojas subsésiles, pecíolo breve, lámina romboidea, $3 \mathrm{~cm}$ long. $\times 1 \mathrm{~cm}$ lat., trinervada, margen entero en el tercio basal y el resto levemente crenadoaserrado, haz con pelos simples, adpresos, envés con pelos estrellados. Flores solitarias, axilares, a lo largo de las ramas. Pedicelo 10$20 \mathrm{~mm}$ long. Cáliz $6 \mathrm{~mm}$ long., con 10 nervios sobresalientes en la base y lóbulos apiculados, cubierto de pelos estrellados y con pelos simples en el margen de los lóbulos. Corola color crema. Pétalos $8 \mathrm{~mm}$ long., con pelos en la uña. Tubo estaminal $4 \mathrm{~mm}$ long., con pelos glandulares. Mericarpos 9, 2,5 mm long. $\times 1,5$ $\mathrm{mm}$ lat., caras laterales y dorso reticulados, con dos aristas muy breves, bifurcadas, con pelos simples en el ápice. Semilla glabra, con pocos pelos en el hilo.

Distribución geográfica: Conocida sólo de la localidad tipo.

Obs.: Sida abadiana se distingue por su porte erecto, flores solitarias, tubo estaminal con pelos glandulares y por sus hojas con pelos simples en el epifilo.

Etimología: El nombre deriva de la localidad tipo Abadia, en el estado de Bahia, Brasil.

\section{Sida arcuata Krapov., sp.nov.}

Fig. 2

Suffrutex erectus, caulis lateralis arcuatis, $40 \mathrm{~cm}$ longis. Caulibus stellato tomentosis. Foliis breviter petiolatis. Lamina rhomboidea, serrata, basin versus integerrima, supra pilis simplicibus. Floribus ad apicem caulibus. Calyce $5 \mathrm{~mm}$ longis, plicatis, nervis 10 basi nodulosoincrassatis, utrinque pilis stellatis, margine ciliate. Tubo stamineo piloso. Carpidiis 6, aristae breviae, bifurcatae.

Typus: Brasil. Minas Gerais: $25 \mathrm{~km} \mathrm{~W}$ de BR 153, camino de Frutal a Itapagipe, MG 255 - km 35, 3-I-1989, A. Krapovickas \& C.L.Cristóbal 42752 [sub Sida viarum] (holotypus HAS, isotypi: CTES, NY).

Subarbusto erecto con ramas arqueadas ca. $40 \mathrm{~cm}$ long. Tallo con una capa densa de pelos estrellados. Estípulas filiformes, $6 \mathrm{~mm}$ long. Pecíolo $5 \mathrm{~mm}$ long., piloso. Lámina romboidea, $2 \mathrm{~cm}$ long. $\times 1 \mathrm{~cm}$ lat., trinervada, base cuneada, ápice subobtuso, margen dentado en los dos tercios superiores, entero en el tercio inferior, haz con pelos simples adpresos, esparcidos y pocos pelos estrellados muy pequeños, envés con pelos pelos estrellados blanquecinos, densos. Flores en cabezuelas hojosas apicales. Pedicelos 8-12 mm long., estrellado-pilosos. Cáliz $5 \mathrm{~mm}$ long., con 10 costillas en la base, cubierto de pelos estrellados medianos, lóbulos $2 \mathrm{~mm}$ long. $\times 2 \mathrm{~mm}$ lat., plegados, con pelos simples $1 \mathrm{~mm}$ long. en el margen. Pétalos con la uña pilosa. Tubo estaminal 2 mm long., con pelos simples. Mericarpos 6, submúticos, $2 \mathrm{~mm}$ long. $\times 1,5 \mathrm{~mm}$ lat., dorso y caras reticulados, dehiscentes en el ápice, aristas breves, dobles, con pelos simples, pequeños en el ápice. Semillas glabras, con pocos pelos en el hilo.

Distribución geográfica: Vive en el sur de Minas Gerais, no lejos del río Grande, en el límite con São Paulo.

Obs.: Duplicados del ejemplar tipo fueron distribuidos como Sida viarum A. St.-Hil., 

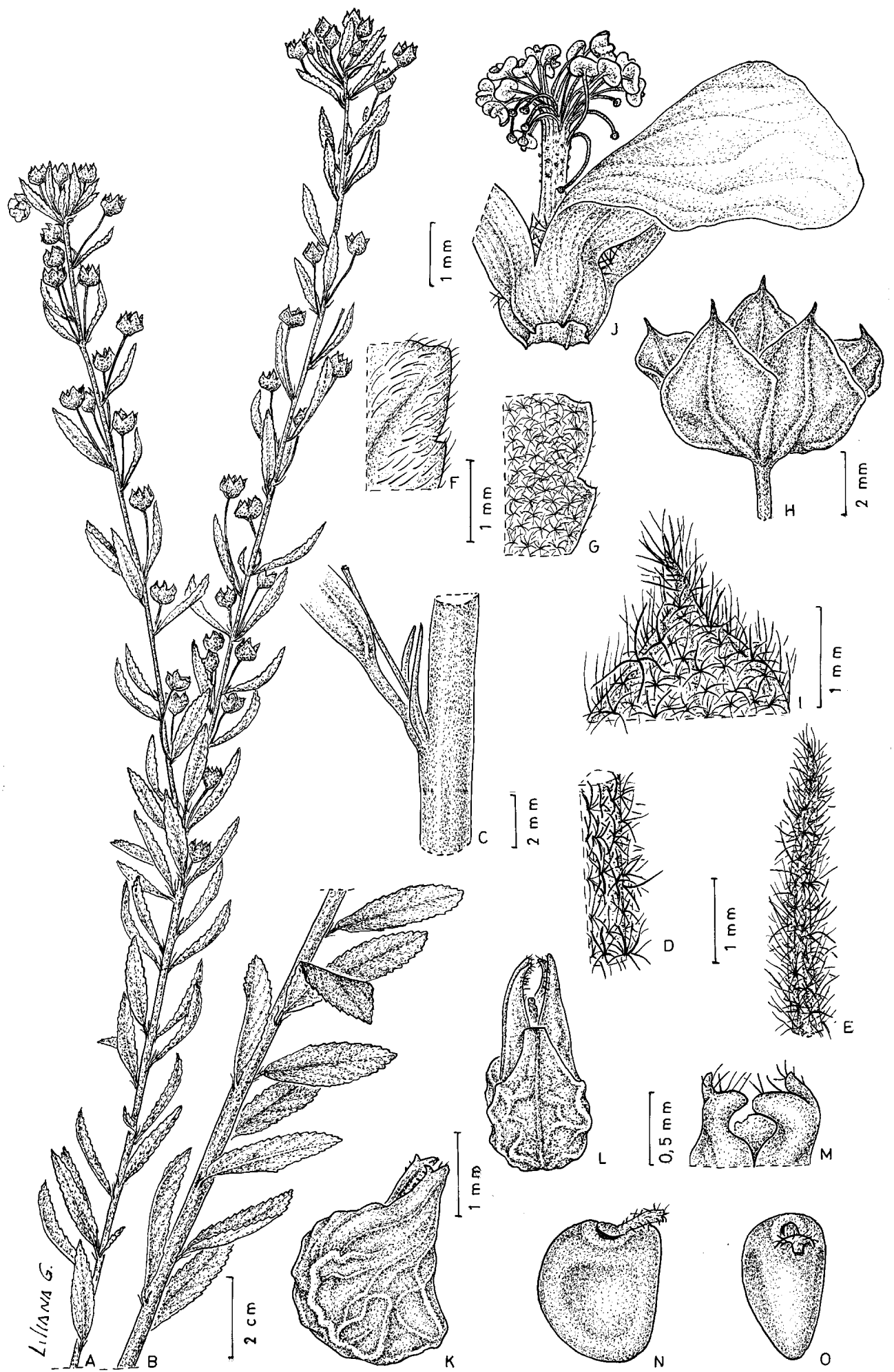

Fig. 1. Sida abadiana. A y B: Rama. C: Estípulas. D: Indumento del tallo. E: Indumento de la estípula. F: Indumento del epifilo. G: Indumento del hipofilo. H: Cáliz. I: Indumento del cáliz. J. Pétalo y tubo estaminal. K. Mericarpo, vista lateral. L: Mericarpo, vista dorsal. M: Ápice de mericarpo. N-O: Semillas (Hatschbach 63162). 


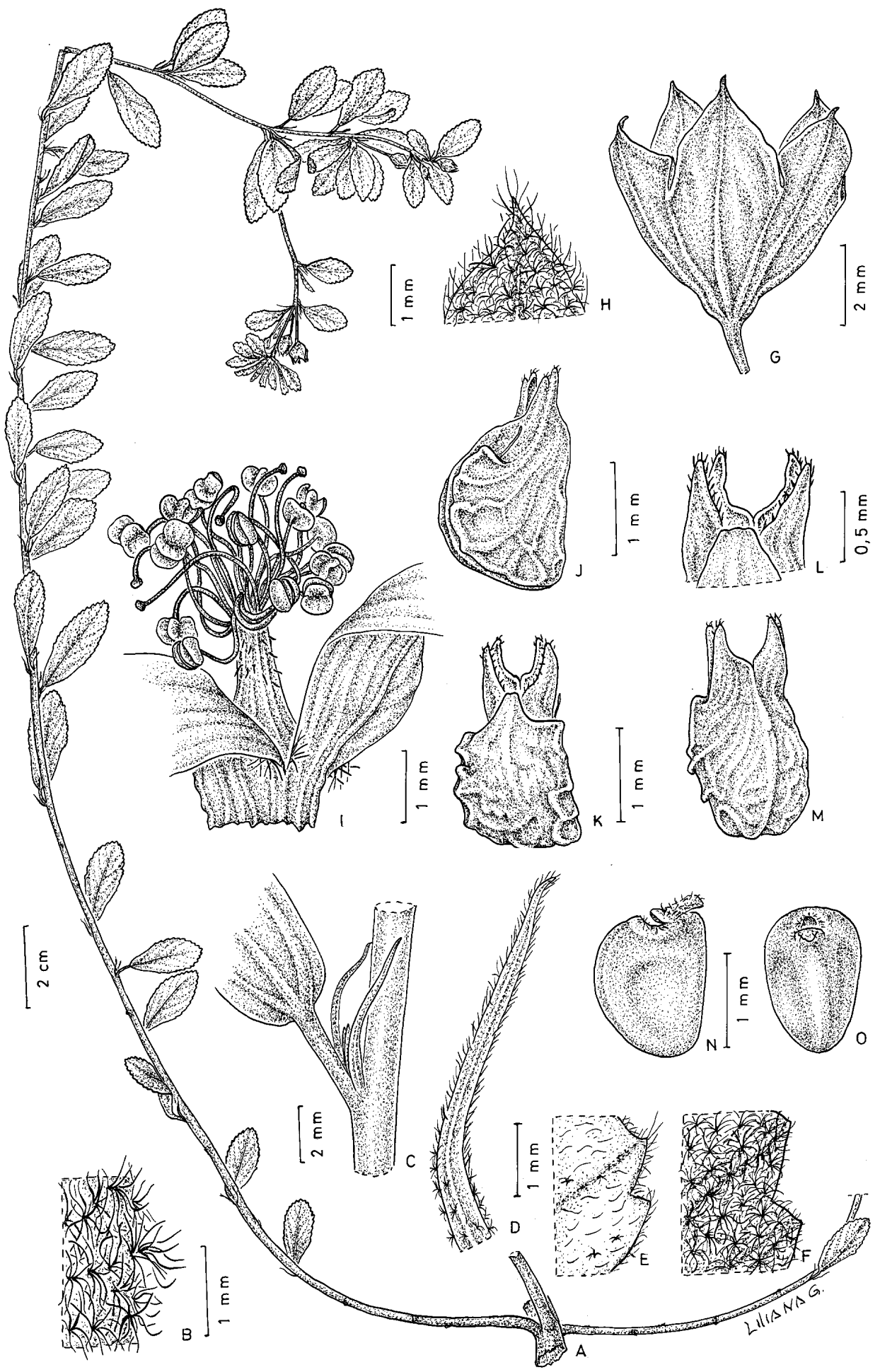

Fig. 2. Sida arcuata. A: Rama. B: Indumento del tallo. C: Estípulas. D: Indumento de la estípula. E: Indumento del epifilo. F: Indumento del hipofilo. G: Cáliz. H: Indumento del cáliz. I: Tubo estaminal. J: Mericarpo vista lateral. K: Mericarpo vista dorsal. L: Ápice de mericarpo. M: Mericarpo vista ventral. N-O: Semillas (Krapovickas \& Cristóbal 42752). 
especie decumbente con ramas más o menos rectas, con 5 carpelos y con pelos simples en el epifilo. Sida arcuata se diferencia por su porte erecto con ramas arqueadas, y por tener 6 carpelos, un número bajo en la sección Sida, y por sus flores en cabezuelas terminales.

Etimología: El nombre deriva de las ramas arqueadas, que caracterizan a esta especie.

\section{Sida blepharoprion Ulbr.}

Ulbrich, Not. Bot. Gart. Berl. 6: 321. 1915. Typus: Brasil. Rio Branco: [actual Roraima], [rio] Surumu, IX-1909, Ule 8223 (holotypus $\mathrm{B} \dagger$, foto F 9372!, lectoholotypus MG! (aquí designado), isotypus $\mathrm{K}$ !).

Monteiro (1936: 26) la considera especie de posición incierta porque no encuentra información precisa para ubicarla en alguna de sus secciones.

Ulbrich la compara con Sida linifolia Cav., pero esta especie tiene hojas con los márgenes lisos. En cambio, en S. blepharoprion, las hojas tienen el margen liso en el tercio inferior y dentado en los 2/3 superiores, carácter que la ubica en la sección Sida.

En el ejemplar de Kew conté 5 mericarpos en un fruto y Ulbrich dice "styli quinque", por ello podría estar en la serie Viarum. Pero como en $S$. acrantha los frutos pueden tener 5 ó 6 mericarpos prefiero ubicarla por ahora en la serie Biapiculata por sus mericarpos con aristas bifurcadas.

Etimología: Del griego blepharis = pestaña y prion $=$ sierra, por el aspecto general de la planta, que con sus hojas oval-lanceoladas arqueadas simulan una sierra.

\section{Sida bortolanensis Krapov., sp.nov.} Fig. 3

Suffrutex erectus. Caulibus stellato tomentosis. Petiolis prope insertionem dorso tuberculo armatis. Folia anguste-rhomboidea, $3 \mathrm{~cm}$ longa, utrinque stellato-pilosa. Floribus solitarii. Petala glabra. Tubo stamineo glabro. Carpidia
7, reticulata, glabra, aristae breviae, bifurcatae.

Typus: Brasil. Minas Gerais: Mun. Poços de Caldas, Reprêsa Bortolan, $8 \mathrm{~km} \mathrm{~W}$ de Poços de Caldas, borde de terraplén, 19-I-1980, $A$. Krapovickas \& C. L.Cristóbal 35364 (holotypus CTES, isotypi $\mathrm{K}, \mathrm{MBM})$.

Subarbusto erecto. Tallo cubierto de pelos estrellados uniformes. Estípulas $6 \mathrm{~mm}$ long., linear-lanceoladas, caras glabras, margen con pelos simples breves. Pecíolo 2-5 mm long., con un pequeño tubérculo en la base. Lámina angusti-romboidea, $2-3 \mathrm{~cm}$ long. $\times$ $0,5 \mathrm{~cm}$ lat., ápice agudo, margen levemente aserrado en los $2 / 3$ superiores, entero hacia la base, haz con pelos estrellados pequeños, esparcidos, envés con pelos estrellados densos. Flores axilares solitarias y en glomérulos apicales. Pedicelo 5-20 mm long., articulado cerca del cáliz, glabro. Cáliz $4 \mathrm{~mm}$ long., con 10 costillas sobresalientes en la base, cubierto de pelos estrellados pequeños y con cilias breves en el margen de los lóbulos, apiculados. Pétalos con la uña glabra. Tubo estaminal $4 \mathrm{~mm}$ long., glabro. Carpelos 7. Mericarpos 2,5 mm long. $\times 2 \mathrm{~mm}$ lat., glabros, indehiscentes, caras laterales y dorso reticulados, con 2 aristas bifurcadas, breves en el ápice. Semillas glabras, con pocos pelos en el hilo.

Distribución geográfica: Conocida sólo de la localidad tipo.

Obs.: Esta especie se distingue por la presencia de un pequeño diente en la base del pecíolo, por sus 7 mericarpos glabros y el tubo estaminal también glabro.

Etimología: El nombre deriva de la localidad tipo, Reprêsa Bortolan, $8 \mathrm{~km}$ de Poços de Caldas, Minas Gerais, en el límite con el estado de São Paulo, en Brasil.

\section{Sida cruziana Krapov., sp. nov.} Fig. 4

Suffrutex erectus. Caulibus stellatotomentosis. Folia rhomboidea, usque ad $7 \mathrm{~cm}$ 


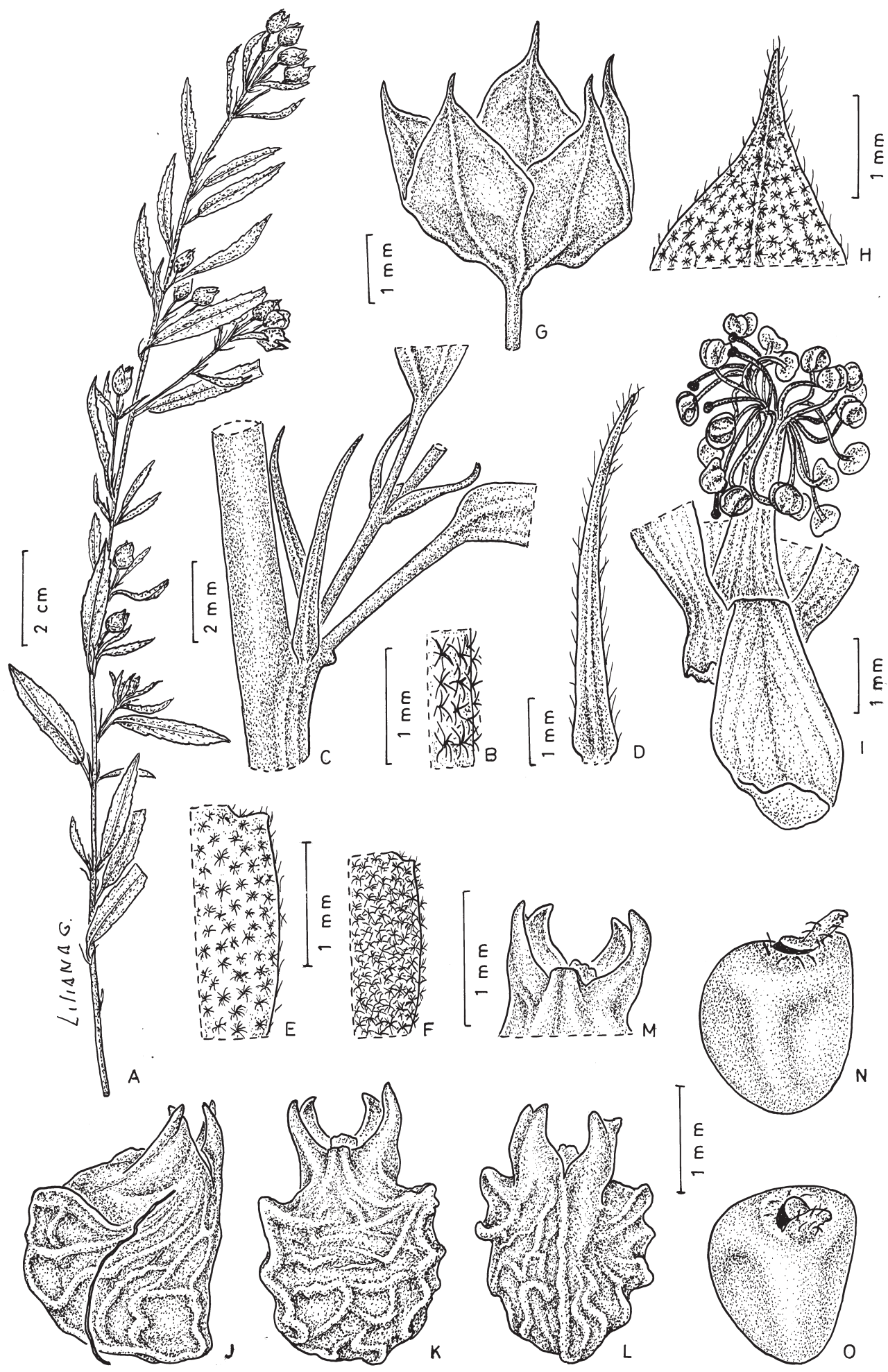

Fig. 3. Sida bortolanensis. A: Rama. B: Indumento del tallo. C: Estípulas. D: Indumento de la estípula. E: Indumento del epifilo. F: Indumento del hipofilo. G: Cáliz. H: Indumento del cáliz. I: Tubo estaminal. J: Mericarpo, vista lateral. K: Mericarpo, vista dorsal. L: Mericarpo, vista ventral. M: Ápice de las aristas. N-O: Semillas (Krapovickas 35364). 


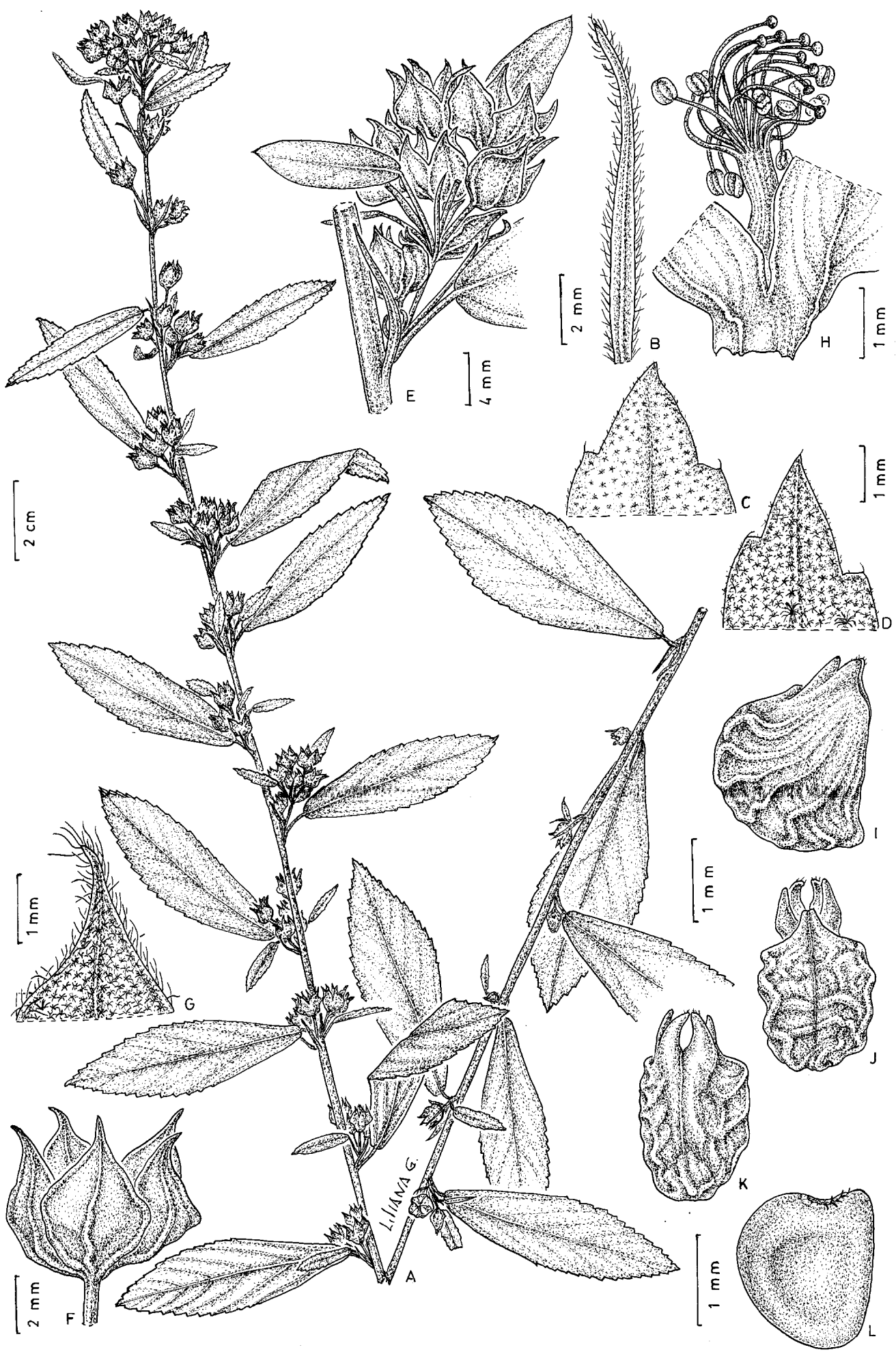

Fig. 4. Sida cruziana. A: Rama. B: Estípula. C: Indumento del epifilo. D: Indumento del hipofilo. E: Glomérulo. F: Cáliz. G: Indumento del cáliz. H: Tubo estaminal. I: Mericarpo, vista lateral. J: Mericarpo, vista dorsal. K: Mericarpo, vista ventral. L: Semilla (Krapovickas 32266). 
longa, utrinque stellato pilosa, Flores ad axillas congesti insertis. Petala glabra. Tubo stamineo glabro. Carpidia 7, reticulata, aristae breviae, bifurcatae.

Typus: Bolivia. Santa Cruz: Prov. Velasco, 10 km W de San Ignacio, 6-V-1977, A. Krapovickas \& A. Schinini 32266 (holotypus CTES).

Subarbusto erecto. Tallo con pelos estrellados pequeños, esparcidos. Estípulas lineares, $10 \mathrm{~mm}$ long., con las caras glabras y con pelos simples, breves, en los márgenes. Pecíolo 5-10 $\mathrm{mm}$ long. Lámina romboidea, hasta $7 \mathrm{~cm}$ long. $\times 2,5 \mathrm{~cm}$ lat., margen aserrado en los $2 / 3$ superiores, entero hacia la base, en los glomérulos el margen liso, ambas caras con pelos estrellados muy pequeños, algo mayores en el envés, epifilo a veces subglabro. Flores en glomérulos axilares parvifloros, a veces con hojas muy pequeñas. Pedicelos breves, 2-5 mm long. Cáliz 6-7 mm long., con 10 costillas sobresalientes, cubierto de pelos estrellados muy pequeños y con pelos simples en el margen de los lóbulos. Pétalos glabros. Tubo estaminal glabro. Mericarpos 7-9, $2 \mathrm{~mm}$ long. $\times 2 \mathrm{~mm}$ lat., reticulados, submúticos, aristas muy breves, bifurcadas, con pocos pelos en el ápice. Semillas glabras, con pocos pelos breves en el hilo.

Distribución geográfica: Conocida hasta ahora de las cercanías de San Ignacio de Velasco, en el departamento de Santa Cruz, Bolivia, donde predomina el cerrado.

Obs.: Sida cruziana es la única especie de la serie que vive en Bolivia, en la Chiquitanía. Se distingue por el tamaño de sus hojas con lámina hasta $7 \mathrm{~cm}$ de longitud, cuando en el resto de la serie no pasan de $4 \mathrm{~cm}$.

Etimologia: El nombre deriva del departamento de Santa Cruz, Bolivia, donde fue coleccionada.

\section{Sida piraporana Krapov., sp. nov.}

Fig. 5

Suffrutex $1 \mathrm{~m}$ altus. Caulibus stellato-pilosus.
Folia rhomboidea, utrinque stellato-pilosa. Flores axilares, subsesilibus. Petala flava, ugnis pilosis. Tubo stamineo glabro. Carpidia 8 , dorso pauce reticulato, aristae bifurcatae $0,5 \mathrm{~mm}$ longae.

Typus: Brasil. Minas Gerais: Mun. Pirapora, Rod. BR-496, km 14, ereta, $1 \mathrm{~m}$, flor amarela, cerrado degradado, 13-IV-1996, G. Hatschbach 64620, A. Schinini \& J. M. Silva (holotypus MBM, isotypi CTES, NY).

Subarbusto erecto, $1 \mathrm{~m}$ alt. Tallo cubierto de pelos estrellados. Estípulas lineares, hasta $5 \mathrm{~mm}$ long. Pecíolo $5 \mathrm{~mm}$ long. Lámina romboidea, hasta $4 \mathrm{~cm}$ long. $\times$ $1,5 \mathrm{~cm}$ lat., margen levemente crenadoaserrado en la mitad superior, ambas caras con pelos estrellados pequeños y algunos pelos estrellados mayores esparcidos. Flores solitarias o de a dos, axilares. Pedicelos 5 mm long., más breves que los pecíolos. Cáliz 4-5 mm long., con 10 nervios sobresalientes, cubiertos de pelos estrellados pequeños y pelos estrellados mayores en el margen. Pétalos amarillos, $5 \mathrm{~mm}$ long., uña pilosa. Tubo estaminal $2 \mathrm{~mm}$ long., glabro. Mericarpos 8, $2 \mathrm{~mm}$ long. × 1,5 $\mathrm{mm}$ lat., cara dorsal levemente reticulada, aristas 2, dobles, 0,5 mm long., con pocos pelos simples, pequeños. Semilla glabra, con pocos pelos en el hilo.

Distribución geográfica: Conocida sólo de la localidad tipo, en el norte del estado de Minas Gerais.

Obs.: Por las aristas dobles de los mericarpos Sida piraporana se asemeja a $S$. arcuata, también de Minas Gerais. Se diferencian porque en $S$. arcuata las ramas son arqueadas, tiene pelos simples en el haz de la hoja y sus flores sólo forman cabezuelas en el ápice de las ramas. En $S$. piraporana las dos caras de la hoja y el cáliz tienen dos clases de pelos, una capa de pelos estrellados pequeños y pelos estrellados mayores esparcidos.

Etimología: El nombre deriva del nombre del municipio Pirapora (ca. $17^{\circ} \mathrm{S}-45^{\circ} \mathrm{W}$ ), donde fue coleccionada. 


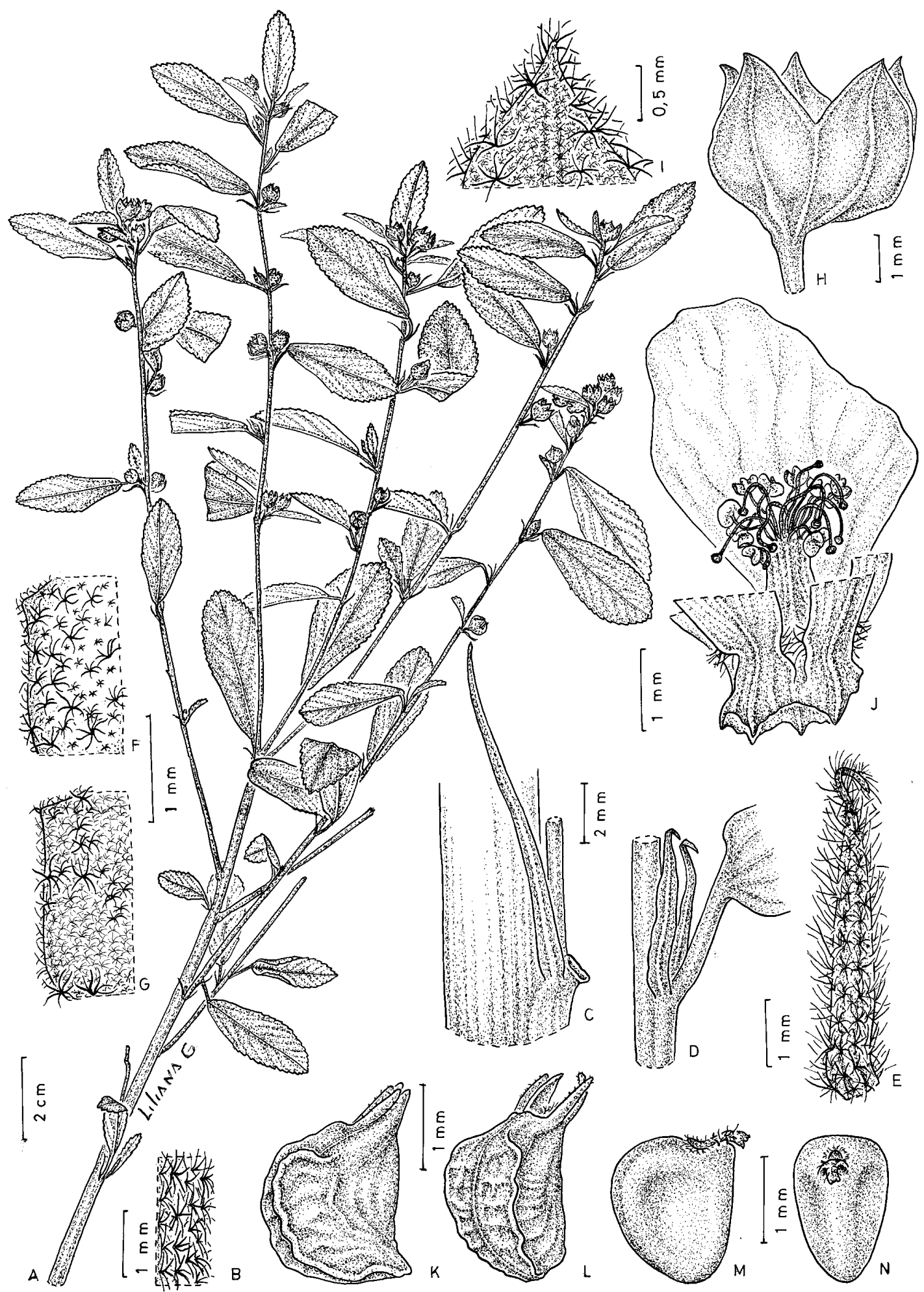

Fig. 5. Sida piraporana. A: Rama. B: Indumento del tallo. C y D: Estípulas. E: Indumento de la estípula. F: Indumento del epifilo. G: Indumento del hipofilo. H: Cáliz. I: Indumento del cáliz. J: Pétalo y tubo estaminal. K: Mericarpo, vista lateral. L: Mericarpo, vista dorsal. M-N: Semillas (Hatschbach 64620). 


\section{Sida Santosii Krapov., sp. nov.}

Fig. 6

Suffrutex $1 \mathrm{~m}$ altus. Caulibus stellato-pilosus. Folia anguste-rhomboidea, $4 \mathrm{~cm} \times 1 \mathrm{~cm}$, utrinque stellato-pilosa. Floribus ad apicem caulibus congesti. Corolla flava, glabra. Tubo stamineo glabro. Carpidia $2 \mathrm{~mm} \times 2 \mathrm{~mm}$, dorso pauce reticulato, aristae bifurcatae.

Typus: Brasil. Bahia: Mun. Sta. Cruz de Cabrália, Reserva Biológica de Pau Brasil, planta de $1 \mathrm{~m}$ de alt., amarelo claro ant. amarelo-ouro, 15-IX-1971, T. S. Santos 1937 (holotypus CEPEC, isotypus CTES).

Subarbusto $1 \mathrm{~m}$ alt. Tallo cubierto de pelos estrellados. Estípulas lineares, 9-10 mm long. Pecíolo breve, $4 \mathrm{~mm}$ long. Lámina angustiromboidea, $4 \mathrm{~cm}$ long. $\times 1 \mathrm{~cm}$ lat., margen aserrado en los $2 / 3$ superiores, liso hacia la base, ambas caras cubiertas de pelos estrellados pequeños. Flores solitarias, axilares, agrupadas en el ápice de ramitas 4-8 cm long. Pedicelo 2-4 mm long., articulado cerca de la base del cáliz. Cáliz $8 \mathrm{~mm}$ long., con 10 costillas basales sobresalientes, lóbulos apiculados, cubierto de pelos estrellados pequeños y con pelos estrellados mayores en el margen de los lóbulos. Pétalos amarillos, uña glabra. Tubo estaminal $4 \mathrm{~mm}$ long., glabro. Mericarpos 9, reticulados, $2 \mathrm{~mm}$ long. $\times 2 \mathrm{~mm}$ lat., con dos aristas $0,5 \mathrm{~mm}$ long, bífidas, glabros salvo pocos pelos simples en las aristas. Semillas glabras, con pocos pelos en el hilo.

Distribución geográfica: Conocida sólo de la localidad tipo.

Obs.: Sida Santosii es la única especie de la serie con flores en glomérulos apicales en ramitas axilares 4-8 cm long. Además, se distingue por sus hojas en ambas caras con pelos estrellados y los lóbulos del cáliz con pelos estrellados grandes en el margen.

Etimologia: Especie dedicada a su coleccionista T. S. Santos.

\section{Sida tapiraguensis Krapov., sp. nov.} Fig. 7

Suffrutex procumbens. Caulibus stellato-pilosus. Petiolus $5 \mathrm{~mm}$ longus. Folia ovata, usque $5 \mathrm{~cm} x$ $1,5 \mathrm{~cm}$, supra pilis simplicibus et pilis stellatis, infra pilis stellatis. Floribus solitarii, pedicellus 5 mm longus. Calyx 6-7 mm longus. Corolla glabra. Tubo stamineo glabro. Carpidia 9, dorso reticulato, aristae bifurcatae.

Typus: Paraguay. San Pedro: río Tapiraguay, $8 \mathrm{~km}$ de San Estanislao, camino a Rosario, campo cerca del río, procumbente, 17-II-1968, A. Krapovickas, C. L. Cristóbal \& L. Z. Ahumada 13918 (holotypus CTES, isotypi BAA, FCQ).

Subarbusto procumbente. Tallo cubierto de pelos estrellados. Estípulas lineares, 6 $\mathrm{mm}$ long., estrellado-pilosas. Pecíolo breve, $5 \mathrm{~mm}$ long. Lámina ovada, hasta $4 \mathrm{~cm}$ long. $\times 1,5 \mathrm{~cm}$ lat., margen levemente crenadoaserrado en los $2 / 3$ superiores, epifilo con pelos simples y estrellados esparcidos, hipofilo con pelos estrellados densos. Flores solitarias, axilares. Pedicelo breve, 5-10 mm long. Cáliz 6-8 mm long., cubierto de pelos estrellados pequeños. Corola glabra. Tubo estaminal glabro. Carpelos 9. Mericarpos 2,5 mm long. $\times$ $1,5 \mathrm{~mm}$ lat., glabros, dorso reticulado, con dos aristas bifurcadas breves.

Distribución geográfica: Especie conocida hasta ahora del Paraguay Oriental.

Paratypus: PARAGUAY. Amambay: Cabecera Aquidabán (Sierra Amambay), II1934, T. Rojas 6657 (AS, CTES).

Obs.: Sida tapiraguensis es la única especie de la sección Sida con ramas postradas. También es la única especie de la serie Bifurcata que vive en Paraguay.

Etimología: Nombre tomado del río Tapiraguay, en cuyas cercanías se coleccionó el ejemplar tipo. 


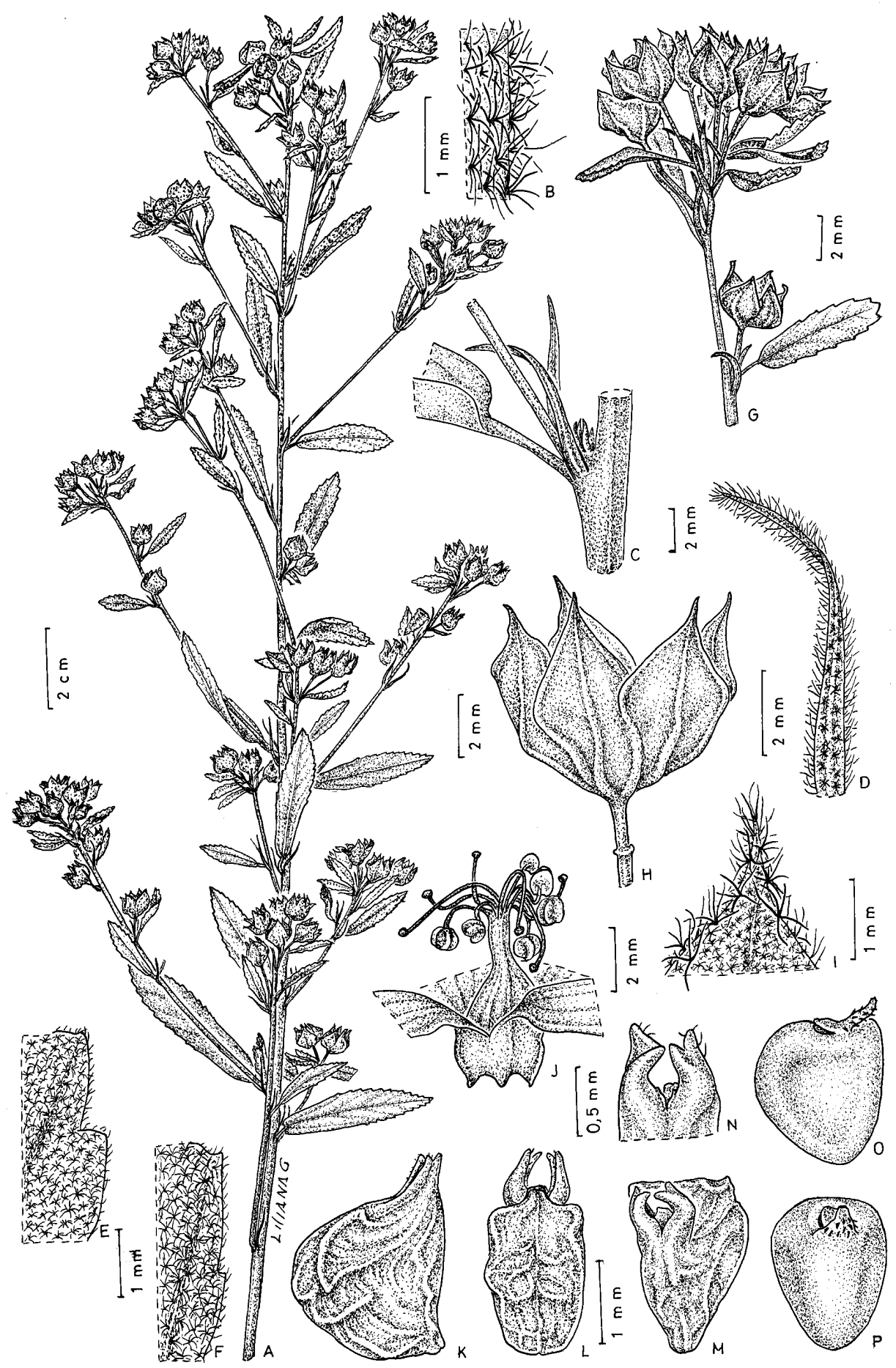

Fig. 6. Sida Santosii. A: Rama. B: Indumento del tallo. C: Estípulas. D: Indumento de la estípula. E: Indumento del epifilo. F: Indumento del hipofilo. G: Ápice de rama. H: Cáliz; I: Indumento del cáliz. J: Tubo estaminal. K: Mericarpo, vista lateral. L: Mericarpo, vista dorsal. M: Mericarpo, vista ventral. N: Ápice de mericarpo. O-P: Semillas (Santos 1937). 


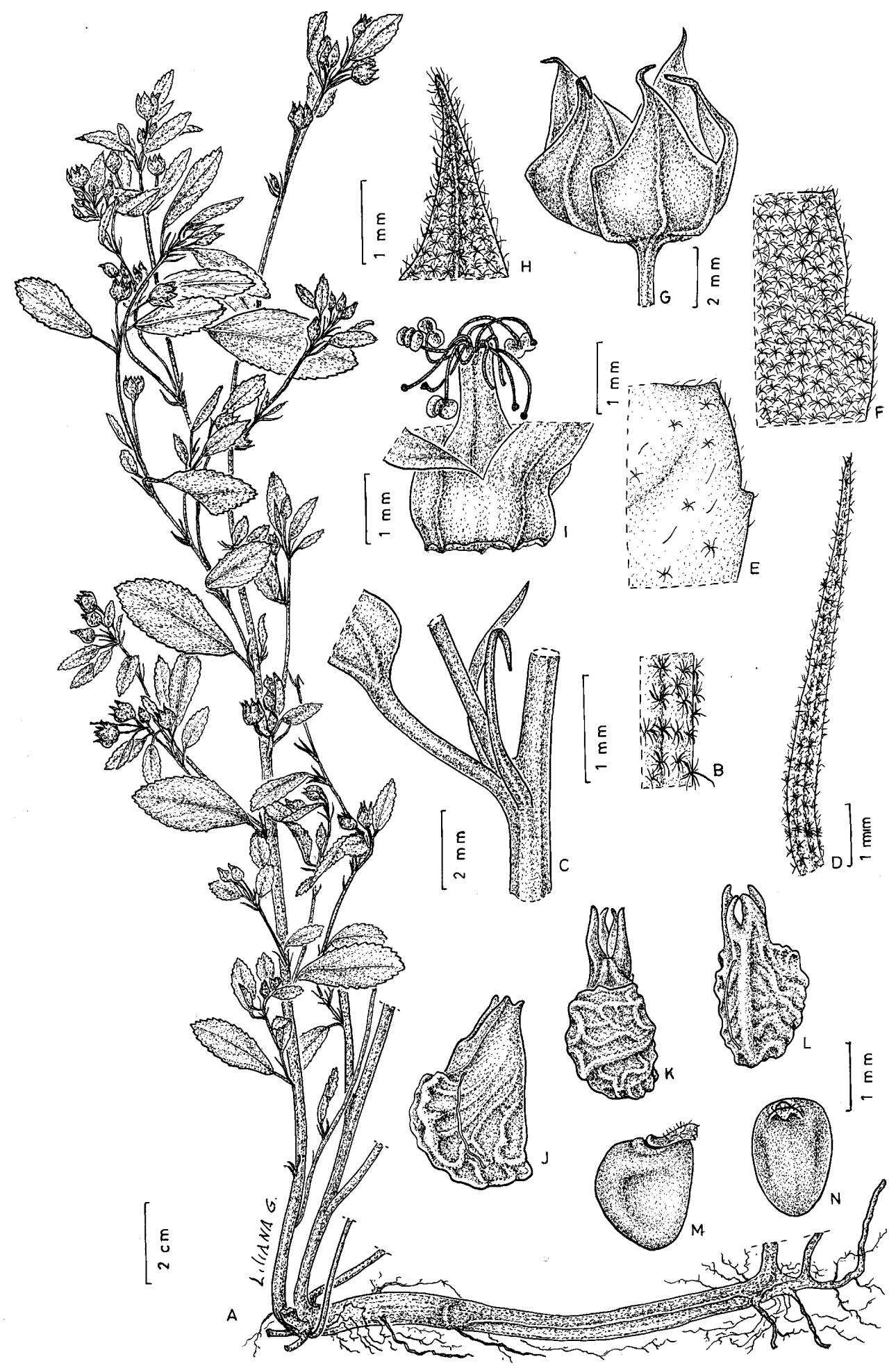

Fig. 7. Sida tapiraguensis. A: Raíz y ramas procumbentes. B: Indumento del tallo. C: Estípulas. D: Indumento de la estípula. E: Indumento del epifilo. F: Indumento de hipofilo. G: Cáliz. H: Indumento del cáliz. I: Tubo estaminal. J: mericarpo, vista lateral. K: Mericarpo, vista dorsal. L: Mericarpo, vista ventral. M-N: Semillas (Krapovickas 13918). 


\section{Series Sida}

Mericarpos (6) 8-16, múticos o con dos aristas simples.
Especie tipo: Sida rhombifolia L.

Las especies del cono sur de Sudamérica se pueden distinguir por medio de la siguiente clave.

\section{Clave para la identificación de las especies de la Serie Sida}

1. Carpelos (6) 8-10 (14).

2. Flores principalmente en cabezuelas terminales. Epifilo con pelos simples. Mericarpos (5)-7, múticos.

Arbusto $1,80-2 \mathrm{~m}$ alt. BR. 9. S. acrantha Link

2'. Flores axilares, solitarias o en glomérulos a lo largo de las ramas.

3. Lámina subglabra, sólo pocos pelos estrellados muy pequeños en los nervios. BO.

13. S. Beckii Krapov.

3'. Hojas pubescentes.

4. Hojas farinosas. Cáliz puberulento, sin pelos largos.

5. Epifilo con pelos simples. Mericarpos con un pico en la base. Arbusto 1,50 m alt. Corola amarilla con mancha oscura basal. BO, AR.

12. S. ambatense Krapov.

5'. Epifilo subglabro, sólo pelos estrellados diminutos. Mericarpos lisos, sin pico basal. Subarbusto hasta $1 \mathrm{~m}$ alt. Corola amarilla sin mancha basal.

$2 \mathrm{n}=14$. Cosmopolita.

29. S. rhombifolia $\mathrm{L}$.

4'. Hojas pubescentes. Cáliz con pelos \pm largos.

5. Hojas con nervaduras blancas. Mericarpos 10 , aristas $1,5 \mathrm{~mm}$, aristas y dorso con pelos estrellados. Tallo con una capa de pelos estrellados pequeños y pelos simples $1 \mathrm{~mm}$ long. esparcidos. Flores solitarias, pedicelo $15 \mathrm{~mm}$ long. BO: Chapare. .... 11. S. albinervia Krapov.

$5 '$. Hojas de color uniforme, con nervaduras verdes.

6. Mericarpos múticos o submúticos.

7. Pedicelo y base del cáliz con pelos simples. Hipofilo con pelos simples sobre los nervios. AR: Misiones. 28. S. ramoniana Krapov.

7'. Pedicelo y cáliz sólo con pelos estrellados.

8. Flores solitarias.

9. Pedicelos 1,5-4 cm long. Mericarpos $4 \times 2,5 \mathrm{~mm}$, submúticos, dorso reticulado. Epifilo con pelos estrellados diminutos. Arbusto hasta $2 \mathrm{~m}$ alt. $2 \mathrm{n}=14$. BR: MG, SP. 22. S. Leitaofilhoi Krapov.

9'. Pedicelos 2-6 mm long. Mericarpos 3,5 × $2 \mathrm{~mm}$, submúticos. Epifilo con pelos simples. PE. 35. S. Weberbaueri Ulbr.

8'. Flores en glomérulos axilares.

10. Todas las flores subsésiles. Epifilo con pelos de pocas ramas, algunos simples. Lámina hasta $4 \mathrm{~cm} \times 1,5 \mathrm{~cm}$. Pedicelos breves, 3-5 mm long. Mericapos 9, múticos, redondeados. BO: Santa Cruz. 14. S. carandana Krapov.

10'. Una flor con pedicelo $15 \mathrm{~mm}$ long. y en la axila un glomérulo de flores subsésiles.

11. Lámina hasta $9 \mathrm{~cm}$ long. $\times 2,5 \mathrm{~cm}$ lat. Epifilo con pelos simples y de pocas ramas. Flores con pedicelo $2 \mathrm{~cm}$ long. y glomérulos axilares. Mericarpos 14, múticos. AR: Misiones. 20. S. Kelleri Krapov.

11'. Lámina hasta $4 \mathrm{~cm}$ long. $\times 1,5 \mathrm{~mm}$ lat. Epifilo con pelos estrellados y en el margen pelos simples. 
12. Flores axilares subsésiles en el eje principal, y agrupadas en el ápice de ramitas. Cáliz con pelos estrellados pequeños, y mayores de pocas ramas. Mericarpos 6, submúticos. BR: GO, MA. 33. S. silvaniana Krapov.

12'. Glomérulos densos a lo largo de las ramas. Cáliz con pelos estrellados pequeños, uniformes y simples en el margen de los lóbulos.

$2 \mathrm{n}=28$. 34. S. tuberculata R.E.Fr.

12a. Epifilo con pelos simples. BO, BR. 34a. var. tuberculata

12b. Epifilo con pelos estrellados.

AR, BO, BR, PA, UR, VE. 34b. var. pseudo-rhombifolia Monteiro

6'. Mericarpos aristados.

13. Aristas hasta el doble que el cuerpo del mericarpo. Flores en glomérulos sobre pedúnculo 1-6 cm llong. Arbusto hasta $2 \mathrm{~m}$ alt. Panamá, norte de Sudamérica hasta Paraguay. 32. S. setosa Mart.ex Colla

13'. Aristas igual o más cortas que el cuerpo.

14. Mericarpos con un pico basal, dehiscentes hasta la mitad del cuerpo. Epifilo con pellos estrellados y simples. BR: PR. 10. S. adrianopolitana Krapov.

14'. Mericarpos dehiscentes sólo en el ápice.

15. Flores solitarias. Sin brácteas bífidas.

16. Hojas ovado-rómbicas, 3-5-nervadas. Epifilo con pelos simples. Subarbusto $0,50 \mathrm{~m}$ alt. BR: RS. 15. S. farroupilhensis Krapov. \& Bueno

16'. Hojas rómbico-lanceoladas, 3- nervadas

17. Tallo, hipofilo y cáliz con pelos simples. Epifilo con pelos estrellados. Aristas de los mericarpos 1,5-4 mm long. con pelos estrellados. Arbusto hasta $2 \mathrm{~m}$ alt. Colombia a Bolivia. ... 27. S. Poeppigiana (K. Schum.) Fryxell

17'. Pelos simples sólo en el hipofilo y en el epifilo. Aristas de los mericarpos 0,5-1,5 mm long., con pelos estrellados pequeños.

18. Hojas hasta $18 \mathrm{~cm}$ long $\times 7 \mathrm{~cm}$ lat., pecíolo hasta $4 \mathrm{~cm}$ long. Epi- e hipofilo con pelos simples. Mericarpos $8,5 \times 3 \mathrm{~mm}$. Arbusto hasta 1,50 $\mathrm{m}$ alt. BR: DF, GO. 25. S. magnifolia Krapov.

18'. Hojas hasta 5-7 cm long.

19. Epifilo e hipofilo con pelos simples. Pedicelo hasta $3 \mathrm{~cm}$ long. Hoja hasta $7 \mathrm{~cm}$ long. Mericarpos con cara lateral lisa, dehiscentes sólo en el ápice. Arbusto hasta 1,50 m alt. 2n=14. Bolivia a NW de Argentina. 31. S. Saraviae Krapov.

19'. Epifilo sólo pelos estrellados punctiformes, hipofilo con pelos simples. Hoja hasta $5 \mathrm{~cm}$ long. Mericarpos con un pico vertical en la base, dehiscentes en el ápice y en la cara ventral.

BR: MG. 17. S. Heringeri Krapov.

15'. Flores en glomérulos. Brácteas bífidas presentes.

20. Pedicelo $5 \mathrm{~mm}$ long., articulado en la base. Glomérulos en el ápice de un pedúnculo axilar, 1-4 cm long. Mericarpos glabros, 7-8, con pico basal y aristas breves. Arbusto 2,50 m alt. AR: Misiones. .... 19. S. ignaciana Krapov.

20 '. Pedicelo articulado en el centro o en el tercio superior.

21. Mericarpos con aristas iguales o algo más cortas que el cuerpo. Epifilo por lo común con pelos simples. Cáliz sólo con pelos estrellados pequeños. Arbusto hasta $2 \mathrm{~m}$ alt. Sur de Brasil,

NE de Argentina. 8. S. Honoriana Krapov. 
21'. Mericarpos con aristas breves. Haz con pelos estrellados pequeños.

22. Tallo con pelos simples $1 \mathrm{~mm}$ long. Epifilo con pelos simples. Cáliz con pelos estrellados medianos y pelos simples en los nervios y en el margen. Arbusto hasta $1,70 \mathrm{~m}$ alt.

AR: Misiones. 26. S. palustris Krapov.

22'. Tallo sin pelos simples.

23. Mericarpos $3 \times 2 \mathrm{~mm}$, submúticos, dorso y aristas con pelos. Epifilo con pelos estrellados.

$2 n=14$. BR: PR. 23. S. lonchitis A. St.- Hil.\& Naudin

23'. Mericarpos $2 \times 1 \mathrm{~mm}$, submúticos, glabros. Epifilo con pelos simples. BR: PR. 21. S. Kranzii Krapov. \& Bueno

21". Flores en glomérulos axilares. Sin brácteas bífidas.

24. Cáliz acrescente, en fruto $9 \mathrm{~mm} \times 6 \mathrm{~mm}$. Follaje verde. Mericarpos subglabros. Subarbusto hasta $0,80 \mathrm{~m}$ alt.

BR, PA, AR.

30. S. santaremensis Monteiro

24'. Cáliz no acrescente. Follaje amarillento, dorado Mericarpos dorso y aristas con pelos estrellados amarillentos.

$2 \mathrm{n}=28 . \mathrm{BR}$.

16. S. Glaziovii K. Schum.

1'. Carpelos 14-16. Flores solitarias. Pedicelos hasta $25 \mathrm{~mm}$ long. Epifilo con pelos estrellados hasta 1 mm long. Mericarpos 3 x 2 mm, submúticos, glabros. Subarbusto hasta $1 \mathrm{~m}$ alt. Hojas 7 x 3,5 cm. AR: Misiones. 24. S. loretana Krapov.

\section{Sida acrantha Link}

Sida acrantha Link, Enum. pl. hort. Berol. 2: 203. 1822. Typus: Brasil. Sello, B (ex Herb. Link), (B, foto F 9367!).

Sida subcuneata A. St.-Hil., Fl. Bras. mer. 1: 184. 1827. Typus: Brasil. Minas Gerais: "in sylvulis prope Villa Rica [Ouro Preto], januario", (holotypus P!, foto F 35544!, isotypus MPU!).

Sida urosepala R. E. Fr., Kung. Svenska Vetenskapsakad. Ser. III, 24 (2): 13-14, tab.1, figs. 7-8, tab. 4, fig. 1. 1947. Typus: Brasil. São Paulo: Jaragua, A. C. Brade 5558 (holotypus S, isotypi CTES, SP).

Sida subcuneata var. acrantha (Link) Monteiro, Lilloa 17: 514. 1949.

Iconografía: Monteiro, 1936, Tab. 1, fig. 9 (sub S. subcuneata).

Material estudiado: BRASIL. Bahia: $50 \mathrm{~km}$

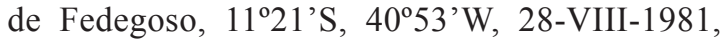
Pinto 278/81 (CTES). Minas Gerais: São Juliao de Ouro Branco, 9-III-1891, Glaziou 18138 (P); Rodrigo Silva, III-1893, Coehlho 734 (CTES,
OUPR); Rancharia, $15 \mathrm{~km} \mathrm{~S}$ de Ouro Preto, $20^{\circ} 26^{\prime} \mathrm{S}, 43^{\circ} 31^{\prime} \mathrm{W}, 1260 \mathrm{~m}, 13-\mathrm{V}-1990$, Arbo et al. 4015 (CTES, SPF); $34 \mathrm{~km} \mathrm{E} \mathrm{of} \mathrm{Belo} \mathrm{Horizonte,}$ road BR-31, to Roças Novas, 1500 m, 17-I-1971, Irwin \& al. 30607 (CTES, NY). Rio de Janeiro: Parqe Nacional Itatiaia, 4-V-1947, Occhioni 808 (CTES, RFA). São Paulo: Jundiaí, Alto da Serra dos Cristaes, 5-IV-1939, Viegas 3952 (CTES, SP); Est. Ecológica UFMG, 14-XI-1990, Tameirão Neto 246 (CTES, BHCB); Alto da Lapa, 3-IV-1946, W. Hoehne 11524 (CTES, SPF).

Obs.: Schumann (1891) reconoce que $S$. acrantha y $S$. subcuneata son muy afines y recomienda estudios futuros en el campo.

Monteiro (1949) sostiene que sin dudas $S$. acrantha y $S$. urosepala son sinónimos de S. subcuneata. Sin embargo, a continuación publica $S$. subcuneata var. acrantha (Link) Monteiro sin notar que $S$. acrantha es más antiguo.

Kearney (1958) mantiene separadas estas tres especies. Sida acrantha y $S$. subcuneata muy afines y $S$. urosepala muy diferente.

Según los fototipos de $S$. acrantha y $S$. 
subcuneata, estas dos entidades se diferencian por las hojas, agudas en la primera y obtusas en la segunda, caracteres muy variables en el material estudiado que no permiten una separación neta. El análisis del tipo de $S$. urosepala confirma la opinión de Monteiro (1949).

\section{Sida adrianopolitana Krapov., sp. nov. Fig. 8}

Suffrutex $30 \mathrm{~cm}$ alt. Caulibus stellato tomentosis, pilisque simplicibus inspersis. Petiolus 2-3 cm longus. Folia rhombico-lanceolata, 5-7 cm longa et $2 \mathrm{~cm}$ lata, supra stellato-tomentosa et pilis simplicibus presentia, infra dense stellatotomentosa. Floribus solitariis, pedicelis 1-2 cm. Calyce $6 \mathrm{~mm}$ long. Carpidia 2,5 mm longa et $2 \mathrm{~mm}$ lata, dorso reticulato, aristae $2 \mathrm{~mm}$ longae, pilosae.

Typus: Brasil. Paraná: Mun. Adrianópolis, Fazenda Tanque, Berneck, subarbusto, $30 \mathrm{~cm}$, flor amarelo-pálida, mata degradada, 26-X-2004, J. M. Silva \& L. M. Abe 4168 (holotypus MBM, isotypus CTES).

Subarbusto $30 \mathrm{~cm}$ alt., con ramas $50 \mathrm{~cm}$ long. Tallo cubierto de pelos estrellados medianos y hacia la base aparecen también pelos simples $0,5 \mathrm{~mm}$ long. Estípulas $5 \mathrm{~mm}$ long., linear-lanceoladas. Pecíolo 2-3 cm long. Lámina rómbico-lanceolada, $5-7 \mathrm{~cm}$ long. $\times 2 \mathrm{~cm}$ lat., margen levemente aserrado casi hasta la base, $1 \mathrm{~cm}$ basal entero, haz con pelos estrellados y algunos simples, dejan ver la epidermis, envés con pelos estrellados, densos, más claros. Flores solitarias axilares. Pedicelo 1-2 cm long., articulado 4-5 $\mathrm{mm}$ por debajo del cáliz. Cáliz $6 \mathrm{~mm}$ long., con 10 costillas sobresalientes en la base, lóbulos $4 \mathrm{~mm}$ long. $\times 4 \mathrm{~mm}$ lat., apiculados, plegados, cubierto de pelos estrellados pequeños y con algunos pelos simples en el ápice. Corola amarillopálida. Mericarpos 2,5 mm long. $\times 2 \mathrm{~mm}$ lat., dehiscentes hasta la mitad del cuerpo, con 2 aristas apicales $2 \mathrm{~mm}$ long., con pelos simples, dorso reticulado y en la base un pico destacado.

Distribución geográfica: Conocida hasta ahora sólo de la localidad tipo.
Obs.: Por sus mericarpos aristados y dehiscentes hasta la mitad del cuerpo, $S$. adrianopolitana es afín a $S$. setosa, de la cual se distingue por la presencia de un pico en la base de los mericarpos. Además, S. setosa es pubérula a glabra y $S$. adrianopolitana está cubierta de pelos estrellados mayores y además con algunos pelos simples en el tallo.

Etimología: El nombre deriva de la localidad tipo, Municipio de Adrianópolis, en el NE del estado de Paraná, Brasil [ca. $24^{\circ} 40^{\prime} \mathrm{S}, 49^{\circ} \mathrm{W}$ ].

\section{Sida albinervia Krapov., sp. nov. Fig. 9}

Suffrutex erectus. Caulibus stellato tomentosis, pilisque simplicibus inspersis. Foliis breviter petiolatis. Lamina rhombeo-lanceolata, serrata, basin versus integerrima, utrinque pilis stellatis, supra nervis albis. Floribus solitariis, pedicelis $15 \mathrm{~mm}$ longis. Calyce $7 \mathrm{~mm}$ longis, nervis 10 basi noduloso-incrassatis, utrinque pilis stellatis, ad nervis pilis simplicibus longiusculis instructo. Tubo stamineo piloso. Carpidiis 10, biaristatis, dorso et aristis stellato pilosis.

Typus: Bolivia. Cochabamba: Prov. Chapare, camino a Locotal, $5 \mathrm{~km}$ a Paractí, $1760 \mathrm{~m}, 2-\mathrm{VI}$ 1988, D. Candia 38 (holotypus LPB, isotypus CTES).

Hierba erecta. Tallo con pelos estrellados pequeños y pelos simples rígidos, $1 \mathrm{~mm}$ long., esparcidos. Estípulas lanceoladas, $5 \mathrm{~mm}$ long., estrellado-pilosas. Pecíolo $5 \mathrm{~mm}$ long. con una capa de pelos estrellados pequeños y pelos simples $1 \mathrm{~mm}$ long. Lámina discolor, rómbicolanceolada, trinervada, hasta $5 \mathrm{~cm}$ long. $\times$ $1,5 \mathrm{~cm}$ lat., margen $1 \mathrm{~cm}$ basal liso y el resto aserrado; haz cubierto de pelos estrellados diminutos y con pelos estrellados blancos, densos, en los nervios, envés blanquecino, cubierto densamente de una capa de pelos estrellados y con pelos simples $0,5 \mathrm{~mm}$ long. en nervio medio. Flores solitarias axilares, pedicelo $15 \mathrm{~mm}$ long., articulado unos $7 \mathrm{~mm}$ por debajo del cáliz, cubierto de una capa de pelos estrellados y con pelos simples, rígidos, $1 \mathrm{~mm}$ long. abundantes. Cáliz $7 \mathrm{~mm}$ long., 


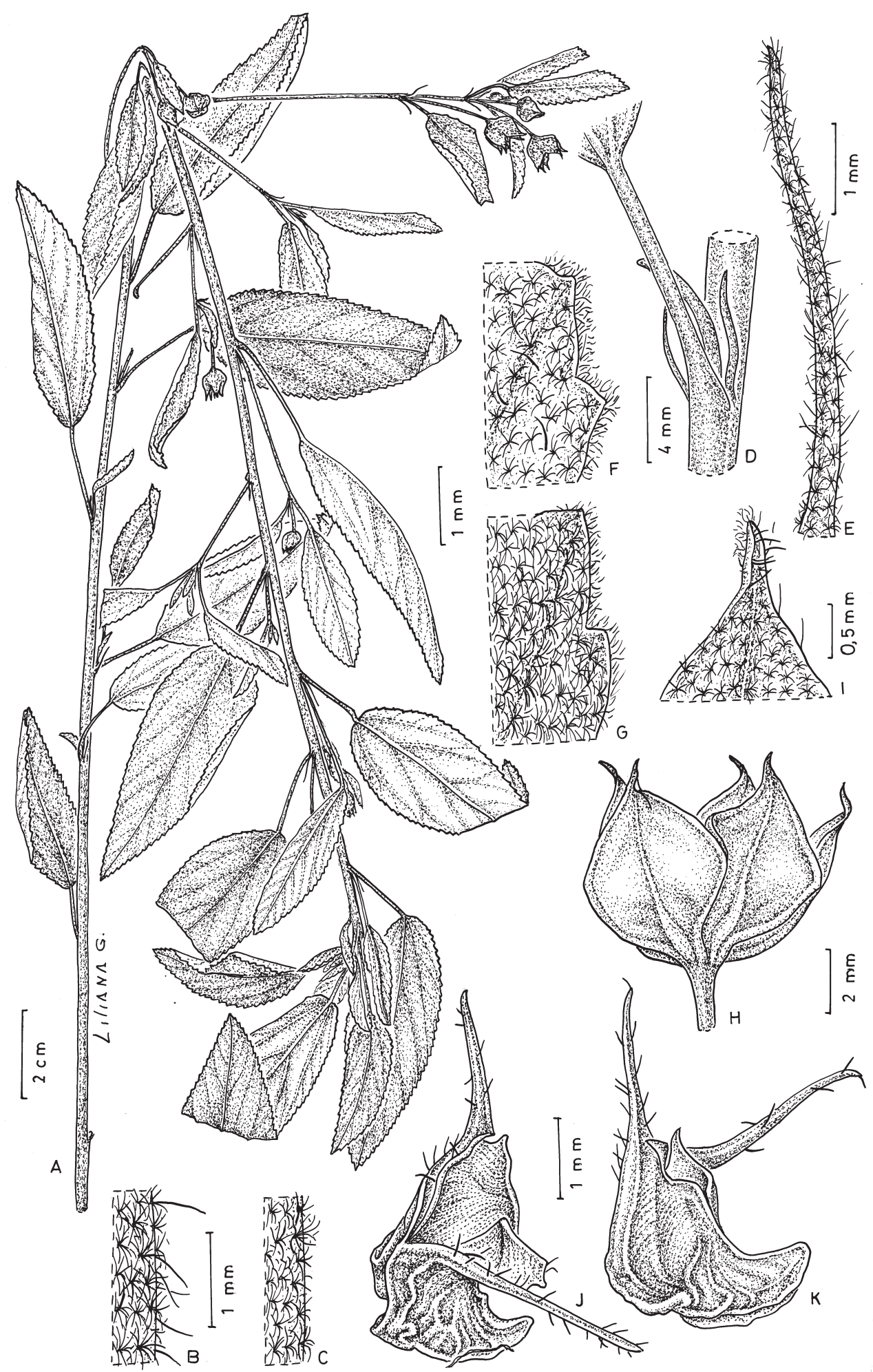

Fig. 8. Sida adrianopolitana. A: Rama. B: Tomento hacia la base del tallo. C: Tomento hacia el ápice del tallo. D: Estípulas. E: Indumento de la estípula. F: Indumento del epifilo. G: Indumento del hipofilo. H: Cáliz. I: Indumento del cáliz. J: Mericarpo vista lateral. K: Mericarpo vista ventral (Silva 4168). 


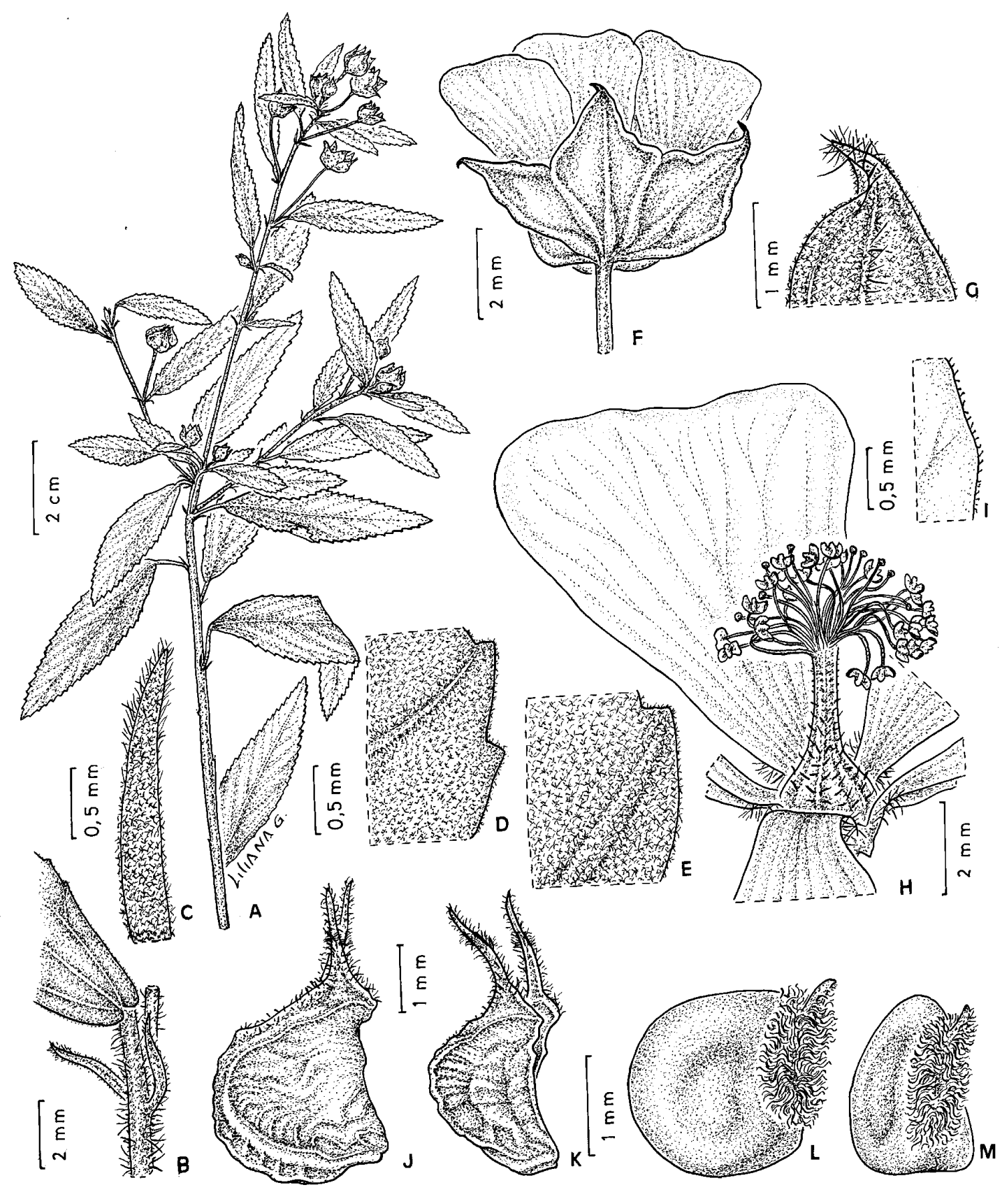

Fig. 9. Sida albinervia. A: Rama. B: Estípulas. C: Indumento de la estípula. D: Indumento del epifilo. E: Indumento del hipofilo. F: Flor. G: Indumento del cáliz. H: Pétalo y tubo estaminal. I: Indumento del pétalo. J-K: Mericarpos, vista lateral. L-M: Semillas (Candia 38). 
con 10 nervaduras sobresalientes en la base, lóbulos triangulares, $3 \mathrm{~mm}$ long. $\times 4 \mathrm{~mm}$ lat., plegados, cubierto de pelos estrellados diminutos y con pelos simples, 0,5 mm long., sobre los nervios. Pétalos $10 \mathrm{~mm}$ long., margen con pelos simples, pequeños, uña pilosa. Tubo estaminal $4 \mathrm{~mm}$ long. con pelos simples o de 2 ramas. Carpelos 10. Mericarpos $3 \mathrm{~mm}$ long. $\times$ $2 \mathrm{~mm}$ lat. y dos aristas apicales 1,5 mm long., caras laterales reticuladas hacia la base y dorso $\mathrm{y}$ aristas con pelos estrellados.

Distribución geográfica: Vive en la región de los Yungas de Cochabamba en Bolivia.

Obs.: Esta especie se distingue por los nervios blancos en el epifilo de las hojas y por la presencia de pelos simples 0,5-1 $\mathrm{mm}$ en el tallo, pecíolo, pedúnculo y cáliz.

Etimología: El nombre hace alusión a las nervaduras blancas de las hojas.

\section{Sida ambatense Krapov., sp. nov.}

Fig. 10

Suffrutex $1,50 \mathrm{~cm}$ alt. Caulibus stellato tomentosis. Petiolus 10-15 mm longus. Folia rhombica, usque ad 9-10 cm longa et $3 \mathrm{~cm}$ lata, supra stellato-tomentosa, infra pilis simplicibus et pilis stellati. Floribus solitariis, pedicelis $2,5-4 \mathrm{~cm}$. Calyce $5 \mathrm{~mm}$ longus, stellato-tomentosus. Petala flava, $7 \mathrm{~mm}$ longa, extus pilis simplicibus. Tubo stamineo piloso. Carpidia 10, $3 \mathrm{~mm}$ longa et $2 \mathrm{~mm}$ lata, dorso reticulato, aristae 1-1,5 mm longae, pilosae.

Typus: Argentina. Catamarca: Dep. Ambato, Piedras Blancas, camino Las Juntas-Humaya, 1650 m, 3-IV-1995, C. Saravia Toledo, A. Schinini, A. Sanchez \& A. Quiroga 13387 (holotypus CTES).

Arbusto 1,50 m alt. Tallo con pocos pelos estrellados pequeños. Estípulas lanceoladas, $5 \mathrm{~mm}$ long. Pecíolo 10-15 mm long. Lámina rómbica, hasta $9-10 \mathrm{~cm}$ long. $\times 3 \mathrm{~cm}$ lat., margen levemente crenado-aserrado, hacia la base entero, haz con pelos simples esparcidos y algunos pelos estrellados pequeños, envés con pelos estrellados muy pequeños. Flores solitarias, axilares. Pedicelo 2,5-4 cm long., articulado, subglabro, con pocos pelos estrellados muy pequeños. Cáliz $5 \mathrm{~mm}$ long. cubierto de pelos estrellados muy pequeños, uniformes. Pétalos $7 \mathrm{~mm}$ long., con pelos simples en la cara externa, uña pilosa. Tubo estaminal $2 \mathrm{~mm}$ long., con pelos simples, abundantes. Mericarpos 10, $3 \mathrm{~mm}$ long. $\times$ $2 \mathrm{~mm}$ lat., aristas 1-1,5 mm long., glabras o con pelos estrellados muy pequeños, dorso reticulado y con una prominencia en la base. Semilla glabra.

Distribución geográfica: Vive en el noroeste de Argentina y en el sud de Bolivia, entre 900 y 1200 m s.n.m.

Paratypi: ARGENTINA. Catamarca: Dep. Ambato. Arroyo Piedra Áspera, en "El Bolsón", 1240 m, 29-III-1995, Saravia Toledo et al. 13128 (CTES); Dep. Ancasti, Sierra de Ancasti, ruta 66, intersección con el río Anquincila, entre Taco y Ancasti, 1000 m, 23-II-1964, A. T. Hunziker \& Di Fulvio 17101 (CORD, CTES); Dep. Capayán, Los Ángeles (Río Los Pinos), km 7, 8-I-1947, Risso 522 (CTES, LIL); Dep. Paclín, Balcozna Afuera (35 km NW de La Merced), 1300 m, 8-IV-1971, $A$. T. Hunziker \&. Di Fulvio 21161 (CORD, CTES). Jujuy: Dep. Capital, Sierra de Zapla, Mina 9 de Octubre, 25-II-1971, Cabrera et al. 21582 (CTES, LP). Salta: Dep. Metán, Metán, Río de las Conchas, 28-III-1975, Krapovickas et al. 27942 (CTES). BOLIVIA. Tarija: Rincón de la Victoria, 17 km W de Tarija, 18-V-1971, Krapovickas et al. 18855 (CTES); id., Krapovickas et al. 18858 (CTES).

Obs.: Por su indumento casi farináceo, $S$. ambatense es afín a $S$. rhombifolia, de la que se separa por sus hojas de mayor tamaño, por el epifilo con pelos simples, el tubo estaminal tomentoso y sus mericarpos con un pequeño pico en la base.

Etimología: E1 nombre deriva del departamento de Ambato, prov. Catamarca, donde se coleccionó el ejemplar tipo. 


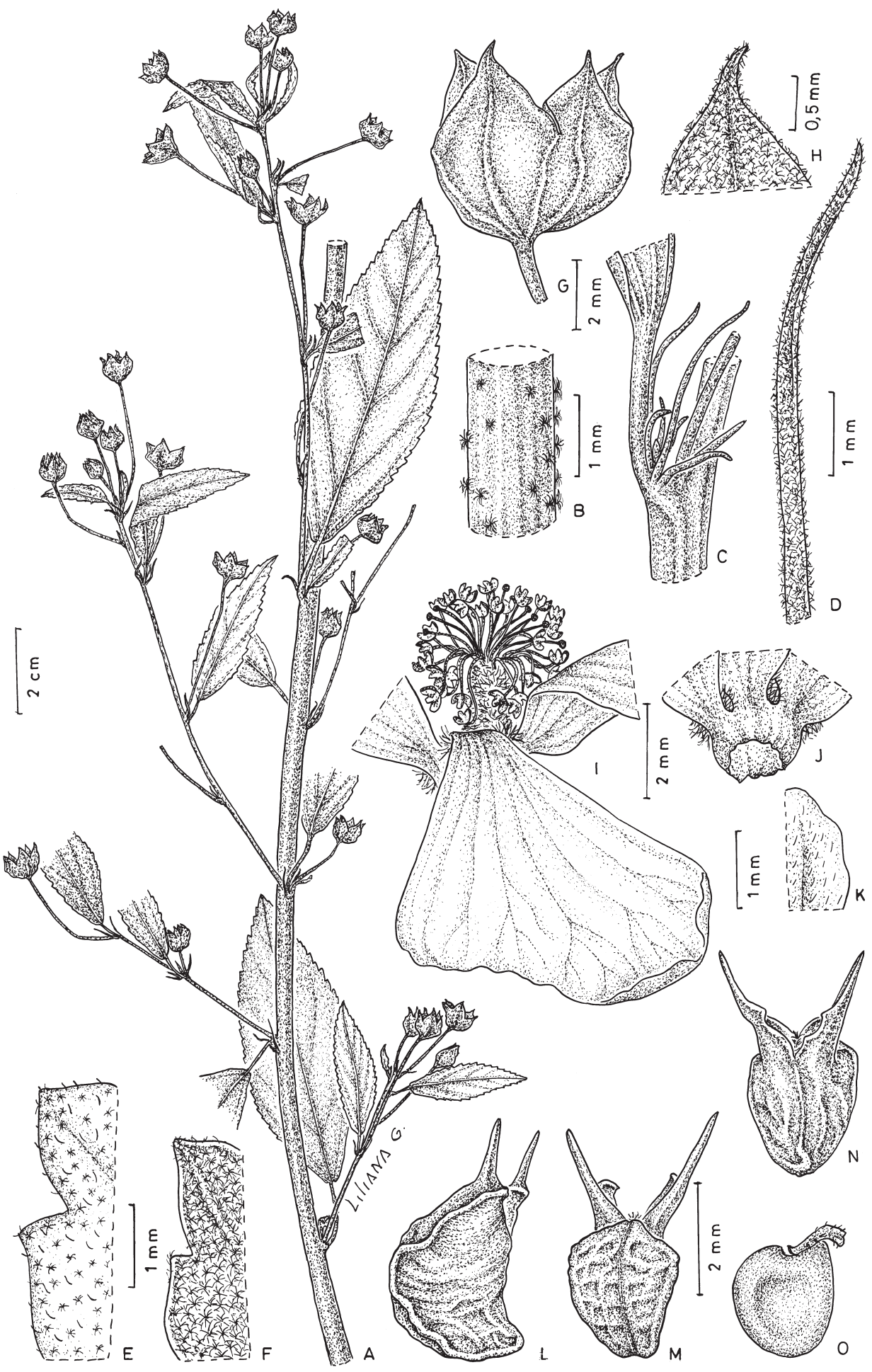

Fig. 10. Sida ambatense. A: Rama. B: Indumento del tallo. C: Estípulas. D: Indumento de la estípula. E: Indumento del epifilo. F: Indumento del hipofilo. G: Cáliz. H: Indumento del cáliz. I: Pétalo y tubo estaminal. J. Uña de los pétalos. K: Haz del pétalo. L: Mericarpo, vista lateral. M: Mericarpo, vista dorsal. N: Mericarpo, vista ventral. O: Semilla (Saravia Toledo 13387). 


\section{Sida Beckii Krapov.}

Sida Beckii Krapov., Bonplandia 19(1): 85-87, fig. 3. 2010. Typus: Bolivia. Cochabamba: Prov. José Carrasco Torrico, camino a Villa Tunari, El Sillar (km 389), $17^{\circ} 04^{\prime} 32^{\prime \prime} \mathrm{S}, 65^{\circ} 40^{\prime} \mathrm{W}$, alt. 800 m, 8-I-2009, St. G. Beck 33051 (holotypus LPB, isotypus CTES).

Distrbución geográfica: Vive en la selva húmeda de los Yungas del Chapare, a $800 \mathrm{~m}$ s.n.m., en la ladera norte de la cordillera de Cochabamba, en Bolivia.

\section{Sida carandana Krapov., sp. nov.}

Fig. 11

Planta $1,80 \mathrm{~m}$ altis. Caulibus stellato tomentosis. Foliis breviter petiolatis. Lamina obovata, serrata, basin versus integerrima, supra pilis simplicibus vel bifidus, infra stellato pilosa. Flores subsessiles ad axillas congesti. Calyce 7-9 mm longis, nervis 10 basi noduloso-incrassatis, utrinque pilis stellatis. Tubo stamineo piloso. Carpidiis 9, muticiis, glabris.

Typus: Bolivia. Santa Cruz: Prov. Ichilo, Caranda, $20 \mathrm{~km} \mathrm{SW}$ de Portachuelo, 1,80 m alt., 7-IV-1979. A. Krapovickas 34642 (holotypus LPB, isotypi CTES, K, NY, SI, USZ).

Planta $1,80 \mathrm{~m}$ alt., tallo erecto, no ramificado. Tallo cubierto de pelos estrellados pequeños. Estípulas lanceoladas, 4-5 mm long. $\times 0,5 \mathrm{~mm}$ lat., margen piloso. Pecíolo 3-5 mm long., piloso. Lámina obovada, hasta $40 \mathrm{~mm}$ long. $\times 15 \mathrm{~mm}$ lat., margen crenado-aserrado en la mitad superior, liso en la mitad inferior, cara superior con pelos de pocas ramas y algunos simples, 0,2 $\mathrm{mm}$ long., esparcidos, envés con pelos estrellados algo más densos. Flores en glomérulos axilares paucifloros. Pedicelo 3-5 mm long., articulado más o menos en la mitad, piloso. Cáliz 7-9 mm long., lóbulos triangulares 5 $\mathrm{mm}$ long. $\times 4 \mathrm{~mm}$ lat., plegados, cubiertos de pelos estrellados. Pétalos con la uña pilosa. Tubo estaminal $3 \mathrm{~mm}$ long., con pelos glandulares breves. Mericarpos 9, 2,5-3 mm long. $\times 2 \mathrm{~mm}$ lat., múticos, glabros, lisos, apenas reticulados en el dorso, dehiscentes en el ápice. Semilla glabra, con pocos pelos en el hilo.

Distribución geográfica: Vive en matorrales arbustivos poco o nada alterados, entre Portachuelo y Buena Vista, en el sur de la provincia de Ichilo en el departamento de Santa Cruz, Bolivia. También fue coleccionada al este en la prov. Ñuflo de Chávez.

Paratypi: BOLIVIA. Santa Cruz: Prov. Ichilo,

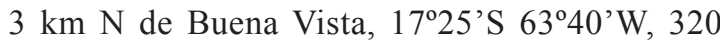
m, 19-V-1991, Krapovickas \& Fortunato 43928 (CTES); Prov. Ñuflo de Chávez, Concepción,

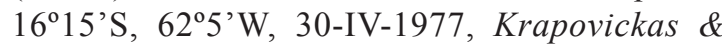
Schinini 32038 (CTES); 20 km N de San Ramón, camino a San Javier, 16 $28^{\prime} 06^{\prime \prime S}, 62^{\circ} 29^{\prime} 25^{\prime} \mathrm{W}$, 22-VII-2003, Ferrucci et al. 1841 (CTES).

Obs.: Por sus hojas con la mitad basal con margen entero Sida carandana pertenece a la sección Sida. Se diferencia del resto de las especies de esta sección por sus mericarpos lisos, no reticulados, y múticos y por sus tallos erectos, derechos, con hojas pequeñas, subsésiles.

De $S$. tuberculata se separa por el porte, en ésta no pasa de $1 \mathrm{~m}$ alt. mientras que en $S$. carandana llega a $1,80 \mathrm{~m}$ alt. Los mericarpos son múticos en ambas, pero en $S$. tuberculata son indehiscentes y en $S$. carandana dehiscentes en el ápice.

Etimología: El nombre deriva de la localidad tipo, Caranda.

15. Sida farroupilhensis Krapov. \& Bueno, sp. nov.

Fig. 12

Suffrutex 0,60-1 $m$ altus. Caulibus stellato tomentosis. Folia ovato-rhombica, quintuplinervia, serrata, basis versus integerrima, supra pilis simplicibus et paucis stellatus, infra stellato-pilosa. Floribus solitariis. Pedicellis 15-20 mm longis. Calyx $8 \mathrm{~mm}$ long. Petala flava, extus stellato-pilosa. Tubo stamineo piloso. Carpidia 11, reticulata, $3 \mathrm{~mm}$ longa et $2 \mathrm{~mm}$ lata, aristae $1 \mathrm{~mm}$ longae. 


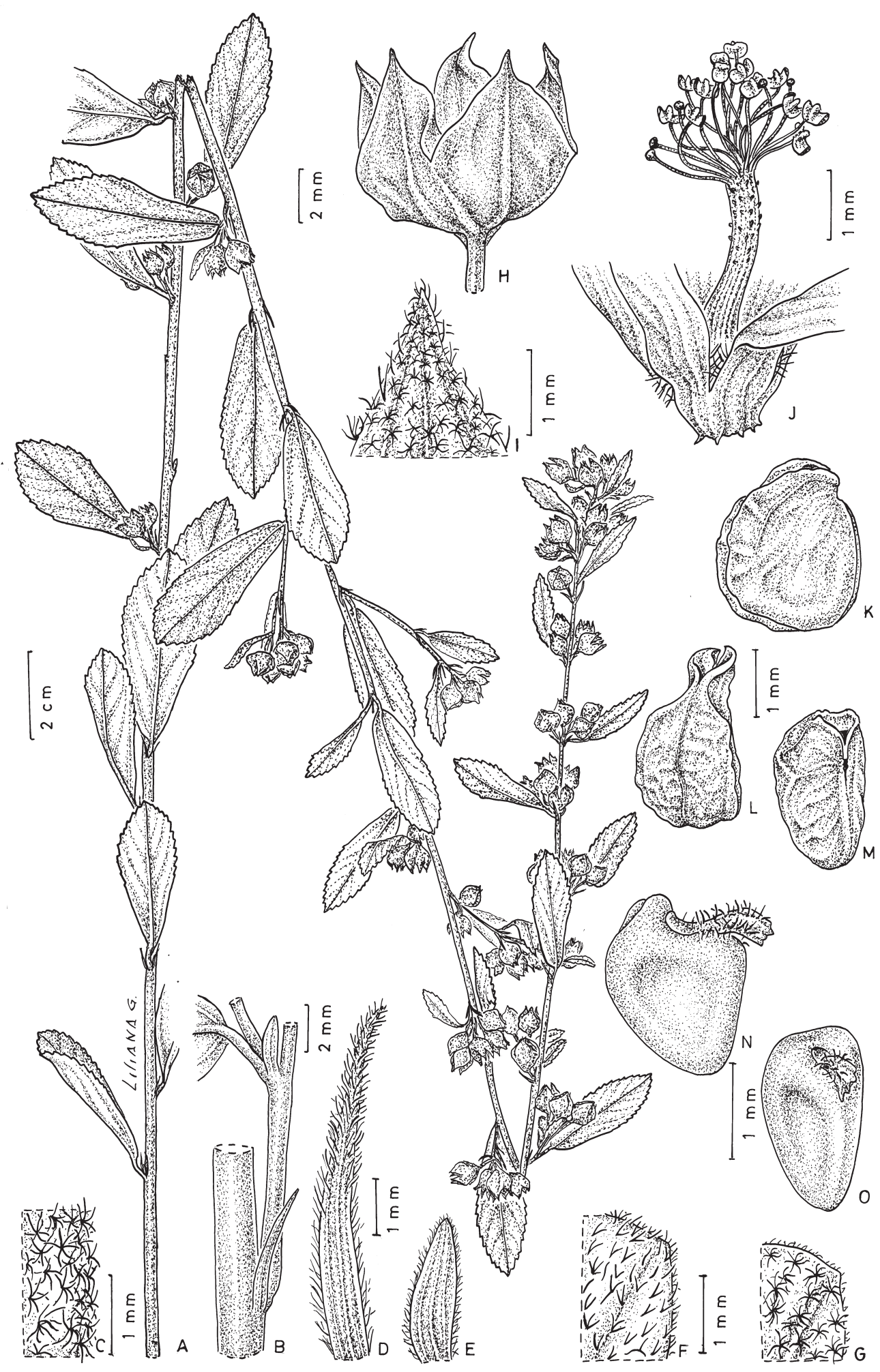

Fig. 11. Sida carandana. A: Rama. B: Estípulas. C: Indumento del tallo. D: Estípula basal. E: Estípula superior. F: Indumento del epifilo. G: Indumento del hipofilo. H: Cáliz. I: Indumento del cáliz. J: Tubo estaminal. K: Mericarpo, vista lateral. L: Mericarpo, vista dorsal. M: Mericarpo, vista ventral. N-O: Semillas (Krapovickas 34642). 


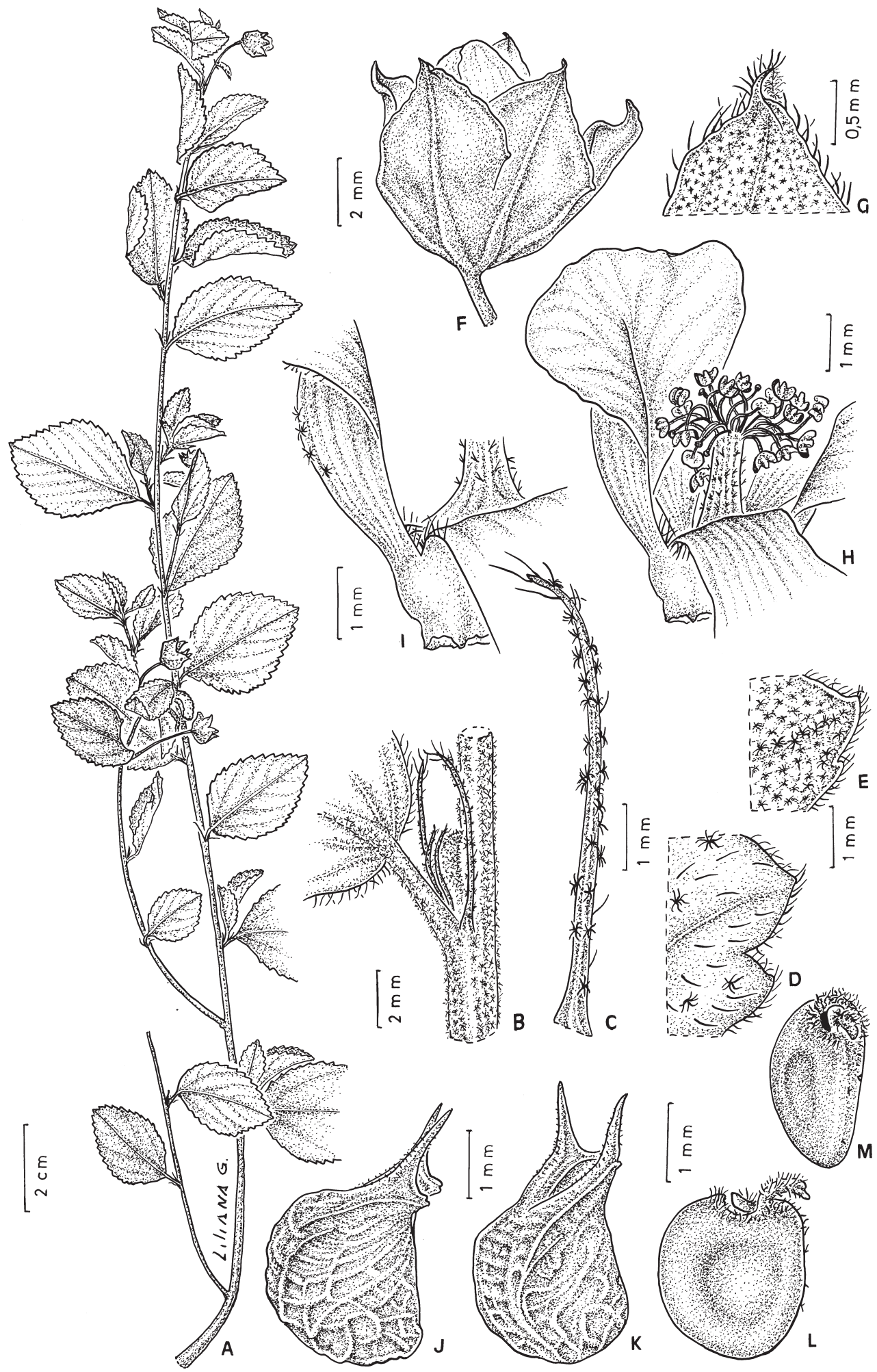

Fig. 12. Sida farroupilhensis. A: Rama. B: Estípulas. C: Indumento de la estípula. D: Indumento del epifilo. E: Indumento del hipofilo. F: Cáliz. G: Indumento del cáliz. H: Corola y tubo estaminal; I: Indumento de la corola y del tubo estaminal. J-K: Mericarpos. L-M: Semillas (Bueno 676). 
Typus: Brasil. Rio Grande do Sul: Mun. Farroupilha, Parque dos Pinheiros, erva con aproximadamente $1 \mathrm{~m}$ de altura, bastante frequente nos lugares úmidos e sombreados, flores amarelas que fecham-se ao ser coletadas, 23-V-1978, O. Bueno 676 (holotypus HAS, isotypus CTES).

Hierba 0,60-1 m alt. Tallo con pelos estrellados pequeños. Estípulas lineares, 5 $\mathrm{mm}$ long., con pelos estrellados y algunos pelos simples en el ápice. Pecíolo $2 \mathrm{~mm}$ long., con indumento similar al del tallo. Lámina ovado-rómbica, 3-4 cm long. $\times$ 2-2,5 cm lat., pentanervada, margen crenadoaserrado, 5-10 $\mathrm{mm}$ basales lisos, haz con pelos simples y algunos estrellados, envés con pelos estrellados pequeños. Flores solitarias, axilares. Pedicelos 15-20 mm long., articulados $5 \mathrm{~mm}$ por debajo de la flor, indumento similar al del tallo. Cáliz 6-6,5 $\mathrm{mm}$ long., lóbulos $3,5 \mathrm{~mm}$ long. $\times 3 \mathrm{~mm}$ lat., plegados, cubierto de pelos estrellados pequeños y con los márgenes ciliados. Corola amarilla. Pétalos $6 \mathrm{~mm}$ long., con pelos estrellados en la cara externa y con la uña pilosa. Tubo estaminal $3 \mathrm{~mm}$ long., con pelos estrellados. Mericarpos 11, $3 \mathrm{~mm}$ long. $\times 2$ $\mathrm{mm}$ lat., caras laterales y dorso levemente reticulados, aristas $1 \mathrm{~mm}$ long., pilosas. Semilla glabra y con pocos pelos en el hilo.

Distribución geográfica: Vive en la zona montañosa del NE de Rio Grande do Sul, a unos $800 \mathrm{~m}$ s.n.m. Prefiere lugares sombreados y húmedos, especialmente en bosques de Araucaria.

Paratypi: BRASIL: Rio Grande do Sul: BR-285, $\mathrm{km}$ 61, 17 km E de Lagoa Vermelha, 23-X-1982, Krapovickas \& Schinini 38219 (CTES); Porto Alegre, Jardim Botânico, 9-VI-1977, Bueno 4601 (CTES, HAS); São Francisco de Paula, 18-XI-1986, Bueno 4673 (CTES, HAS); Mun. Farroupilhas, Parque dos Pinheiros, 5-IX-1978, Bueno 1015 (CTES, HAS); íd., 7-XI-1978, Bueno 1090 (CTES, HAS); Farrhoupilha, 13-VII-1974, Rambo 42550 (CTES, LIL).

Obs.: Esta especie fue señalada como Sida santaremensis Monteiro en un trabajo anterior (Bueno, 1979), basada en una identificación mía, apresurada, del ejemplar tipo. Sida santaremensis se diferencia por su cáliz mucho mayor, acrescente en el fruto, por sus hojas ovadas, no rómbicas, con pelos estrellados en el epifilo.

Etimología: El nombre deriva de la localidad tipo, Farroupilha, en Rio Grande do Sul.

\section{Sida Glaziovii K. Schum.}

Sida Glaziovii K. Schum., Mart. Fl. Bras. 12(3): 322. 1891. Typus: Brasil. Minas Gerais: "probabiliter in campis provinciae Minas Geraes" [Casa Branca a Ouro Preto, route du Sabara, 26-II1884], Glaziou 14510 (B, foto F 9379!, destruído) (lectoholotypus P!, aquí designado).

Sida Bradei Ulbrich, Notizbl. Bot. Gart. Berlin 9: 42. 1924. Typus: Brasil. São Paulo: São Paulo, A. C. Brade 7356 (holotypus B?). Monteiro, Lilloa 17: 521. 1949. Non Sida Bradei E. G. Baker, 1925.

Sida Bradei E. G. Baker, J. Bot. 63: 239. 1925. Typus: Brasil, São Paulo, Botequim, Butantan, $A$. C. Brade 6864 (holotypus BM). Monteiro, Bol. Soc. Portug. Ci. Nat. 5, $2^{\circ}$ serie (vol. XIX) fasc. II: 141 142, 1955. NON Sida Bradei Ulbrich, 1924.

Obs.: Sida Glaziovii es una especie fácil de reconocer por su follaje color amarillo claro y por sus mericarpos con pelos estrellados amarillentos en el ápice y en las aristas.

Etimología: Especie dedicada a A. F. M. Glaziou, quien coleccionó el material tipo.

\section{Sida Heringeri Krapov., sp. nov.} Fig. 13

Suffrutex $1 \mathrm{~m}$ altus. Caulibus stellato pilosus et setis $1 \mathrm{~mm}$ longis sparsis. Folia rhombicolanceolata, usque ad $5 \mathrm{~cm}$ longa et $1,5 \mathrm{~cm}$ lata, supra stellato-pilosa, infra stellato-pilosa et setis $1 \mathrm{~mm}$ longis sparsis. Flores ad axilas solitarii. Pedicelli 10-25 mm longi. Calyx $8 \mathrm{~mm}$ longus. Tubo stamineo piloso. Carpidia $3 \mathrm{~mm}$ longa et $2,5 \mathrm{~mm}$ lata, aristae $1 \mathrm{~mm}$ longae, stellato-pilosae.

Typus: Brasil. Minas Gerais: Carandaí, [205's, $\left.43^{\circ} 50^{\prime} \mathrm{W}\right]$, solo vermelho, planta até $1 \mathrm{~m}$ de altura, 5-VII-1960, E. P. Heringer 7636 (holotypus UB, isotypus CTES). 


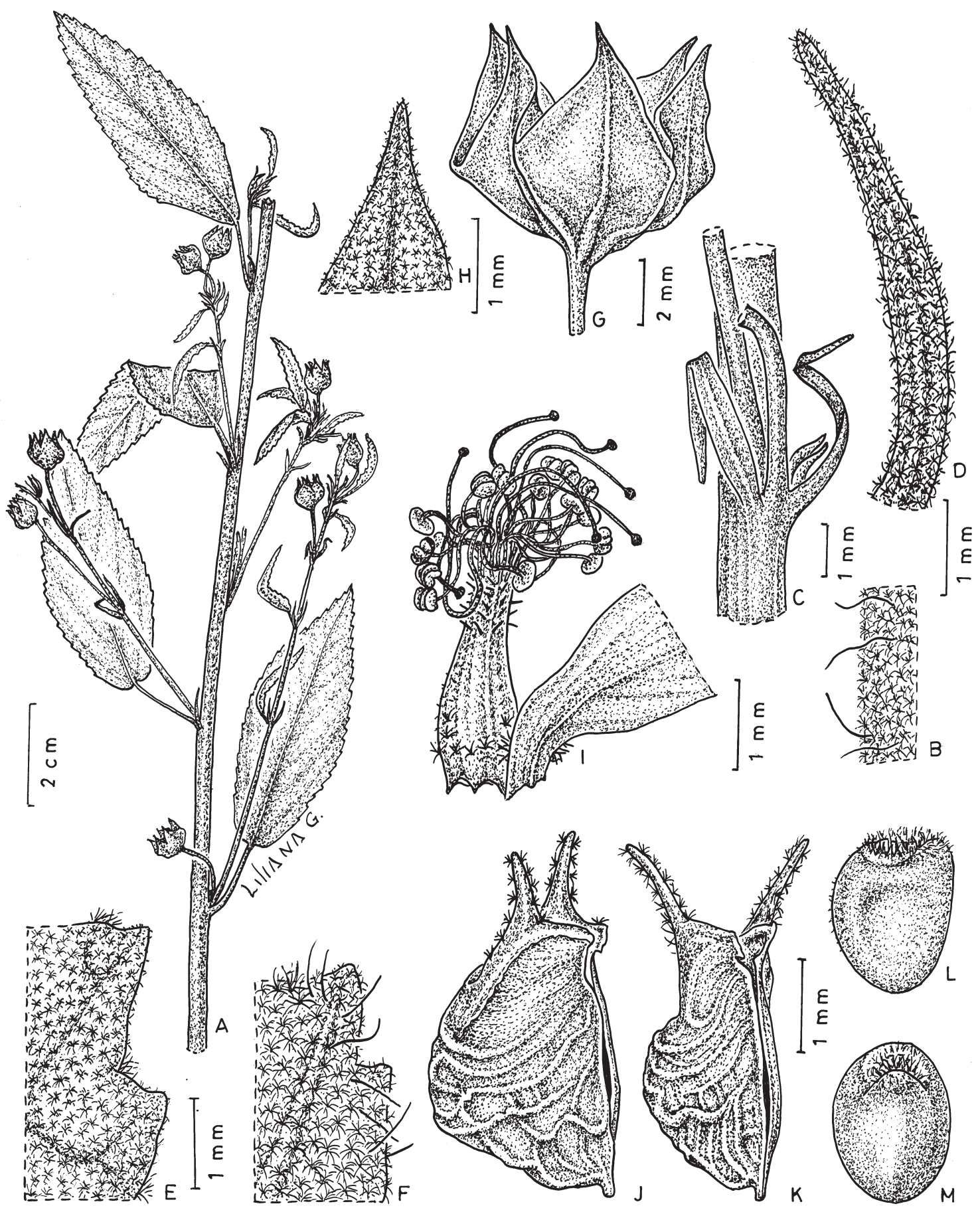

Fig. 13. Sida Heringeri. A: Rama. B: Indumento del tallo. C: Estípulas. D: Indumento de la estípula. E: Indumento del epifilo. F: Indumento del hipofilo. G: Cáliz. H: Indumento del cáliz. I: Tubo estaminal. J: Mericarpo, vista lateral. K: Mericarpo, vista ventral. L-M: Semillas (Heringer 7636). 
Subarbusto hasta $1 \mathrm{~m}$ alt. Tallo con pelos estrellados punctiformes, dejan ver la epidermis y pocos pelos simples $1 \mathrm{~mm}$ long. en las partes jóvenes. Estípulas filiformes, 5-7 mm long. Pecíolo $10 \mathrm{~mm}$ long., con pelos estrellados punctiformes como los del tallo pero más densos y pelos simples $1 \mathrm{~mm}$ long., esparcidos. Lámina rómbico-lanceolada, hasta $5 \mathrm{~cm}$ long. $\times 1,5 \mathrm{~cm}$ lat., trinervada, ápice agudo, margen con el tercio basal entero y el resto crenado-aserrado, haz con pelos estrellados muy pequeños, esparcidos, envés con pelos estrellados mayores, densos, blanquecinos y pelos simples $1 \mathrm{~mm}$ long., esparcidos. Flores solitarias, axilares. Pedicelo 10-25 mm long., articulado en el tercio superior y con indumento similar al del tallo. Cáliz $8 \mathrm{~mm}$ long., cubierto de pelos estrellados punctiformes, lóbulos 4 mm long. Tubo estaminal con pelos simples hacia el ápice y pelos estrellados en la base. Mericarpos 9, $3 \mathrm{~mm}$ long. $\times 2,5 \mathrm{~mm}$ lat., reticulados, aristas $1 \mathrm{~mm}$ long. y con un pico vertical en la base, dehiscentes en el ápice y en la cara ventral, aristas y porción superior del dorso con pelos estrellados.

Distribución geográfica: Sólo conocida de la localidad tipo.

Obs.: Especie afín a $S$. Poeppigiana por la presencia de pelos simples 1-2 mm long. en el tallo y en el envés de la hoja. Se diferencia por el cáliz sólo con pelos estrellados punctiformes en $S$. Heringeri, y con pelos simples, principalmente en su base y lóbulos en S. Poeppigiana. Además, S. Poeppigiana es una especie andina cuya área se extiende desde Colombia hasta Bolivia.

Etimología: Especie dedicada a E. P. Heringer, quién coleccionó el ejemplar tipo.

\section{Sida Honoriana Krapov.}

Sida Honoriana Krapov., Bonplandia (Corrientes) 16(3-4); 194-196, fig. 1. 2007. Typus. Brasil. Rio de Janeiro: Therezopolis, 21-III-1917, Sampaio 1965 (holotypus R 27854) (aquí designado) (sub Sida rhombifolia L. var. surinamensis (Miq.) K. Schum. f.
Sampaioi Monteiro. 1936. O genero Sida: 46, tab. XI).

Iconografía: Krapovickas, 2007, fig. 1.

Distribución geográfica: Sur de Brasil y noreste de Argentina.

Etimología: Especie dedicada a Honorio da C. Monteiro Filho, autor de varios trabajos sobre el género Sida.

\section{Sida ignaciana Krapov., sp. nov.}

Fig. 14

Frutex 2-2,5 $m$ altus. Caulibus stellato-piloso. Folia rhombico-lanceolata, usque ad $9 \mathrm{~cm}$ longa et $1,5 \mathrm{~cm}$ lata, utrinque stellato-pilosa. Flores glomerati, pedúnculo $1-4 \mathrm{~cm}$ longus, pedicelli 5 mm longi, bracteis bifidis. Corolla flava. Carpella 8. Carpidia $3 \mathrm{~mm}$ longa et $2 \mathrm{~mm}$ lata, reticulata, aristae $1 \mathrm{~mm}$ longae.

Typus: Argentina. Misiones: Dep. San Ignacio, $27^{\circ} 16^{\prime} 24,6^{\prime \prime} \mathrm{S}, 55^{\circ} 30^{\prime} 45,7^{\prime \prime} \mathrm{W}, 85 \mathrm{~m}$, pastizal en bajo pantanoso, suelo arenoso, 20-III-2010, H. A. Keller \& N. G. Paredes 8623 (holotypus CTES, isotypi FCQ, LIL, MBM, NY, SI).

Arbusto 2-2,5 alt. Tallo con una capa de pelos estrellados diminutos, más o menos compacta. Estípulas filiformes 4-10 mm long. Pecíolo 5-10 mm long., con indumento igual al del tallo. Lámina bicolor, rómbicolanceolada, trinervada, hasta $9 \mathrm{~cm}$ long. $\times$ $1,5 \mathrm{~cm}$ lat., ápice agudo, margen liso en los 10-20 mm basales, luego levemente crenadoaserrado, haz totalmente cubierto de pelos estrellados muy pequeños, envés cubierto de pelos estrellados algo mayores, blanquecinos. Flores en cabezuelas axilares con pedúnculo 1-4 cm long. Pedicelos $5 \mathrm{~mm}$ long., articulados cerca de la base. Brácteas bífidas presentes en la base de las flores. Cáliz $5 \mathrm{~mm}$ long., con 10 nervios gruesos y sobresalientes en la base, lóbulos triangulares $2 \mathrm{~mm}$ long. $\times 3 \mathrm{~mm}$ lat., plegados, cubierto de una capa uniforme de pelos estrellados muy pequeños. Corola amarilla. Pétalos con pelos en la uña. Tubo estaminal $2 \mathrm{~mm}$ long., con pelos punctiformes glandulares. Mericarpos 8, $3 \mathrm{~mm}$ long. $\times 2$ 


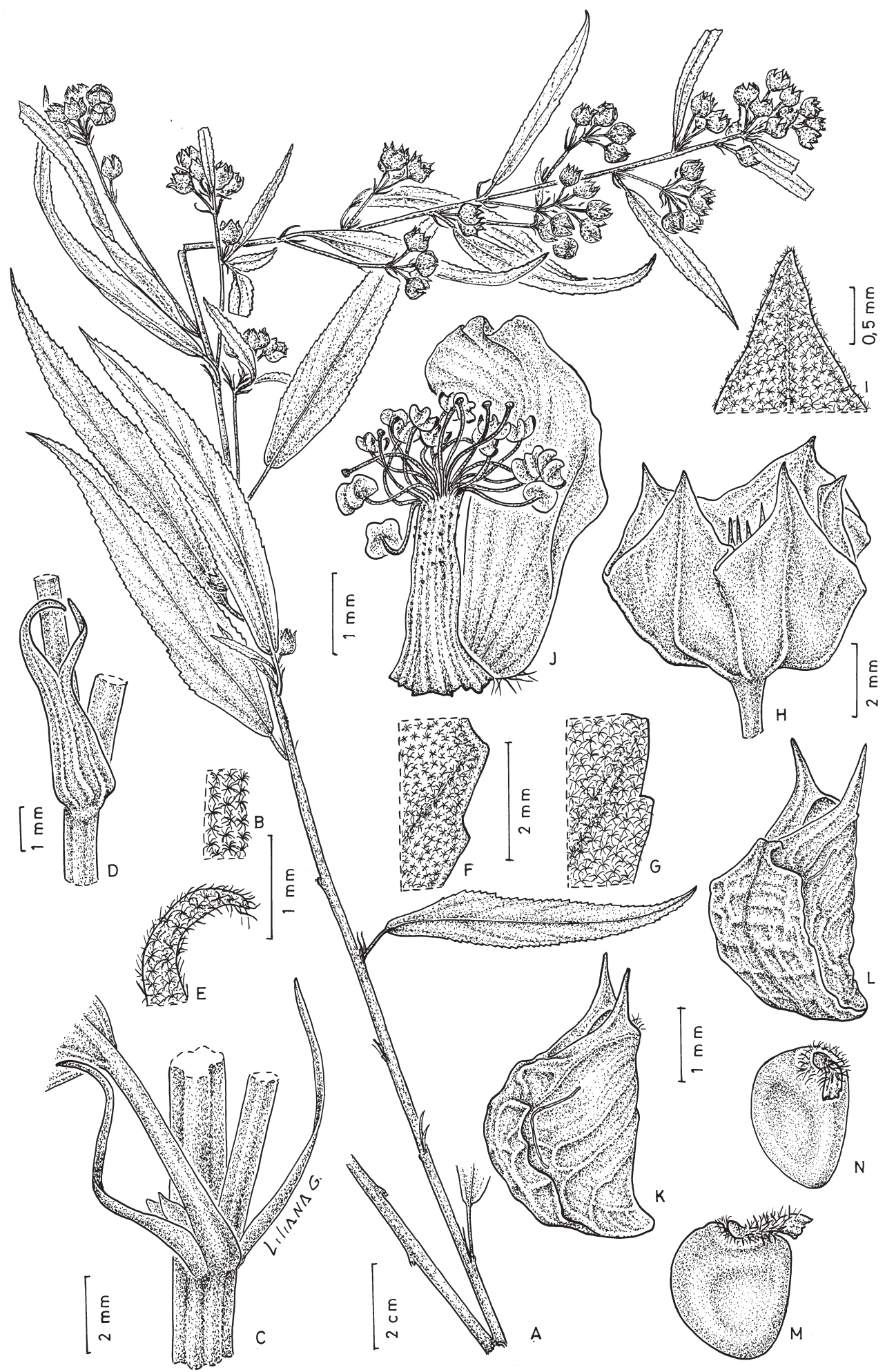

Fig. 14. Sida ignaciana. A: Rama. B: Indumento del tallo. C: Estípulas. D: Bráctea bífida. E: Indumento de la bráctea. F: Indumento del epifilo. G: Indumento del hipofilo H: Cáliz. I: Indumento del cáliz. J: Pétalo y tubo estaminal. K: Mericarpo, vista lateral. L: Mericarpo, vista dorsal. M-N: Semillas (Keller 8623). 
$\mathrm{mm}$ lat., con dos aristas $1 \mathrm{~mm}$ long..y con pico basal. dehiscentes en el ápice, dorso y caras laterales reticuladas, glabros. Semillas glabras, con pocos pelos en el hilo.

Distribución geográfica: Esta especie vive en bañados o bajos pantanosos en el departamento de San Ignacio, Misiones, Argentina.

Paratypus: ARGENTINA. Misiones: Dep. San

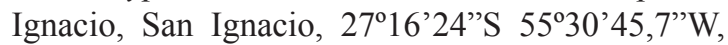
85 m, 23-II-2012, H. A. Keller \& C. J. Keller 10817 (CTES, FCQ, K, MBM).

Obs.: Esta especie se distingue por ser arbusto de 2,50 $\mathrm{m}$ de altura con hojas hasta 9 $\mathrm{cm}$ de longitud, por sus flores en glomérulos sobre pedúnculos 1-4 cm long., con pedicelos articulados cerca de la base, y por presentar brácteas bífidas en las inflorescencias.

Etimología: El nombre deriva de la localidad tipo, departamento de San Ignacio, en el sur de la provincia de Misiones, Argentina.

\section{Sida Kelleri Krapov., sp. nov.}

\section{Fig. 15}

Frutex $1,50 \mathrm{~m}$ alt. Caule stellato-piloso. Folia rhombico-lanceolada, usque $9 \mathrm{~cm}$ longa et 2,5-3 cm lata, supra pilis simplicibus vel stellatis, infra pilis stellatis. Floribus pedicellati et subsessilibus ad axillas congeste. Calyx 7-9 mm longus, stellato-piloso. Tubo stamineo piloso. Carpella 11-14. Carpidia $2 \mathrm{~mm}$ longa et 2 mm lata, mutica, dorso reticulato.

Typus: ARGENTINA. Misiones: Acceso al Parque Provincial Teyú Cuaré, $27^{\circ} 03$ ' 42 'S, 5534'3”W, $210 \mathrm{~m}$ s.m, borde de selva, arbusto, flores amarillas, 21-II-2011, H. A. Keller \& C. J. Keller 9700 (holotypus CTES, isotypus SI).

Arbusto erecto, ramificado, hasta 1,50 m alt. Tallo cubierto de pelos estrellados pequeños. Estípulas lanceoladas, 5-10 mm long. $\times 1$ $\mathrm{mm}$ lat., pilosas. Pecíolo 5-10 mm long., con indumento similar al del tallo. Lámina rómbico-lanceolada, hasta $9 \mathrm{~cm}$ long. $\times$ 2,5-4 $\mathrm{cm}$ lat., trinervada, margen crenado-aserrado, entero en los 10-20 mm basales, haz con pelos simples y de pocas ramas, más o menos adpresos, envés con una capa densa de pelos estrellados blanquecinos. Flores en glomérulos paucifloros axilares, con pedicelo articulado en el medio, hasta $2 \mathrm{~cm}$ long. Cáliz $7 \mathrm{~mm}$ long., en el fruto $9 \mathrm{~mm}$ long., con 10 costillas sobresalientes en la base, cubierto de pelos estrellados medianos, lóbulos $5 \mathrm{~mm}$ long. $\times 5 \mathrm{~mm}$ lat., plegados, margen con pelos simples. Corola amarilla, pétalos con la uña pilosa. Tubo estaminal $3 \mathrm{~mm}$ long., con pelos simples hialinos. Mericarpos 11-14, 2 mm long. $\times 2 \mathrm{~mm}$ lat., múticos, dorso y caras laterales reticulados, dehiscentes en el ápice, pelos simples sólo en el borde de la porción dehiscente. Semilla glabra, con pelos en el hilo.

Distribución geográfica: Sólo conocida para Paraguay oriental y el sur de la provincia de Misiones, Argentina, sobre el río Paraná.

Paratypus: PARAGUAY. Amambay: 65 km W de P. J. Caballero, hasta 1,50 m alt., 24-II-1968, Krapovickas et al. 14186 (CTES).

Material afin: ARGENTINA. Misiones: Dep. Guaraní, Predio Guaraní, 265' -59'S 54º12' 18'W, 3-III-2001, Keller 644 (falta fruto) (CTES); Dep. San Ignacio, acceso hacia parque Teyú Cuaré, Reserva Temaiken, $27^{\circ} 17^{\prime} 06^{\prime \prime} \mathrm{S}$ 55³4'14”'W, 203 m., 30-III-2012, Keller 10964 (CTES).

Obs.: Sida Kelleri de Misiones, AR y $S$. carandana de Santa Cruz, BO son las únicas especies con mericarpos múticos, se diferencian porque esta última es una planta de $1,80 \mathrm{~m}$ con tallo no ramificado y con mericarpos redondos completamente glabros, en cambio en $S$. Kelleri son de perímetro triangular, con pelos estrellados en el ápice.

Etimología: Esta especie está dedicada a Héctor H. Keller quién coleccionó el ejemplar tipo.

21. Sida Kranzii Krapov. \& Bueno, sp. nov. Fig. 16

Suffrutex 1,20-1,50 m alt. Caule stellato-piloso. Folia ovata, usque ad $10 \mathrm{~cm}$ longa et $4 \mathrm{~cm}$ lata, supra et infra stellato-pilosa. Flores glomerati, bracteis 


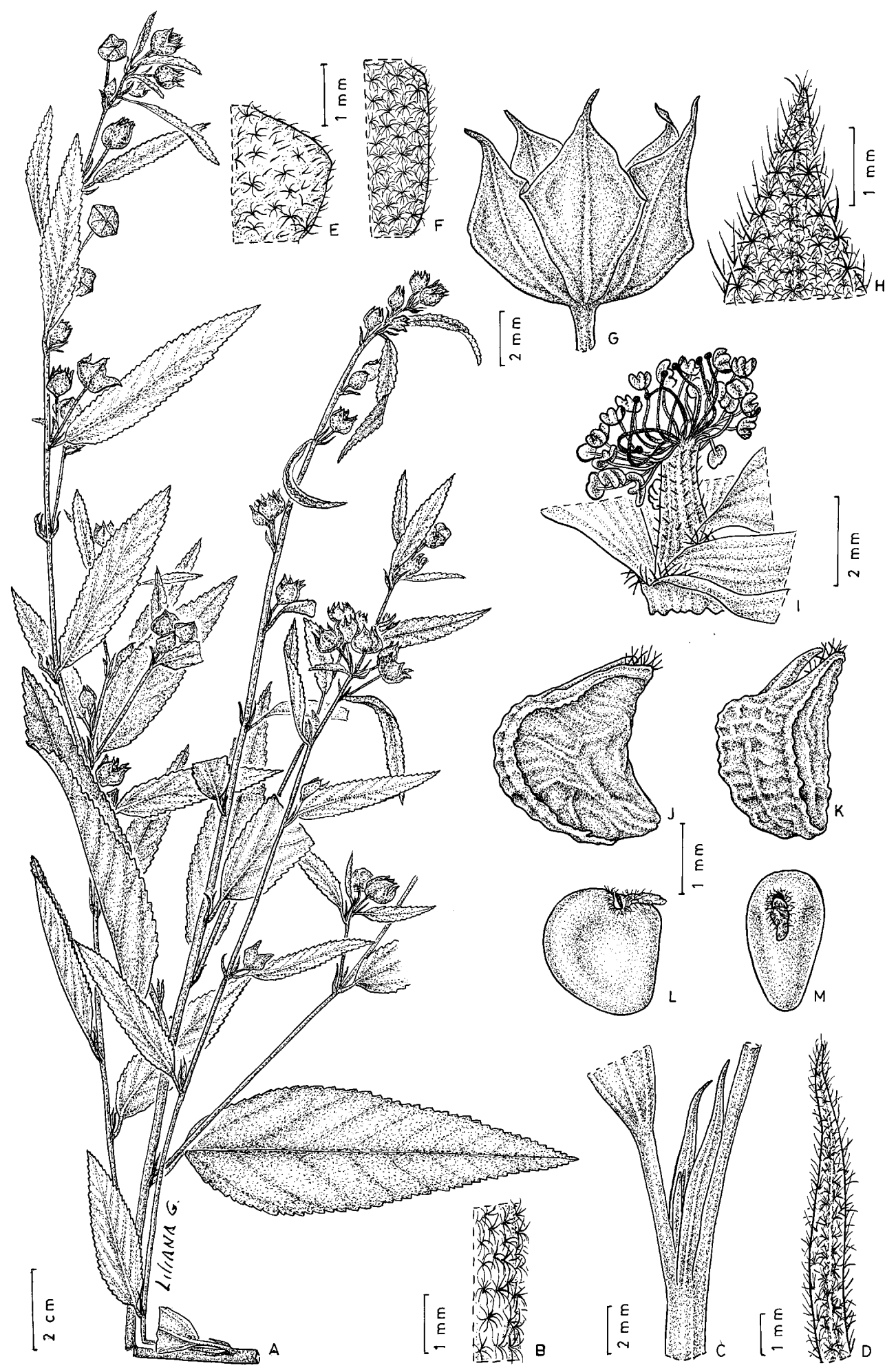

Fig. 15. Sida Kelleri. A: Rama. B: Indumento del tallo. C: Estípulas. D: Indumento de la estípula. E: Indumento del epifilo. F: Indumento del hipofilo. G: Cáliz; H: Indumento del cáliz. I: Tubo estaminal. J: Mericarpo, vista lateral. K: Mericarpo, vista dorsal. L-M: Semillas (Keller 9700). 


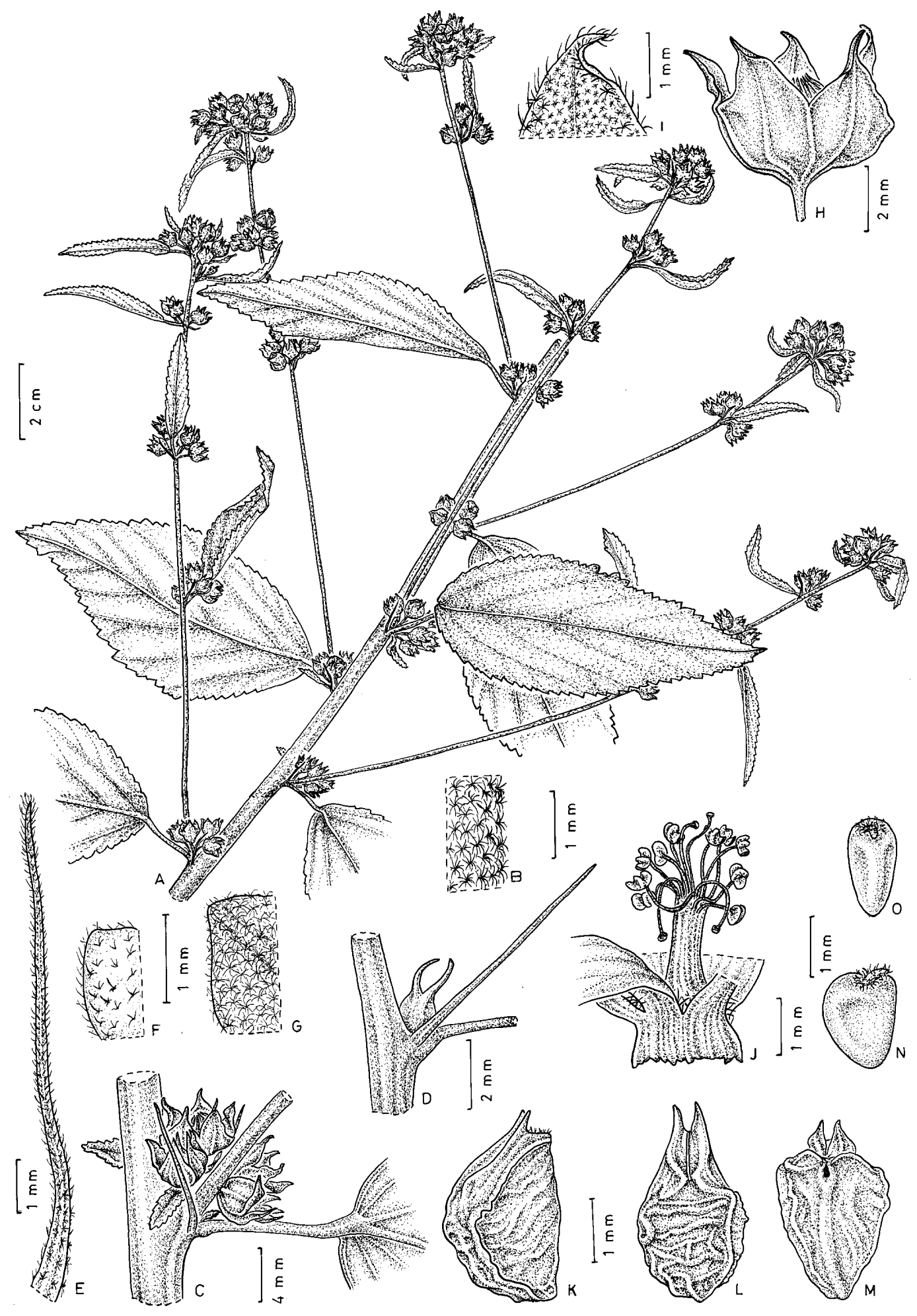

Fig. 16. Sida Kranzii. A: Rama. B: Indumento del tallo. C: Glomérulo axilar. D: Estípula y bráctea bífida. E: Estípula. F: Indumento del epifilo. G: Indumento del hipofilo. H: Cáliz. I: Indumento del cáliz. J: Tubo estaminal. K: Mericarpo, vista lateral. L: Mericarpo, vista dorsal. M: Mericarpo, vista ventral. N-O: Semillas (Kranz 495). 
bifidis. Calyx 4-5 mm longus. Tubo stamineo glabro. Mericarpia 7-10, reticulata, submutica, 3 mm longa et $2 \mathrm{~mm}$ lata.

Typus: Brasil. Paraná: Palmas, Distrito de Retiro, à beira do rio Chopim, 12-IV-1989, W. Kranz 495 (holotypus HAS 31616, isotypus CTES).

Subarbusto erecto, 1,20-1,50 m alt. Tallo con pelos estrellados muy pequeños. Estípulas filiformes, 7-13 mm long., pilosas. Pecíolo 10-15 mm long., con pelos estrellados más densos que en el tallo. Lámina ovada, ápice agudo, tri-pentanervada, margen liso hacia la base y el resto crenado-aserrado, hasta $10 \mathrm{~cm}$ long. $\times 4 \mathrm{~cm}$ lat; haz con pelos estrellados muy pequeños, algunos con un brazo más largo, blanquecino, esparcidos, envés algo más claro, con pelos estrellados algo mayores y más densos, margen con pelos simples muy pequeños. Flores en glomérulos parvifloros axilares y en cabezuelas plurifloras apicales, brácteas bífidas presentes, de $2 \mathrm{~mm}$ long. Pedicelos breves, 2-4 mm long. Cáliz 4-5 mm long., lóbulos triangulares, aguzados, $3 \mathrm{~mm}$ long. $\times 3 \mathrm{~mm}$ lat., plegados, cubierto de pelos estrellados pequeños y el margen de los lóbulos ciliado, con pelos simples breves. Corola amarilla. Uña de los pétalos pilosa. Tubo estaminal $2 \mathrm{~mm}$ long., glabro. Mericarpos 7-10, $3 \mathrm{~mm}$ long. $\times 2 \mathrm{~mm}$ lat., submúticos, reticulados, glabros. Semilla glabra, con pocos pelos en el hilo.

Nombre vernáculo: guanxuma.

Distribución geográfica: Vive en el centro-sur del estado de Paraná, donde fue coleccionada en cultivos de soja y maíz.

Paratypi: BRASIL. Paraná: Pitanga, em Rio Feio, 10-IV-1989, W. Kranz 491. (CTES, HAS); Teixeira Soares, na localidade de Fernandes Pinheiro, 6-III-1989, W. Kranz 453 (CTES, HAS).

Obs.: En general las especies de la sección tienen flores pediceladas, sólo $S$. carandana y $S$. Kranzii tienen glomérulos axilares con flores subsésiles con pedicelos 2-5 mm long. Sida Kranzii se diferencia por presentar brácteas bífidas en los glomérulos.
Etimología: El nombre de esta especie está dedicado al coleccionista W. Kranz.

\section{Sida Leitaofilhoi Krapov.}

Sida Leitaofilhoi Krapov., Bonplandia 16 (3-4): 198, fig. 3. 2007. Typus: Brasil. Minas Gerais: Mun. Santa Bárbara, Serra do Caraçá, Leitão Filho et al. 9649 (holotypus UEC, isotypi CTES, SP).

Iconografía: Krapovickas, 2007: 199, fig. 3.

Distribución geográfica: Vive en áreas montañosas, entre 800 y $1500 \mathrm{~m}$ de altura, en la Serra do Espinhaço, en el centro de Minas Gerais, Brasil.

Etimología: El nombre de esta especie está dedicado a Hermógenes de Freitas Leitao Filho, quien coleccionó el ejemplar tipo.

\section{Sida lonchitis A. St.-Hil. \& Naudin}

Sida lonchitis A. St.-Hil. \& Naudin, Ann. Sci. Nat. Bot., ser. 2, 18: 50. 1842. Lectotypus. Bresil. Rio de Janeiro: Gaudichaud 938 (P!) (Krapovickas, 2007: 196).

Sida incerta A. St.-Hil. \& Naudin, Ann. Sci. Nat. Bot. ser. 2, 18: 50. 1842. Holotypus. Bresil. Minas Geraes: (Hrb. Imperial Brasil n 95), Herb. Mus. Paris, C. Gaudichaud 1833 P!

Iconografía: Krapovickas, 2007: 197, fig. 2, A-C.

Distribución geográfica: Sur de Brasil.

Etimología: Del griego lonchitis, planta con hojas en forma de lanza o venablo.

\section{Sida loretana Krapov., sp. nov.}

Fig. 17

Suffrutex 0,80 $\mathrm{m}$ alt. Caule stellato-piloso. Folia rhombica, usque $7 \mathrm{~cm}$ longa et 3,5 cm lata, supra et infra stellato-pilosa. Flores ad axillas solitarii. Pedicelli $25 \mathrm{~mm}$ longi. Calyx 5-7 mm longus. Petala $9 \mathrm{~mm}$ longa et 5-6 mm lata. Tubo stamineo glabro. 


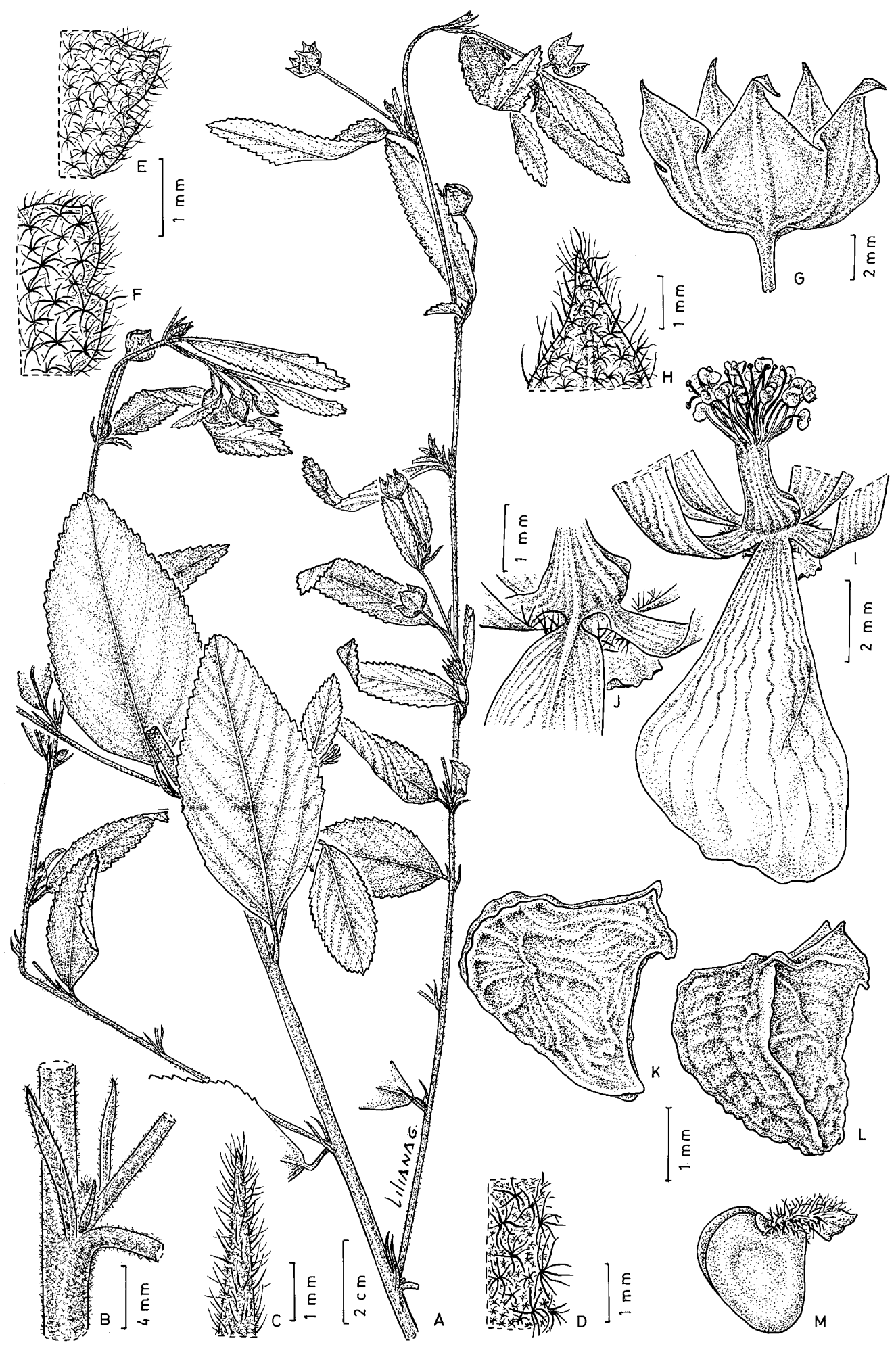

Fig. 17. Sida loretana. A: Rama. B: Estípulas. C: Indumento de la estípula. D: Indumento del tallo. E: Indumento del epifilo. F: Indumento del hipofilo. G: Cáliz. H: Indumento del cáliz. I: Pétalo y tubo estaminal. J: Base de los pétalos. K-L: Mericarpos. M: Semilla (Keller 8365). 
Carpidia 14-16, reticulata, submutica, glabra, $3 \mathrm{~mm}$ longa et $2 \mathrm{~mm}$ lata.

Typus: Argentina. Misiones: Dep. Candelaria, ruta Nac. 12, Loreto, $27^{\circ} 18^{\prime} 54,4^{\prime \prime}$ 'S - 55'32'43,3'W, 28-II2010, H. A. Keller \& N. G. Paredes 8365 (holotypus CTES)

Subarbusto erecto, $0,80 \mathrm{~m}$ alt. Tallo cubierto de una capa de pelos estrellados aplanados y con pelos estrellados mayores con radios $0,5-1 \mathrm{~mm}$ long., caedizos. Estípulas lanceoladas, 6-8 mm long. $\times 1 \mathrm{~mm}$ lat., pilosas. Pecíolo $5 \mathrm{~mm}$ long., piloso. Lámina rómbica, tri-pentanervada, las inferiores $7 \mathrm{~cm}$ long. $\times 3,5 \mathrm{~cm}$ lat., las superiores hasta $5 \mathrm{~cm}$ long. $\times 1 \mathrm{~cm}$ lat., margen entero hacia la base y luego crenado-aserrado; ambas caras cubiertas de pelos estrellados, densos, los del envés blanquecinos. Flores solitarias axilares, pedicelos $25 \mathrm{~mm}$ long., con indumento similar al del tallo. Cáliz 5-7 mm long., lóbulos aguzados, 3-4 mm long. $\times 3-5 \mathrm{~mm}$ lat., plegados, cubierto de una capa densa de pelos estrellados pequeños, margen con pelos simples breves. Pétalos $9 \mathrm{~mm}$ long. $\times$ 5-6 mm lat., uña pilosa. Tubo estaminal 2,5 mm long., glabro. Mericarpos 14-16, $3 \mathrm{~mm}$ long. $\times 2 \mathrm{~mm}$ lat., submúticos, glabros. Semilla glabra, con pocos pelos en el hilo.

Distribución geográfica: Conocida hasta ahora sólo de la localidad tipo, en el sur de la provincia de Misiones, Argentina.

Obs.: Sida loretana se caracteriza por el alto número de carpelos, 14-16, cuando en el resto de la sección la gran mayoría de las especies no pasan de los 12. De las especies que llegan a 14 carpelos se distingue porque $S$. rhombifolia es una planta farinosa, $S$. santaremensis tiene hojas dentadas casi hasta la base, S. Kelleri posee el epifilo con pelos simples y glomérulos y $S$. ramoniana tiene cáliz con pelos simples y glomérulos sobre pedúnculos 5-6 cm long.

Etimología: El nombre deriva de la localidad tipo Loreto, Misiones, Argentina.

\section{Sida magnifolia Krapov., sp. nov.}

Fig. 18

Frutex 1,50 m alt. Caule stellato-piloso. Folia rhombico-lanceolata usque ad $18 \mathrm{~cm}$ longa et $7 \mathrm{~cm}$ lata, supra pilis simplicibus, infra pilis simplicibus et stellatus. Flores axillaris. Pedicellis $3-4 \mathrm{~cm}$ longis. Calyx 10-12 mm longis. Tubo stamineo glabro. Carpidia 8, dorso reticulato, $5 \mathrm{~mm}$ longa et $3 \mathrm{~mm}$ lata, aristae 1,5 $\mathrm{mm}$ longae.

Typus: Brasil. Goiás: Mun. Cristalina, Rod. BR040, Lageado, arbusto delgado, 1,50 m, flor amarela, clareira de capão, 12-IV-1981, G. Hatschbach 43838 (holotypus MBM, isotypus CTES).

Arbusto 1,50 m alt. Tallo con pelos estrellados pequeños, esparcidos. Estípulas lineares, $7 \mathrm{~mm}$ long., con pelos estrellados pequeños. Pecíolo hasta $5 \mathrm{~cm}$ long. Lámina rómbico-lanceolada, hasta $18 \mathrm{~cm}$ long. $\times 7$ $\mathrm{cm}$ lat., trinervada, margen liso en el tercio inferior y luego crenado-aserrado, haz con pelos simples esparcidos y algunos pelos estrellados diminutos, envés con pelos simples $\mathrm{y}$ con pelos estrellados en los nervios. Flores axilares, pedicelos 3-4 cm long., articulados, en la axila presentan una rama breve, florífera. Cáliz 10-12 mm long., con 10 costillas en la base, sobresalientes, lóbulos plegados, con pelos estrellados pequeños, esparcidos. Corola amarilla, pétalos con la uña pilosa. Tubo estaminal $2 \mathrm{~mm}$ long., glabro. Mericarpos 8, 5 $\mathrm{mm}$ long. $\times 3 \mathrm{~mm}$ lat., dorso reticulado, caras laterales estriadas, aristas $1,5 \mathrm{~mm}$ long. con pelos estrellados. Semilla glabra, con pelos en el hilo.

Distribución geográfica: Sólo conocida de dos localidades próximas, Brasilia y el municipio limítrofe de Cristalina, en Goiás. Fue coleccionada en el "margen da mata ciliar" y en una "clareira de capão".

Paratypus: BRASIL. Distrito Federal: Brasilia, na Zoobotanica de Brasilia, 26-V-1966, Heringer 11108 (CTES, HB).

Obs.: Sida magnifolia se destaca por tamaño de sus hojas, hasta $18 \mathrm{~cm}$ long. cuando en el resto de la sección la gran mayoría de sus especies apenas llegan a los $10 \mathrm{~cm}$ con excepción de $S$. Honoriana, que llega a $13 \mathrm{~cm}$.

Etimología: El nombre se refiere al gran 


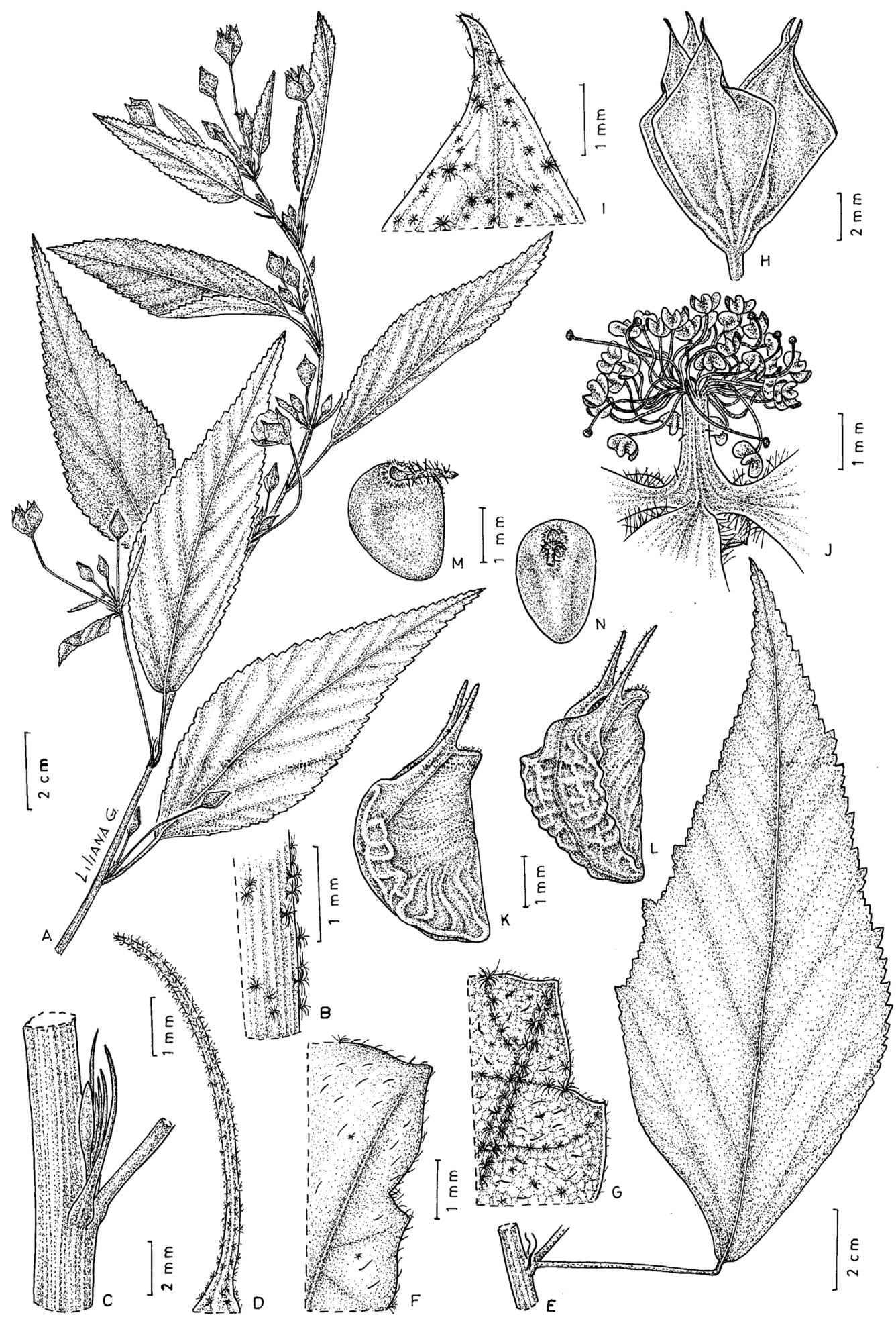

Fig. 18. Sida magnifolia. A: Rama. B: Indumento del tallo. C: Estípulas. D: Indumento de la estípula. E: Hoja. F: Indumento del epifilo. G: Indumento del hipofilo. H: Cáliz. I: Indumento del cáliz. J: Tubo estaminal. K: Mericarpo, vista lateral. L: Mericarpo, vista dorsal. M-N: Semillas (A-I, Hatschbach 43838, J-N Heringer 11108). 
tamaño de la hoja, que se destaca entre todas las especies de la sección Sida.

\section{Sida palustris Krapov., sp. nov.}

Fig. 19

Frutex 1,70 m alt. Caule stellato-piloso et pilis simplicibus $1 \mathrm{~mm}$ long. inspersis. Folia rhombicolanceolata, usque ad $9 \mathrm{~cm}$ longa et $3,5 \mathrm{~cm}$ lata, supra et infra stellato-pilosa. Flores glomerati, bracteis bifidi praesenti. Calyx 5-7 mm long. Carpidia 9, reticulata, $4 \mathrm{~mm}$ longa et $2,5 \mathrm{~mm}$ lata, aristae 0,5-0,7 longae.

Typus: Argentina. Misiones: Dep. Candelaria, $10 \mathrm{~km} \mathrm{E}$, del cruce de ruta 12 y camino a Oberá, en pantano, erecta, flores amarillas, 24-II-1985, $A$. Schinini, I. Caponio \& M. Urbani 24301 (holotypus CTES).

Arbusto erecto, 1,70 m alt. Tallo con pelos estrellados pequeños que dejan ver la epidermis y pelos simples $1 \mathrm{~mm}$ long., abundantes en las partes jóvenes. Estípulas lineares, 7-10 mm long. Pecíolo 5-10 mm long. Lámina rómbicolanceolada, hasta $9 \mathrm{~cm}$ long. $\times 3,5 \mathrm{~cm}$ lat., ápice agudo, margen crenado-aserrado, entero hacia la base; haz cubierto de pelos estrellados muy pequeños, envés con pelos estrellados algo mayores, densos, blanquecinos y en hojas jóvenes también algunos pelos simples $1 \mathrm{~mm}$ long. Flores agrupadas en glomérulos axilares 5-10-floros, brácteas bífidas presentes. Pedicelo 2-10 mm long., con pelos estrellados muy pequeños y pelos simples $1 \mathrm{~mm}$ long. Cáliz 5-7 $\mathrm{mm}$ long., con 10 nervios gruesos en la base, estrellado tomentoso y con pelos simples en los nervios principales y en el margen de los lóbulos, lóbulos plegados. Corola amarilla. Uña de los pétalos con pelos. Tubo estaminal 2 $\mathrm{mm}$ long., con pelos glandulares punctiformes. Mericarpos 9, negros, subglabros, $4 \mathrm{~mm}$ long. $\times 2,5 \mathrm{~mm}$ lat., aristas $0,5-0,7 \mathrm{~mm}$ long., caras laterales reticuladas hacia la base. Semillas glabras, sólo con pelos en el hilo.

Distribución geográfica: Vive en pantanos en el sur de la provincia de Misiones, Argentina.

Obs.: De las especies de la sección Sida sólo dos tienen brácteas bífidas y pelos simples en el tallo: S. Honoriana y S. palustris. Se diferencian porque la primera tiene flores solitarias, cáliz sólo con pelos estrellados muy pequeños, mericarpos con aristas del largo del cuerpo, con pelos estrellados. En cambio $S$. palustris tiene flores en glomérulos axilares, el margen de los lóbulos del cáliz con pelos simples y mericarpos glabros con aristas breves, 0,5-0,7 $\mathrm{mm}$ long.

Etimología: El nombre se refiere al habitat acuático de esta especie.

\section{Sida Poeppigiana (K. Schum.) Fryxell}

Sida Poeppgiana (K. Schum.) Fryxell. Malvaceae in G. Harling \& Andersson, Flora of Ecuador 44: 106-108. 1992.

Sida rhombifolia L. var. Poeppigiana K. Schum., Martius, Fl. bras. 12 (3): 339. 1891. Typus. PERU. Poeppig 45 [lectotypus G!, aquí designado, Foto F-7985!)] (B, destruído).

\section{Iconografia: Fuertes 1995, fig. 19.}

Arbusto erecto, hasta $2 \mathrm{~m}$ alt. Tallo pubescente con pelos simples 0,5-1,5 mm long. y también pelos estrellados pequeños. Estípulas 4-8 mm long. Pecíolos 1-1,5 cm long. Lámina elíptica o subrómbica, $2,5-9 \mathrm{~cm}$ long., truncada o cuneada, margen entero hacia la base y aserrado hacia el ápice, discolora, ambas caras puberulentas y con frecuencia algunos pelos largos sobre los nervios en el envés. Flores solitarias o de a dos en las axilas. Pedicelos 1-3 cm long., articulados 10-13 mm por debajo del cáliz, pubescentes como el tallo. Cáliz 8-9 mm long., con 10 costillas en la base, hirsuto, especialmente en la base. Pétalos algo más largos que el cáliz, amarillos, usualmente con una mancha roja en la base. Estilos 8-12. Mericarpos 3-4 mm long. $\times 2,5 \mathrm{~mm}$ lat., aristas apicales 1,5-4 mm long., rectas.

Distribución geográfica: Especie andina que se extiende desde Venezuela hasta el norte de Bolivia, entre los 1000 y 2300 m de altura.

Material estudiado: VENEZUELA. Lara: 


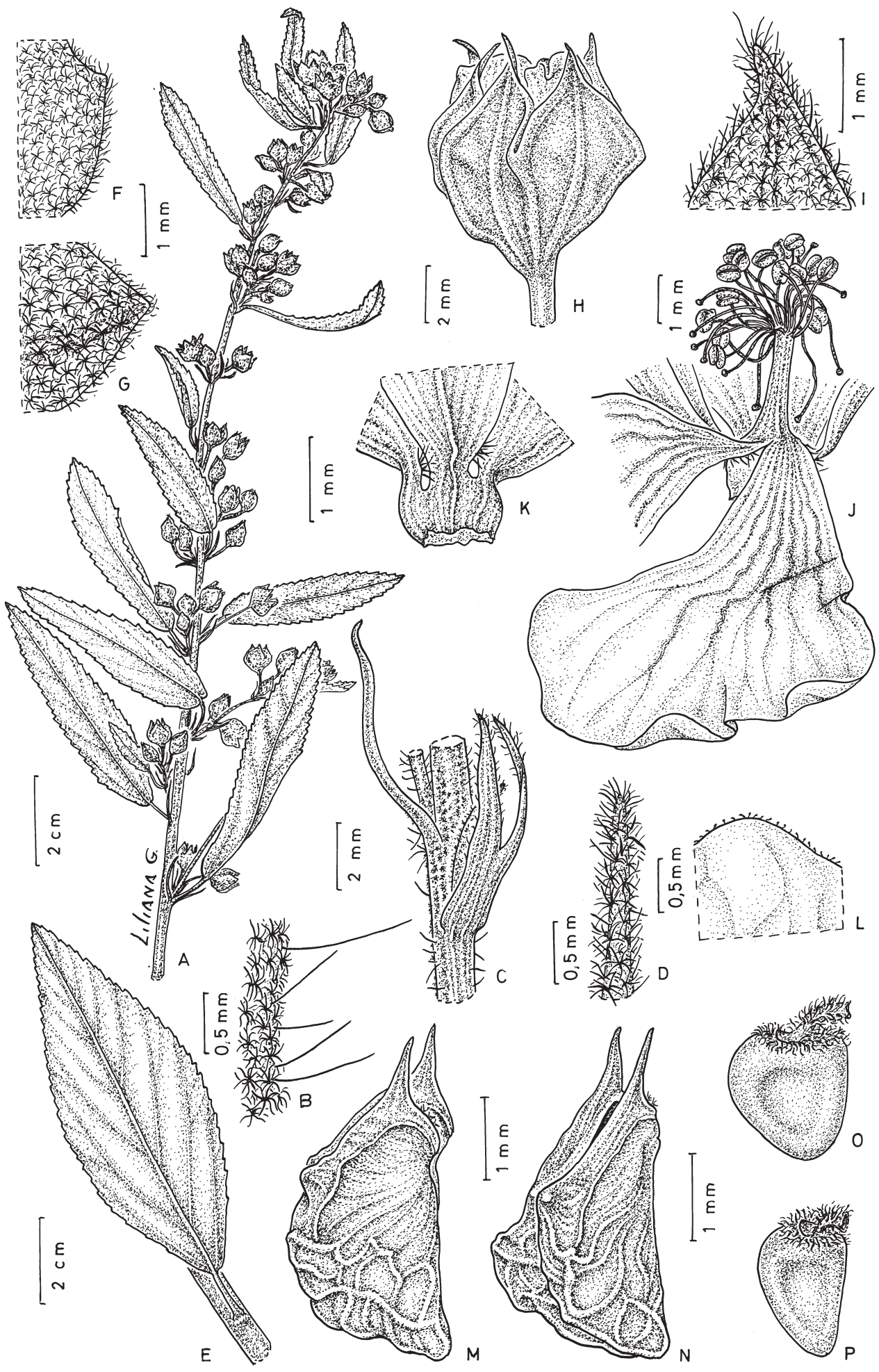

Fig. 19. Sida palustris. A: Rama. B: Indumento del tallo. C: Bráctea bífida y estípula. D: Indumento de la estípula. E: Hoja. F: Indumento del epifilo. G: Indumento del hipofilo. H: Cáliz. I: Indumento del cáliz. J: Pétalo y tubo estaminal. K: Base de la corola. L: Margen de pétalo. M-N: Mericarpos. O-P: Semillas (Schinini 24301). 
road Fila las Goteras - Buenos Aires, $1350 \mathrm{~m}$, 31-I-1984, Fryxell \& Burandt 4382 (CTES). Mérida: Mérida, 1800 m., 30-VI-1964, Breteler 3984 (NY); Mérida, 1600 m, 30-I-1984, Fryxell \& Aymard 4368 (CTES). Portuguesa: Dep. Sucre, La Divisoria de la Concepción, $5 \mathrm{~km}$ NW del caserío Las Flores, $9^{\circ} 18^{\prime} \mathrm{N} 70^{\circ} 06^{\prime} \mathrm{W}, 1300-1500 \mathrm{~m}, 17-\mathrm{X}$ 1985, Aymard et al. 4242 (CTES). Tachira: inter Betania, Villa Paz et Delicias, 2200-2300 m, 14XI-1976, Charpin \& Jacquemoud 13328 (CTES, G). Trujillo: Between Trujillo and Boconó, 2200 m, 30-I-1939, Alston 6428 (NY); Dep. Boconó, Laguna Aguas Negras, $8 \mathrm{~km} \mathrm{SW}$ de Batatal, 2000 m, 17-XI-1986, Aymard \& Ortega 4923 (CTES); Parque Nacional Guaramacal, sector quebrada Honda-Pele Ojo, El Santuario, 1960-2100 m, I-2001, Stergios \& Caracas 19016 (CTES); COLOMBIA. Cundinamarca: Finca Los Sauces, 48 km W de Bogotá, 22-V-1999, Silverstone-Sopkin \& Clavijo 8239 (CTES, CUVC). ECUADOR. Guayas: $5 \mathrm{~km} \mathrm{~N}$ of Balzar, $1^{\circ} 20^{\prime} \mathrm{S}, 79^{\circ} 54^{\prime} \mathrm{W}$, 25 m, 18-V-1968, Holm Nielsen \& Jeppesen 44 (AAU, CTES). Pastaza: Topo, río Topo, 1300 m, 11-VI-1962, Dodson \& Thien 2088 (CTES); 3,6 km W of Puyo, 990 m, 1-IX-1979, Stuessy 5821 (CTES). Pichincha: Pampas Argentinas, 15 $\mathrm{km} \mathrm{S}$ de carretera Quito-Aloag-Santo Domingo, $0^{\circ} 23^{\prime} \mathrm{S}, 7^{\circ} 30^{\prime} \mathrm{W}, 1300-1550 \mathrm{~m}, 17-\mathrm{IV}-1988$, Zak \& Jaramillo 3469 (CTES, MO). Tungurahua: Rio Pastaza, between Machai and La Victoria, 1400 m, 24-VII-1939, Asplund 8506 (P). Sucumbíos: Gonzalo Pizarro, Canton Reventador. El Salado, río Quijos, $0^{\circ} 1^{\prime} \mathrm{S}, 7^{\circ} 36^{\prime} \mathrm{W}, 1400 \mathrm{~m}$, Cerón \& Ayala 10028 (CTES, QCNE, MO). PERÚ. Cusco: Machupicchu, 2400 m, 9.VII.1982, Krapovickas \& Cristóbal 38166 (CTES); Machupicchu, 2000 m, 9-VII-1982, Krapovickas \& Cristóbal 38168 (CTES). BOLIVIA. Cochabamba: Prov. Chapare, Paracti, Cachaca, 2600 m, 25-VII-1994, Ferrucci et al. 894 (CTES); $3 \mathrm{~km} \mathrm{~N}$ del río Vinto, $17^{\circ} 12^{\prime} \mathrm{S}$ 6550'W, 27-VII-2003, Ferrucci et al. 1946 (CTES); íd., Ferrucci et al. 1947 (CTES). La Paz: Prov. Murillo, Valle de Zongo, $32 \mathrm{~km}$ después de la cumbre, 2000-2200 m, 20-VIII-1979, Beck 2170 (CTES, LPB); Valle de Zongo, Jarca, 1800 m, 31V-1980, Beck 3655 (CTES, LPB): Valle de Zongo, 2250 m, 1-II-1981, Beck 3994 (CTES, LPB); bajando de la cumbre del Valle de Zongo $32,5 \mathrm{~km}$, 2340 m, 16-VII-1985, Beck 11308 (CTES, LPB); Valle del Zongo, $16^{\circ} 07^{\prime} \mathrm{S} 68^{\circ} 07^{\prime} \mathrm{W}, 2500 \mathrm{~m}, 16-\mathrm{III}-$ 1984, Solomon et al. 11921 (CTES, MO); Valle del
Río Zongo, río Jachona Cruz, $16^{\circ} 07^{\prime} \mathrm{S} 68^{\circ} 04^{\prime} \mathrm{W}$, 2200 m, 14-II-1988, Solomon 17821 (CTES, MO); $74 \mathrm{~km}$ de La Paz por el Valle de Zongo, $2200 \mathrm{~m}$, 24-V-1991, Fortunato 1842 (BAB, CTES); Prov. Nor Yungas, Suapi, NNW de Coroico, $1300 \mathrm{~m}$, 30-IV-1983, Beck 8341 (CTES, LPB); Coroico, 6-VI-1996, Krapovickas 46762 (CTES); 12 km $\mathrm{N}$ de Chupipata, $16^{\circ} 15^{\prime} \mathrm{S}, 67^{\circ} 06^{\prime} \mathrm{W}, 1-\mathrm{VIII}-2003$, Ferrucci et al. 2001 (CTES); Prov. Sud Yungas, Camino de los Incas, ca. $50 \mathrm{~km}$ E de La Paz, entre Taquesi y la mina Chojilla, 2100-2400 m, 13-IXIX-1981, Beck 4774 (CTES, LPB); Chojilla, 2000 m, 14-VII-1991, Schmit 118 (CTES, LPB); Prov. Tamayo, Parque Nacional Madidi, Piñalito, 30 km E de Apolo, 14⒉'S, 68²' 'W, 1750 m, 10VII-2002, Araujo et al. 233 (CTES, LPB, MO). Santa Cruz. Prov. Caballero, K'arawasi, $17^{\circ} 45^{\prime} \mathrm{S}$ 6445'W, 1900 m, 20-VII-1996, Saldias \& Claros 4478 (CTES, USZ).

Obs. 1: Por sus hojas puberulentas Sida Poeppigiana es afín a S. setosa y S. rhombifolia. Se diferencia de ellas por el mechón de pelos simples, largos, en la base del cáliz y ápice del pedicelo. Sida rhombifolia es totalmente pubérula y no tiene ningún pelo mayor de 0,1 $\mathrm{mm}$ long. Sida setosa tiene mericarpos con aristas el doble de largo que la longitud del cuerpo del mericarpo y sus flores están en inflorescencias con pedúnculo de unos $5 \mathrm{~cm}$ long., pedicelos florales de $2 \mathrm{~mm}$ long.

Obs. 2: Hay una serie de ejemplares provenientes de Colombia que tienen mericarpos con una sola arista apical, situación que también se presenta en Sida rhombifolia y que ha llevado a describirlas como especies diferentes y que en general no han sido aceptadas. Por otro lado, el material estudiado no difiere por el resto de sus caracteres de $S$. Poeppigiana típica.

Material estudiado: COLOMBIA. Cauca: Mun. Santander Quilich, Bosque de San Julián, 1000 m s.m., 1-II-1999, Ramos \& Reina 3531 (CTES, CUVC); Valle del Cauca: Mun. Caicedonia, $7 \mathrm{~km} \mathrm{~N}$ de Caicedonia, $4^{\circ} 23^{\prime} \mathrm{N}, 75^{\circ} 48^{\prime} \mathrm{W}, 11-\mathrm{VI}-$ 1994, Silverstone-Sopkin \& Paz 6755 (CTES; CUVC); Mun. La Cumbre, Carretera CrestegalloMontañitas, 1500 m s.m., 14-V-1994, J. E. Ramos \& L. H. Ramos 4533 (CTES; CUVC); Mun. Yumbo, 
Ruta Oleoducto del Pacífico, entre MontañitasMulaló, en su parte más alta. $1350 \mathrm{~m}$ s.m., 16-V1994, J. E. Ramos \& L. H. Ramos 4732 (CTES, CUVC).

Etimología: Especie dedicada al botánico alemán E. F. Poeppig.

\section{Sida ramoniana Krapov., sp. nov.}

Fig. 20

Frutex $2 \mathrm{~m}$ alt. Caule stellato-piloso. Folia oval-lanceolata, usque $10 \mathrm{~cm}$ longa et $2,5 \mathrm{~cm}$ lata, crenato-serrulata, supra et infra stellato-pilosa. Flores subsessiles, ad axillas congeste insertis. Calyx $5 \mathrm{~mm}$ longus, ad basim et ad margines dentium hispido. Petala flava, 8-10 mm longa. Tubo stamineo $4 \mathrm{~mm}$ longus, glabro. Carpidia 12-13, submutica, dorso pauce reticulato, $2,5 \mathrm{~mm}$ longa et $2 \mathrm{~mm}$ lata.

Typus: Argentina. Misiones: Dep. Oberá. Arroyo Ramón, $5 \mathrm{~km}$ E de ruta nac. $14 \mathrm{y}$ acceso a ciudad de Oberá, $27^{\circ} 27^{\prime} 56,4^{\prime}$ 'S-5502'08,4”W, 269 m, bañado, arbusto hasta $2 \mathrm{~m}$, flores amarillas cerradas a media mañana en día lluvioso, follaje verde-amarillento, 16-II-2012, H. A. Keller \& N. G. Paredes 10825 (holotypus CTES, isotypi FCQ, K, LIL, MBM, MO, NY, SI).

Arbusto hasta $2 \mathrm{~m}$ alt. Tallo cubierto de pelos estrellados. Estípulas lineares, $16 \mathrm{~mm}$ long., estrellado-tomentosas. Pecíolo 10-15 $\mathrm{mm}$ long. Lámina oval-lanceolada, hasta 10 $\mathrm{cm}$ long. $\times 2,5 \mathrm{~cm}$ lat., margen levemente crenado-aserrado, hacia la base liso, epifilo estrellado-piloso, hipofilo con pelos estrellados blanquecinos y pelos simples sobre los nervios. Flores en glomérulos sobre pedúnculo 5-6 $\mathrm{cm}$ long. Pedicelos 2-5 mm long. Cáliz 5 $\mathrm{mm}$ long., cubierto de pelos estrellados y con pelos simples en el margen de los lóbulos, en los nervios y ápice del pedicelo, costillas basales pilosas. Corola amarilla. Pétalos 8-10 mm long., uña pilosa. Tubo estaminal $4 \mathrm{~mm}$ long., glabro. Mericarpos 12-13, suavemente reticulados, submúticos, $2,5 \mathrm{~mm}$ long. $\times 2 \mathrm{~mm}$ lat., aristas muy breves, con pelos estrellados muy pequeños. Semilla glabra, con pocos pelos en el hilo.
Distribución geográfica: Vive en bañados, en campos del centro de la provincia de Misiones, Argentina.

Paratypi: ARGENTINA. Misiones: Dep. Oberá, ruta prov. 103, intersección con arroyo Ramón, $27^{\circ} 27^{\prime} 55,6^{\prime \prime}$ S-5502'07,3”W, 272 m, 26-II-2011, Keller \& Paredes 9809 (CTES, SI).

Obs.: Las especies de la sección Sida con pelos simples en la base del cáliz son $S$. ramoniana, de Misiones, AR y S. Poeppigiana, de Colombia a Bolivia. Sida Poeppigiana tiene el tallo y el hipofilo con pelos simples y los mericarpos con aristas 1,5-4 mm long. En cambio en $S$. ramoniana faltan los pelos simples y los mericarpos son submúticos.

Etimología: El nombre deriva del arroyo Ramón, dep. Oberá, Misiones, Argentina, donde se coleccionó el material tipo.

\section{Sida rhombifolia L.}

Sida rhombifolia L., Sp. pl. 2: 684. 1753. "[Sida] rhombifolia 2". "Habitat in India utraque". Lectotypus (Rodrigo 1944. tab. 28) Sida 2 rhombifolia, Herb. Linn. 866.3 (LINN!). Indumento de pelos pequeñísimos. Mericarpos con 2 aristas cortas.

Iconografía: Fuertes (1995; 99, fig. 18), Sivarajan \& Pradep (1994: 72, fig. 2),

Subarbusto hasta $1 \mathrm{~m}$ alt., con raíces profundas, leñosas. Tallo estrellado-pubérulo. Estípulas aleznadas, filiformes 5-8 mm long. Pecíolos breves, 3-7 mm long. Lámina ovalromboidea, rómbica o rombo-lanceolada, 2-7 cm long. $\times 0,3-2 \mathrm{~cm}$ lat., margen dentado en la $1 / 2$ o $2 / 3$ superiores, ambas caras estrelladopuberulentas a farináceas. Flores solitarias. Pedicelos 1-3 cm long., articulados hacia el ápice. Cáliz 5-8 mm long., con 10 costillas en la base, puberulento. Pétalos 7-12 $\mathrm{mm}$ long. $\times 10 \mathrm{~mm}$ lat., amarillos, generalmente sin mancha oscura basal. Gineceo 10-14 carpelar. Mericarpos trígono- aplanados, reticulados en la mitad inferior, $3 \mathrm{~mm}$ long. $\times 2,8 \mathrm{~mm}$ lat., dehiscentes en el ápice y con dos aristas hasta 2 


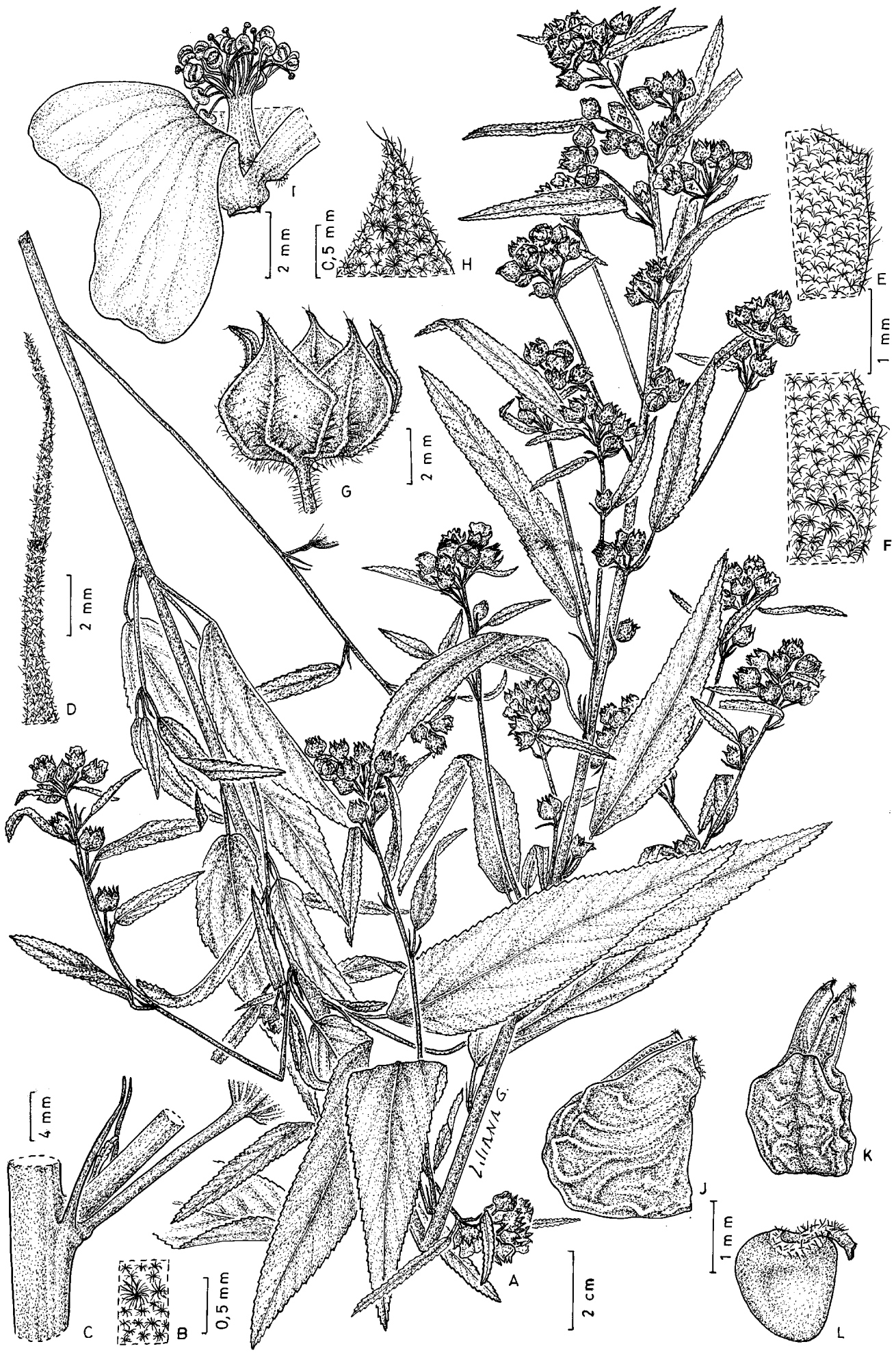

Fig. 20. Sida ramoniana. A: Rama. B: Indumento del tallo. C: Indumento de la estípula. D: Estípula. E: Indumento del epifilo. F: Indumento del hipofilo. G: Cáliz. H: Indumento del cáliz. I: Pétalo y tubo estaminal. J: Mericarpo, vista lateral. K: Mericarpo, vista dorsal. L: Semilla (Keller 10825). 
mm long., a veces indehiscentes con dos aristas rudimentarias unidas. Semilla solitaria, glabra, con pelitos blancos rodeando el hilo.

Nombres vernáculos: "afata", "mataalfalfa", "escoba dura" (Argentina).

Distribución geográfica: Invasora, maleza cosmopolita, ruderal, arvense y viaria.

Obs.: Sida rhombifolia es una especie que se distingue fácilmente por su indumento estrellado-pubérulo o farináceo en toda la planta, con pelos menores de $0,1 \mathrm{~mm}$ long. La importancia de este caracter fue señalada por Fryxell (1988) y Sivarajian \& Pradep (1994), con lo cual queda aclarada su identidad.

\section{Sida santaremensis Monteiro}

Sida santaremnensis Monteiro, O genero Sida: 25 (clave), 44-46, tab. VIII. 1936. Holotypus: Brasil. Pará: Santarém, 1933, B.M. da Costa 49A (RBR!).

Sida santaremensis Monteiro, Lilloa 17: 510 y 512 fig. 1. Corrige la terminación y así figura en el Index Kewensis.

Sida rhombifolia L. var. subtomentosa K. Schum. Mart. Fl. bras. 12 (3): 339. 1891. Lectotypus: PARAGUAY. Asunción, Balansa 1617 (P!) (aquí designado).

Iconografía: Rodrigo, 1944, figs. 36 y 37 (2) (sub Sida Glaziovii K. Schum.). Fuertes Aguilar, 1995: 115, fig. 21.

Subarbusto erecto, $40-80 \mathrm{~cm}$ alt. Tallo estrellado-pubérulo. Estípulas subuladas 2-8 $\mathrm{mm}$ long. Pecíolo 6-10 mm long., estrelladopubérulo. Lámina 3-6 cm long. × 1-2,5 lat., ovado-elíptica, con la base cuneada y ápice agudo, margen dentado-aserrado casi hasta la base, trinervada, haz laxamente estrelladopubérulo y envés densamente estrelladopubérulo. Flores solitarias o en glomérulos axilares. Pedicelos 5-12 mm long., después de la antesis llegan hasta $15-18 \mathrm{~mm}$ long. Cáliz 4,5-6,5 mm long., acrescente, con 10 costillas prominentes en la base, estrellado-pubérulo. Pétalos 6-12 mm long. $\times$ 4-6 mm lat, amarillos. Mericarpos 10, $3 \mathrm{~mm}$ long. $\times 3 \mathrm{~mm}$ lat., caras laterales reticuladas, con dos aristas apicales muy breves, menores de $1 \mathrm{~mm}$.

Distribución geográfica: Es una planta ruderal citada para EEUU, Florida (Fryxell et al., 1984) y para Colombia (Fuertes Aguilar, 1995). Crece en zonas bajas de Brasil, Bolivia, Paraguay y norte argentino.

\section{Sida Saraviae Krapov., sp. nov. Fig. 21}

Frutex 0,50-2 m alt. Caule stellato-piloso. Stipulae lineares, $6 \mathrm{~mm}$ long. Petiolus $0,5 \mathrm{~cm}$ longus. Lamina atque $7 \mathrm{~cm}$ long. et $2 \mathrm{~cm}$ lat., rhombico-lanceolata, supra pilis simplicibus, infra pilis stellatus et pilis simplicibus. Floribus solitaris, pedicellis 1,5-3 cm long. Tubo stamineo piloso. Carpidia 8-10, reticulata, $3 \mathrm{~mm}$ long. et $2 \mathrm{~mm}$ lat., aristae 0,5-1,5 mm long., pilosae.

Typus: Argentina. Salta: Dep. Orán, Cordillera Oriental, Sierra de Zenta, San Andrés, $23^{\circ} 05^{\prime} \mathrm{S}$ 6452'W, 1780-1800 m, A. Schinini, C. Saravia Toledo \& R. Neumann 34766 (holotypus CTES, isotypus NY).

Arbusto 0,50-2 m alt. Tallo cubierto de pelos estrellados pequeños. Estípulas lineares, 6 $\mathrm{mm}$ long. Pecíolo breve, $0,5 \mathrm{~cm}$ long. Lámina rómbico-lanceolada, hasta $7 \mathrm{~cm}$ long. $\times 2 \mathrm{~cm}$ lat., trinervada, margen crenado-aserrado en los $2 / 3$ superiores, haz con pelos simples $0,3 \mathrm{~mm}$ long. y algunos estrellados pequeños, raro con pelos simples o estrellados en una misma rama, envés verde amarillento, con pelos estrellados muy pequeños, pelos simples $0,7 \mathrm{~mm}$ long. y pelos estrellados o ramificados mayores sobre los nervios. Flores solitarias axilares. Pedicelos 1,5-3 cm long. Cáliz $5 \mathrm{~mm}$ long., con 10 costillas basales prominentes, cubierto de pelos estrellados pequeños, lóbulos plegados. Corola amarillo-anaranjada con mancha púrpura basal o sin mancha. Tubo estaminal 2-3 mm long., con pelos estrellados. Mericarpos 8-10, $3 \mathrm{~mm}$ long. $\times 2 \mathrm{~mm}$ lat., caras laterales levemente estriadas, cara dorsal levemente reticulada, casi lisa, glabras, aristas 2, 0,5-1,5 mm long., con pelos estrellados muy pequeños. Semilla glabra, con pocos pelos en el hilo. 2 n=14 cromosomas. 


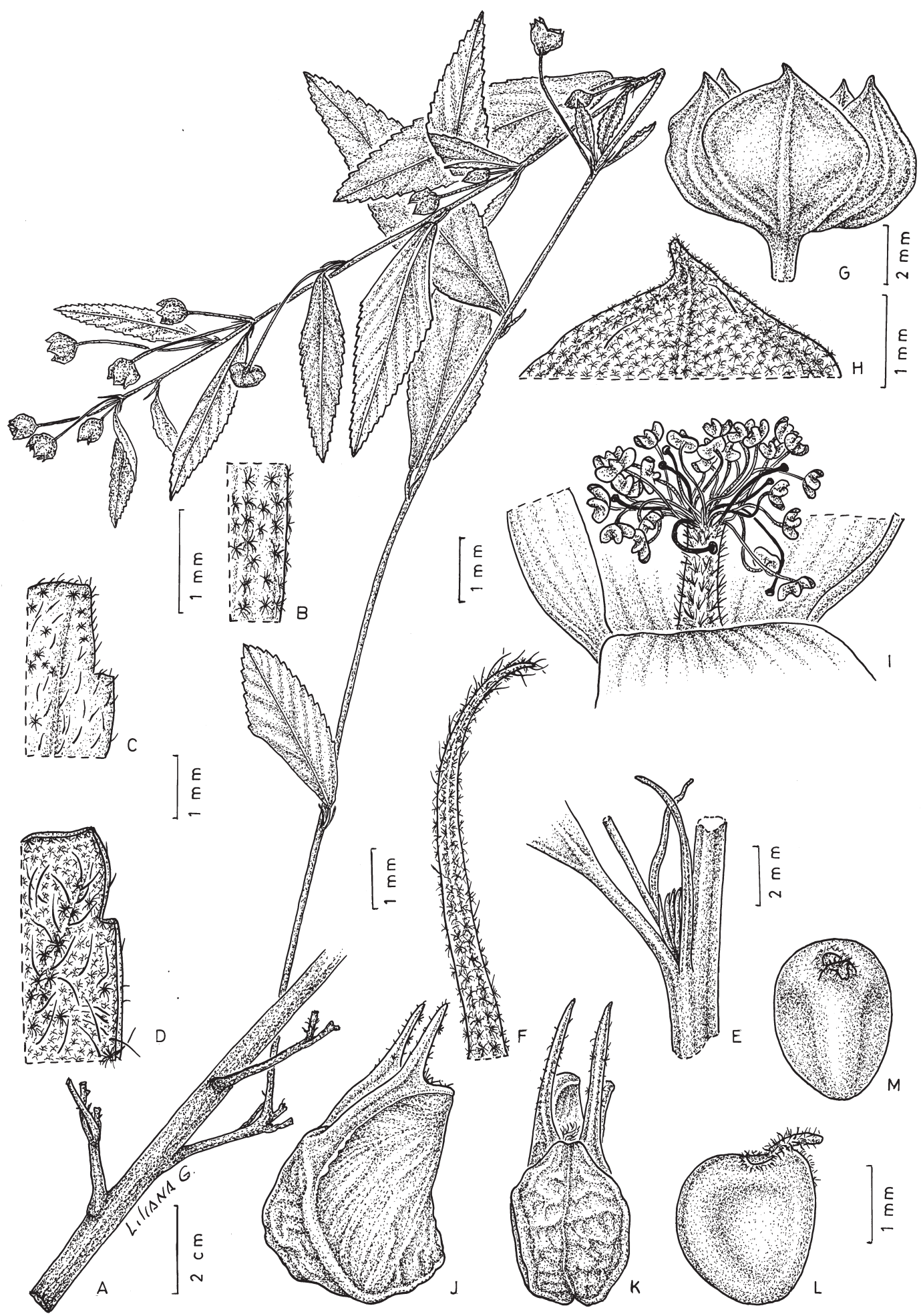

Fig. 21. Sida Saraviae. A: Rama. B: Indumento del tallo. C: Indumento del epifilo. D: Indumento del hipofilo. E: Estípulas. F: Indumento de la estípula. G: Cáliz. H: Indumento del cáliz. I: Tubo estaminal. J: Mericarpo, vista lateral. K: Mericarpo, vista dorsal. L-M: Semillas (A-H, J-M, Schinini \& al. 34766, I, Ahumada 4183). 
Distribución geográfica: Especie del noroeste de Argentina, Bolivia y Perú, entre 800 y $2900 \mathrm{~m}$ de altura.

\section{Paratypi: ARGENTINA. Córdoba:} Ascochinga, IV-1871, Lorentz 286 (CORD); Colón, Río Ceballos, La Quebrada, 2-III-1984, Krapovickas \& Vanni 39505 (CTES); Santa María, Comuna La Paisanita, $31^{\circ} 43^{\prime} \mathrm{S}, 64^{\circ} 28^{\prime} \mathrm{W}, 580$ m, 4-I-2008. Keller 4641 (CTES). Jujuy: Dep. Capital, San Salvador de Jujuy, Parque Botánico, 27-X-1986, Ahumada 5256 (CTES, JUA); Sierra de Zapla, Mina 9 de Octubre, 25-II-1971, Cabrera et al. 21612 (CTES, LP); Yala, 1445 m, 29-III-1977, Krapovickas \& Schinini 30711 (CTES); El Cucho,

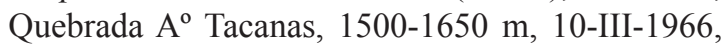
de la Sota 4343 (CTES, LP); entre Los Blancos y El Cucho, 28-IV-1981, Ahumada et al 4183 (CTES, JUA); La Almona, 16-I-1968, Cabrera et al. 19052 (CTES, LP); Dep. Ledesmma, Parque Nacional

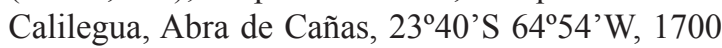
m, 3-XI-1998, Ahumada \& Agüero 8580 (CTES, JUA). La Rioja: $1 \mathrm{~km}$ de Agua Blanca por la quebrada del Salto, faldeo oriental de la Sierra de Velasco, frente a la ciudad de La Rioja, 23-I-1997, Biurrum et al. 4668 (CTES). Salta: Dep. Chicoana, Chicoana, Los Los, 7-V-1975, Krapovickas et al. 28261 (CTES); Dep. Metán, Metán Viejo, río Metán, 28-III-1975, Krapovickas et al. 27925 (CTES); Dep. Orán, San Andrés, 1800 m, 15-XI1997, Saravia Toledo 13968 (CTES); Dep. Santa Victoria, P. N. Baritú, 1-XII-1997, Hilgert 1982 (CTES, MCNS). Tucumán: Siambón, III-1872, Lorentz 278 (CORD); Dep. Famaillá, Quebrada de Lules, río Lules, 4-III-1945, Herrera 221 (CTES, LIL); Dep. Tafí, San Javier, Parque Aconquija, V-1948, Krapovickas 4796 (LIL); San Javier, Ciudad Universitaria, 28-XII-1980, Krapovickas \& Cristóbal 37108 (CTES); Dep. Trancas, S. Pedro de Colalao, 6-I-1969, Krapovickas \& Cristóbal 15338 (CTES). BOLIVIA. Cochabamba: Prov. Cercado, área norte del Valle de Cochabamba, 2570 m, 11IV-1966, Steinbach 51 b (CTES); Inquisivi, rio Khatu, ca. $4 \mathrm{~km} \mathrm{~W}$ of Insiquivi, $16^{\circ} 55^{\prime} \mathrm{S} 67^{\circ} 10^{\prime} \mathrm{W}$, 2450-2500 m, 18-I-1989, Lewiz 35133 (CTES, LPB, MO). La Paz: Prov. Larecaja, Sorata, 2700 m, 27-V-1991, Krapovickas \& Fortunato 43944

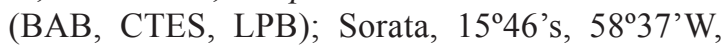
2950 m, 30-XII-2006, Casas Opaza 32 (CTES, LPB). Santa Cruz: Prov. Cordillera, Manuel María Caballero. Río Arriba, 3 km N de Comarapa,
17²42'S, 64³3’W, 1900 m, 30-III-1996, Balcazar \& Franco 469 (CTES, USZ); Prov. Vallegrande, $10 \mathrm{~km}$ NW de Vallegrande, $1820 \mathrm{~m}, 28-\mathrm{I}-1994$, Saravia Toledo 12205 (CTES). Tarija: Prov. Aniceto Arce Ruiz, Comunidad Emboraza, road to Sidra, $22^{\circ} 16^{\prime}$ S, $64^{\circ} 33^{\prime} \mathrm{W}, 25-\mathrm{IV}-1983$, Solomon 10076 (CTES, MO); cerro Pabellón, arriba del poblado Cañas, $21^{\circ} 52^{\prime} \mathrm{S} 64^{\circ} 52^{\prime} \mathrm{W}, 2600 \mathrm{~m}, 15-$ III-1998, Beck et al. 26055 (CTES, LPB). PERÚ. Cajamarca: Prov. Cajamarca, Otuzco, 2700 m, 16VI-1975, Sagástegui et al. 8037 (CTES, HUT); íd., Sánchez V. 1562 (CTES).

Obs.: Son pocas las especies de la sección Sida que presentan pelos simples en ambas caras de la hoja: S. Honoriana, con brácteas bífidas y pelos muy pequeños, $S$. Saraviae sin brácteas bífidas y $S$. magnifolia con hojas hasta $18 \mathrm{~cm}$ long.

Etimología: Esta especie está dedicada a Carlos Saravia Toledo, un buen conocedor de la vegetación del NW argentino y del este de Bolivia, quién participó en la colección del ejemplar tipo.

\section{Sida setosa Mart. ex Colla}

Sida setosa Mart. ex Colla, Herb. Pedem. 1: 416. 1833. Typus: BRASIL. Bahia: Rio Belmonte [ó Jequitinhonha], Martius s.n. (holotypus TO!).

Sida Kohautiana K. Presl, Reliq. Haenk. 2: 108, 1835. Typus: MARTINIQUE: Kohaut s.n. (holotypus PR).

Sida Pohliana K. Presl, Rel. Haenk. 2: 108. 1835. Typus: PERÚ. "in montibus huancorensibus", Haenke s.n. (holotypus PR).

Sida rhombifolia var. Pohliana (K.Presl) E. G. Baker, J. Bot. 30: 239. 1892.

Sida surinamensis Miq. Linnaea 22: 469. 1948. Tipus: Surinam, Hostmann 1079 (isotypi B foto F 9396, K, NY).

Sida rhombifolia var. surinamensis (Miq.) K. Schum., Mart. Fl. bras. 12(3): 339. 1891.

Iconografía: Fryxell, 1992: 111, fig. 12. Fuertes Aguilar, 1995: 111, fig. 20. Krapovickas, 2007: 197, fig. 2, D-G.

Arbusto erecto, hasta $2-3 \mathrm{~m}$ alt. Tallo puberulento a glabro. Estípulas filiformes, 
3-5 mm long. Pecíolos 0,5-1 cm long. Lámina hasta $10 \mathrm{~cm}$ long., elíptica a subrómbica, margen entero en la base y dentado hacia el ápice, puberulenta o glabra. Flores en inflorescencias axilares con pedúnculo ca. 5 cm long. y pedicelos 0,5-2 mm long. Cáliz 6-8 mm long. con 10 costillas basales, puberulento. Pétalos amarillos, poco más largos que el cáliz. Estilos 10-12. Mericarpos $3 \mathrm{~mm}$ long. $\times 2 \mathrm{~mm}$ lat., con dos espinas hasta $6 \mathrm{~mm}$ long., algo curvas, dehiscentes hasta casi la mitad del cuerpo.

Material estudiado: PARAGUAY.Alto Paraná: Puerto Palma, 3-VII-1980, Itaipú Binacional 811 (MO). PERÚ. Amazonas: Huambisa, Valle del río Santiago, 200 m, 20-XII-1979, Tunqui 380 (CTES, MO). Huánuco: cerca Puerto Nuevo, Tulumayo, 600-700 m, 20-VI-1953, Ferreyra 9295 (CTES, USM).

Distribución geográfica: Nicaragua a Paraguay. Vive en zonas selváticas, desde la orilla del mar hasta $2000 \mathrm{~m}$ de altura.

\section{Sida silvaniana Krapov. sp. nov. Fig. 22}

Suffrutex $80 \mathrm{~cm}$ alt. Caule stellato-piloso. Stipulae linearis, $8 \mathrm{~mm}$ long. Petiolus $5 \mathrm{~mm}$ long. Lamina angosto-elliptica, usque $4 \mathrm{~cm}$ long. et $1 \mathrm{~cm}$ lat. Supra pilis stellatis, sparsis, infra stellato piloso. Floribus apicem caulibus congesti. Calyx $7 \mathrm{~mm}$ long. Carpidia 6, pauce reticulata, submutica, $2 \mathrm{~mm}$ longa et $1 \mathrm{~mm}$ lata.

Typus: Brasil. Goiás: Mun. Silvania, Faz. do Sr. Jeová (margem esquerda do ribeirão São Roque, próximo a fóz), $16^{\circ} 17^{\prime} 31^{\prime}$ 'S 48 $24^{\prime} 27^{\prime} \mathrm{W}, 800 \mathrm{~m}$, Area de Influencia Sireta (lago), mata de galeria, solo argiloso, erva com $80 \mathrm{~cm}$ de altura, flor amarela, 2-VI-2003, G. Pereira da Silva et al. 7706 (holotypus $\mathrm{CEN}$, isotypus CTES).

Hierba erecta $80 \mathrm{~cm}$ alt. Tallo cubierto de pelos estrellados $0,5 \mathrm{~mm}$ long. Estípulas filiformes $8 \mathrm{~mm}$ long., con el margen ciliado. Pecíolo $5 \mathrm{~mm}$ long. Lámina angosto-elíptica, hasta $4 \mathrm{~cm}$ long. $\times 1 \mathrm{~cm}$ lat., margen levemente crenado-aserrado en la mitad superior; haz con pelos estrellados de pocas ramas, esparcidos y con pelos simples pequeños en el margen; envés con pelos estrellados blanquecinos, densos. Flores axilares sésiles en el tallo principal, en las ramitas secundarias agrupadas en el ápice con pedicelos hasta $2 \mathrm{~cm}$ long. Cáliz $7 \mathrm{~mm}$ long., con 10 costillas basales prominentes, cubierto de pelos estrellados pequeños y con pelos simples y estrellados mayores hacia el margen, lóbulos $3 \mathrm{~mm}$ long. $\times 4 \mathrm{~mm}$ lat., plegados. Mericarpos 6, submúticos, glabros, apenas dehiscentes en el ápice, $2 \mathrm{~mm}$ long. $\times 1 \mathrm{~mm}$ lat., caras laterales rugosas y dorso reticulado. Semilla glabra, con pocos pelos muy pequeños en el hilo.

Distribución geográfica: Vive en el centro del estado de Goiás y en el sur del estado de Maranhão, Brasil.

Paratypus: BRASIL. Maranhão: Mun. Balsas, Condominio Kissy lote 23, 20-III-1999, PereiraSilva 4124 (CEN, CTES).

Obs.: Es la única especie de la sección Sida con flores solitarias sésiles en el eje principal y en glomérulos en el ápice de ramitas secundarias con una flor basal con pedicelo hasta $2 \mathrm{~cm}$ long. $\mathrm{y}$ el resto con pedicelos muy breves.

Etimología: El nombre deriva del Municipio Silvania, Goiás, donde fue coleccionado el ejemplar tipo.

\section{Sida tuberculata R. E. Fr.}

Kongl. Svenska Vetenskapsakad. 42(12): 33, 1908.

Especie afín a Sida hyssopifolia C. Presl (Fryxell, $2001=S$. collina Schlecht.), de México y Centro América, se distinguen por el tamaño y el tomento del cáliz, 7-10 mm long. y cubierto de pelos estrellados o simples 0,5-1 $\mathrm{mm}$ long. en S. hyssopifolia y de 4-7 mm long., y pubérulo, con algunos pelos simples breves en el margen de los lóbulos, en $S$. tuberculata. Esta afinidad ya la sospechó Fuertes (1995: 121) y es posible que el material que cita para Colombia como $S$. collina corresponda más bien a $S$. tuberculata, cuya variedad pseudorhombifolia vive en Venezuela. 


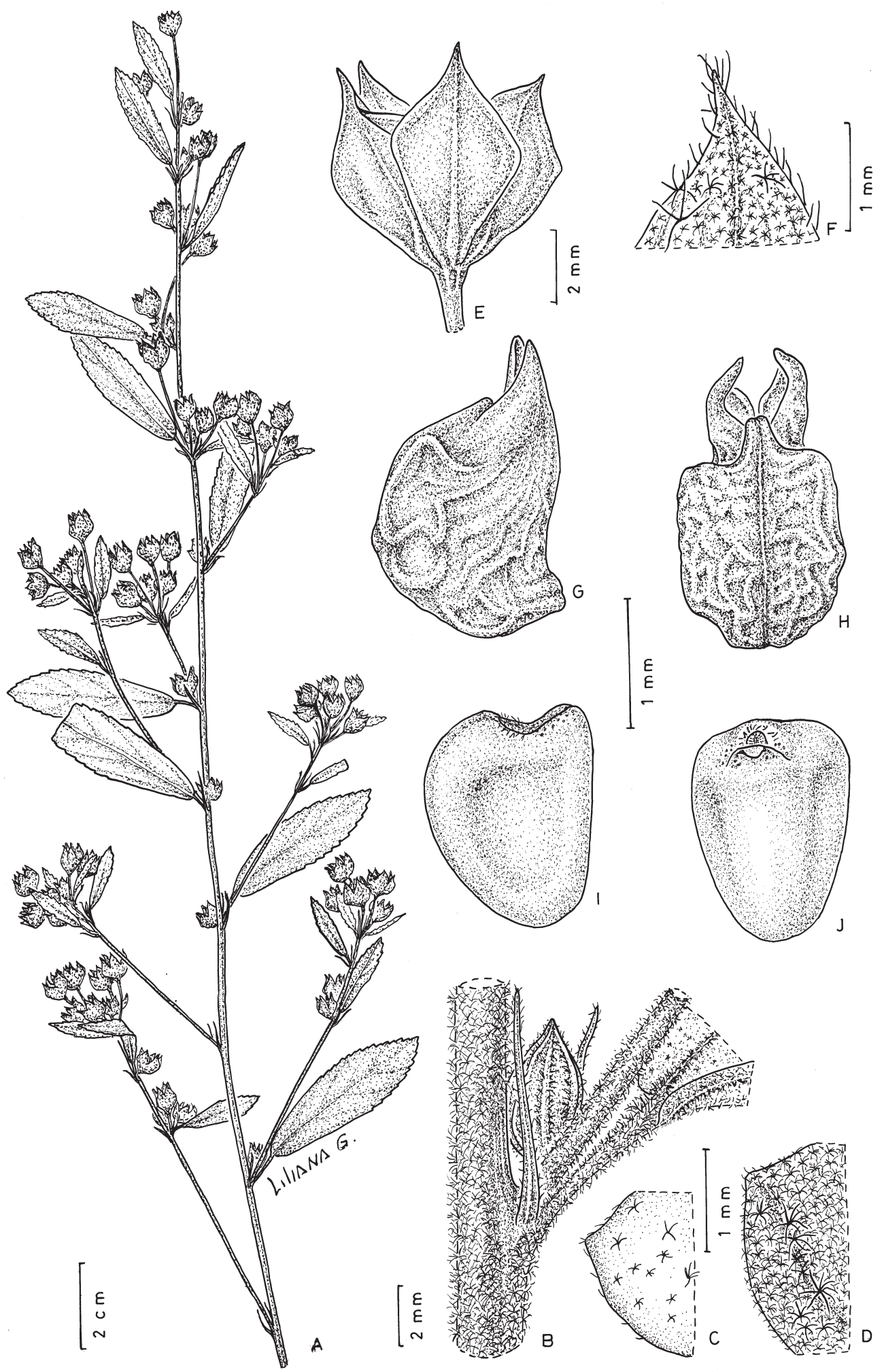

Fig. 22. Sida silvaniana. A: Rama. B: Estípulas. C: Indumento del epifilo. D: Indumento del hipofilo. E: Cáliz. F: Indumento del cáliz. G: Mericarpo, vista lateral. H: Mericarpo, vista dorsal. I-J: Semillas (G. Pereira da Silva 7700 ). 


\section{4a. Sida tuberculata R. E. Fr. var. tuberculata}

Sida tuberculata R. E. Fr., Kung. Svenska Vetenskapsakad. 42(12): 33, Tab. III, fig. 7-9. 1908. Lectoholotypus (aquí designado): BRASIL. Minas Gerais: Caldas, 2155'S 46²0'W, 25-II-1845, Regnell III, $165^{*}(\mathrm{~S})$.

Material estudiado: BOLIVIA. Beni: Prov. Masoré, 7 km S de San Joaquín-Trinidad, 7-XI-1993, Moraes et al. 1624 (CTES, LPB). La Paz: Prov. Iturralde, Luisita, $13^{\circ} 5^{\prime} \mathrm{S}, 67^{\circ} 15^{\prime} \mathrm{W}, 180 \mathrm{~m}, 22-\mathrm{II}-1984$, Beck \& Haase 9903 (CTES, LPB); Prov. Sud Yungas, Yanacachi, 2050 m, 2-IV-1988, Seidel \& Hinojosa 1281 (CTES, LPB). Santa Cruz: Prov. Ichilo, Buena Vista, 400 m, 12-III-1967, Steinbach 828 (CTES); Prov. Sandoval, 3,3 Km W de San Matías, 16²0'42”S, 58'25'21'”, 137 m, 26-I-2005, Solís Neffa et al. 1587 (CTES, LPB); 22,3 km W de San Matías, 16²2'28'S, 5834'23”'W, 143 m, 26-I-2005, Solís Neffa et al. 1620 (CTES, LPB). Tarija: Entre Ríos, 1330 m, 21-V-1971, Krapovickas et al. 19065 (CTES). BRASIL. Amapá: Macapá, 16-III-1980, Rabelo s.n. (CTES, HAMAB 013). Distrito Federal: Bacia do rio S. Bartolomeu, faz Juliana, 15-III-1984, Pereira 931 (CTES, IBGE); Brasilia, UNB, 20-IV-1966, Heringer 11088 (CTES, HB). Goiás: 25 km S of Cristalina, 8-III-1966, Irwin et al. 13804 (CTES, NY); Rio da Prata, vicinity of Posse, 9-IV-1966, Irwin et al. 14537 (CTES, NY). Mato Grosso: Serra do Roncador, $60 \mathrm{~km} \mathrm{~N}$ of Xavantina, 25-V-1966, Irwin et al. 16021 (CTES, NY); Dardanelos, rio Aripuanã, 13-VI-1974, Cordeiro 5 (CTES). Minas Gerais: Poços de Caldas, 15-I-1980, Krapovickas \& Cristóbal 35344 (CTES). Paraná: Vila Velha-Ponta Grossa, 5-IV-1977, Dombrowski 7268 (CTES, MBM). São Paulo: Campinas, 28VII-1966, Krapovickas 12640 (CTES); Carapicuíba, Parnaíba do Sul, 11-III-1959, Hashimoto 616 (CTES, SP); Congonhas, 16-III-1946, W.Hoehne s.n. (CTES, SPF 13451); São Paulo, 2-IV-1974, Silva 265 (CTES, $\mathrm{SP}$; Mun. Botucatu, Gottsberger 21-7471 (CTES); Botucatu, Gottsberger 24-7471 (CTES); $25 \mathrm{~km} \mathrm{SW}$ of Botucatu, Gottsberger 125-13371 (CTES). Tocantins: Ilha do Bananal, Parque Nacional do Araguaia, 24-III1999, da Silva et al. 4116 (CTES, IBGE).

34b. Sida tuberculata R. E. Fr. var. pseudorhombifolia Monteiro

Sida tuberculata R. E. Fr. var. pseudo- rhombifolia Monteiro. Lilloa 17: 522, Lam. VII. 1949. Lectoholotypus (aquí designado): BRASIL. Minas Gerais: Belo Horizonte, 29-I-1934. H. Monteiro 711 (RBR!, isotypus (US!).

Material seleccionado estudiado: ARGENTINA. Corrientes: Dep. Bella Vista, Bella Vista, 3-II-1977, Ahumada 676 (CTES); Dep. Concepción, Estancia Yatay Corá, $28^{\circ} 40^{\prime} \mathrm{S}$, 58¹4'W, 5-XII-1996, Arbo et al. 7097 (CTES); Dep. Empedrado, ayo. Empedrado, 8-III-1950, Schwarz 10051 (CTES, LIL); Estancia Las Tres Marías, 13-III-1966, Pedersen 7729 (C, CTES); Dep. Ituzaingó, Reserva Natural Rincón Santa María, 19-III-2002, Fontana \& Iriart SM405 (CTES, CTESN); Dep. Mburucuyá, ea. Santa Teresa, 3-V-1964, Krapovickas \& Cristóbal 11417 (CTES); ea. Santa María, 14-II-1959, Pedersen 5046 (C, CTES); Dep. Mercedes, 5 km S de Mercedes, 18-XII-1962, Cano 1981 (BAB, CTES); Dep. Monte Caseros, ruta 127 y ayo. Curuzú Cuatiá, 20-II-1979, Schinini et al. 17433 (CTES); Dep. Paso de los Libres, Paso de los Libres, 27-III-1964, Krapovickas \& Cristóbal 11298 (CTES); Dep. San Cosme, ruta 12 km 959, 21-II-1969, Krapovickas \& Cristóbal 14945 (CTES); Dep. San Miguel, 12 km N de San Miguel, 15-III-1978, Ahumada 1885 (CTES); Dep. Santo Tomé, Galarza, 17-XI-1994, Ferrucci et al. 6385 (CTES). Entre Ríos: Dep. Concordia, Concordia, 28-III-1985, Muñoz 2049 (CTES); Dep. Federación, Santa Ana, 21-III1977, Cabrera 28257 (CTES, SI). Misiones: Dep. Cainguás, Mineral, 270 m, 10-III-1958, Montes 27624 (CTES, NY); Dep. Candelaria, Loreto, 220 m, 31-III-1058, Montes 27503 (CTES, NY); Dep. Capital, ruta 12 y ayo. Coatí, 23-I-2007, Keller \& Franco 4919 (CTES); Dep. Concepción, $9 \mathrm{~km}$ NW de Concepción de la Sierra, 11-III1969, Krapovickas et al. 15130 (CTES); Dep. Gral. Belgrano, Campinas de América, 9-II-2007, Keller 4030 (CTES); Dep. San Ignacio, San Ignacio, 31-III-1956, Montes 14938 (CTES, NY); Dep. San Pedro, Campina Barana, 31-III-2007, Keller 4101 (CTES); BOLIVIA. Beni: Prov. Ballivián, Espíritu, río Yacuma, $200 \mathrm{~m}, 21-\mathrm{X}$ 1980, Beck 5240 (CTES, LPB); Prov. Vaca Diez, Guayaramerín, $10^{\circ} 49^{\prime} \mathrm{S}, 65^{\circ} 22^{\prime} \mathrm{W}, 18-\mathrm{IV}-1979$, Krapovickas \& Schinini 35136 (CTES). La Paz: Prov. Sur Yungas, Irupana, 4-VI-1996, Bourdy 1662 (CTES, LPB). Santa Cruz: Prov. Chiquitos, 
Roboré, 1-IV-1959, Krapovickas 10023 (CTES, LIL); Prov. Ñuflo de Chavez, Concepción, $16^{\circ} 15^{\prime} \mathrm{S}, 62^{\circ} 5^{\prime} \mathrm{W}, 30-\mathrm{IV}-1977$, Krapovickas \& Schinini 32036 (CTES). BRASIL. Bahia: Rio de Contas, 14-I-1991, Esteves 2367 (CTES, SPF). Ceará: Serra do Vicente, Capistrano, 13-V-1980, Nunes \& Martins (CTES, EAC 8573). Distrito Federal: Brasilia, 16-V-1982, Krapovickas 38146 (CTES). Goiás: 10 km W of Cristalina, 4-III-1966, Irwin et al. 13451 (CTES, NY, UB). Mato Grosso: Poconé, Porto Cercado, 28-I-1989, Krapovickas \& Cristóbal 43124 (CTES). Mato Grosso do Sul: Ponta Porã, 9-II1993, Hatschbach 58739 (CTES, MBM); BR163, Mundo Novo, 7-II-1993, Hatschbach 58557 (CTES, MBM). Minas Gerais: Mun. Poços de Caldas, Poços de Caldas, Véu das Noivas, 15-I-1980, Krapovickas \& Cristóbal 35345 (CTES). Paraná: Barigui - Curitiba, 8-XII-1971, Dombrowski 3849 (CTES, MBM). Pernambuco: Tapera, 15-IX-1931, Pickel 2770 (CTES). Rio de Janeiro: Vale das Videiras, 20-III-1971, Occhioni 10433 (CTES, RFA). Rio Grande do Sul: Porto Alegra, 11-III-1980, Bueno 2197 (CTES, HAS). Rondonia: $18 \mathrm{~km}$ SE de Pimenta Bueno, $250 \mathrm{~m}$, 22-V-1985, Krapovickas et al. 40159 (CTES). São Paulo: São Paulo, Gottsberger 11-6467 (CTES). PARAGUAY. Alto Paraguay: Cerro León, 20²0'S 60²0'W, 500-600 m, 14-IV-1989, Ramella 2731 (CTES, G). Alto Paraná: 2 km N de Hernandarias, $25^{\circ} 17^{\prime} \mathrm{S}, 5^{\circ} 35^{\prime} \mathrm{W}, 2$-VII-1991, Schinini \& Caballero Marmori 27335 (CTES). Amambay, Mbariguy, $30 \mathrm{~km}$ E de Capitán Bado, 17-II-1959, Gregory \& al. 8677 (LIL); Colonia Yvypyté, $23^{\circ} \mathrm{S}, 56^{\circ} \mathrm{W}, 20-\mathrm{VIII}-1980$, Schinini \& Bordas 20451 (CTES). Caaguazú: $12 \mathrm{~km} \mathrm{~S}$ de

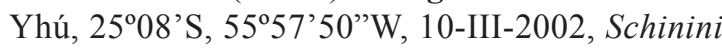
et al. 36163 (CTES). Central: Asunción, Horti Botanici, III-1943, Rojas 10407 (AS, CTES); Itá, Granja Isapy. ayo. Lazarillo, 29-I-1966, Krapovickas et al. 12168 (CTES). Concepción: Valle Mi, $22^{\circ} 11^{\prime}$ S, $57^{\circ} 50^{\prime} \mathrm{W}, 119$ m, 18-X-2000, Kiesling et al. 9755 (CTES, SI). Cordillera: Peribebuy, 6-II-1966, Krapovickas et al. 12451 (CTES); Tobatí, 24-V-1964, Krapovickas \& Cristóbal 11452 (CTES). Itapúa: $16 \mathrm{~km} \mathrm{~N}$ de Cnel. Bogado, $27^{\circ} 7^{\prime} \mathrm{S}, 56^{\circ} 10^{\prime} \mathrm{W}, 21-\mathrm{III}-1993$, Schinini et al. 27644 (CTES). Paraguarí: 10 km $\mathrm{N}$ de Paraguarí, 6-II-1966, Krapovickas et al. 12428 CTES). Pte. Hayes: Ruta Trans-Chaco, km 141, ea. Santa Ana, Taguá, 6-XII-1992,
Krapovickas \& Cristóbal 44174 (CTES); 12 km W de San Ignacio, 15-XI-1978, Arbo et al. 1805 (CTES). URUGUAY. Salto: Ruta 31, by the bridge on r. Itapebí, 1-III-1991, Pedersen 15644 (C, CTES); Termas de Arapey, 3051'42"S, 5741'36”'W, 87 m, 25-II-2001, Seijo et al. 2399 (CTES). VENEZUELA. Guárico: Mesa de El Sombrero, 10-IX-1927, Pittier 12497 (NY); Estación Biológica de Los Llanos, $12 \mathrm{~km}$ SE de Calabozo, $8^{\circ} 56^{\prime} \mathrm{N}, 67^{\circ} 25^{\prime} \mathrm{W}, 75 \mathrm{~m}$, Ramírez 2419 (CTES); íd., 24-IX-1978, Ramírez 017 (CTES). Miranda: Las Mostazas, Los Teques, 963 m, XI-1924, Allart 215 (NY); Baruta, 10001500 m, 21-X-1966, Agostini 677 (NY); Sucre: Cancamure, 18-X-1092, Galantón 045 (CTES, IRBR). Trujillo: Valera, 21-XI-1922, Pittier 10766 (NY).

\section{Sida Weberbaueri Ulbr.}

Sida Weberbaueri Ulbr., Bot. Jahrb. Syst. 54 (Beibl. 117): 68-70. 1916. Typus: PERÚ. "Zwiischen Piura und der Hda. Nomala. 100-250 m". Weberbauer 5959 (B?, isotypus F [foto F 56912], GH).

Distribución geográfica: Noroeste de Perú y en el oeste de Ecuador (Manabí y Guayas), cerca del Océano Pacífico.

Material estudiado: PERÚ. Piura: Hacienda Nomala, Malinguita, Chulucanas, $5^{\circ} 02^{\prime} \mathrm{S}, 80^{\circ} 13^{\prime} \mathrm{W}$, 75 m, 31-1989, Emperaire 5078 (CTES).

\section{Series Viarumae Krapov., ser. nov.}

Sida L. sect. Malvinda grupo Viarumae Moteiro, O genero Sida. Monographia das Malvaceas Brasileiras, fasc. I: 20. 1936. Nombre no válido por falta de descripción latina.

Affine Series Sida, sed carpidia 5.

Especie tipo: Sida viarum A. St.-Hil.

Clave para distinguir las especies de la Series Viarumae:

1. Cáliz $5 \mathrm{~mm}$ long. Planta decumbente, ramificada. 37. S. viarum A. St.-Hil.

1'. Cáliz $10 \mathrm{~mm}$ long. Planta erecta, poco o nada ramificada. 36. S. linearifolia A. St.-Hil. 


\section{Sida linearifolia A. St.-Hil.}

Sida linearifolia A. St.-Hil., Fl. Bras. mer. 1: 180. 1827. "Minas Geraes quam vocant Certao prope Contendas". Holotypus: "Donné par le ami de Contendas Ant. Nogueira Duarte" P! (foto F 35539). [Santa Ana de Contendas = Brasilia de Minas, ca. $\left.16^{\circ} \mathrm{S} 44^{\circ} \mathrm{W}\right]$.

Hierba erecta, poco ramificada, hasta $1 \mathrm{~m}$ alt. Estípulas lanceoladas a lineares, 7-12 mm long., persistentes. Pecíolo 3-5 $\mathrm{mm}$ long. Lámina linear-lanceolada, hasta 5 $\mathrm{cm}$ long. $\times 10 \mathrm{~mm}$ lat., margen aserrado en la mitad superior, discolora, haz con pelos simples, adpresos, envés canescente con pelos estrellados pequeños, densos. Flores solitarias, axilares, a veces con un pequeño rámulo en la axila. Pedicelo 1-1,5 cm long. Cáliz 10 $\mathrm{mm}$ long. con 10 costillas sobresalientes basales, hirsuto. Pétalos $11 \mathrm{~mm}$ long., blancos o cremosos con mancha roja basal. Carpelos 5 . Mericarpos 2-2,5 long. $\times 2$ mm lat., múticos, caras laterales y dorso reticulados. Semilla glabra.

Material seleccionado estudiado: BOLIVIA. La Paz: Prov. Iturralde, Luisita, $13^{\circ} 5^{\prime} \mathrm{S}, 67^{\circ} 15^{\prime} \mathrm{W}$, 180 m, 26-II-1984, Beck \& Haase 10043 (CTES, LPB). Santa Cruz: Prov. Ñuflo de Chavez, Concepción, $16^{\circ} 15^{\prime} \mathrm{E}, 62^{\circ} 5^{\prime} \mathrm{W}, 29-\mathrm{IV}-1977$, Krapovickas \& Schinini 31999 (CTES); Prov. Sandoval, $3 \mathrm{~km}$ E de San Matías, 18-IV-1980, Krapovickas \& Schinini 36248 (CTES); Prov. Velasco, $15 \mathrm{~km} \mathrm{~S}$ de San Rafael, 16 ${ }^{\circ} 54^{\prime} \mathrm{S}, 60^{\circ} 37^{\prime} \mathrm{W}$, 1-II-2005, Solis Neffa et al. 1748 (CTES); 16 km SE de San Ignacio, 19-IV-1988, Bruderreck 358 (CTES, LPB). BRASIL. Bahia: $32 \mathrm{~km}$ of Barreiras, Espigão Mestre, $600 \mathrm{~m}$, 5-III-1971, Irwin et al. 31544 (CTES, NY). Distrito Federal: Brasilia, 19-II-1966, Irwin et al. 12990 (CTES, NY). Goiás: $6 \mathrm{~km}$ E de Morrinhos, 29-I-1978, Krapovickas et al. 33266 (CTES); $30 \mathrm{~km}$ de Couto Magalhaes, 11I-1974, Rizzo 9542 (CTES, UNG). Mato Grosso: 3,5 km de Barra dos Bugres, $130 \mathrm{~m}, 1-\mathrm{VI}-1985$, Krapovickas et al. 40264 (CTES); Chapada dos Guimarães, 850 m, 2-II-1995, Dubs 1831 (CTES, E, ESA, K, Z); Barra do Garças, 24-III-1997, Arbocz s.n. (ESA 39173, CTES). Mato Grosso do Sul: Mun. Campo Grande, río Abhndui, 12-VII-1960, Hatshbach 21805 (CTES, MBM). Minas Gerais: entre Frutal y Campina Verde, 3-IV-1951, Gregory et al. 10111 (CTES, LIL). São Paulo: San Carlos, 18-I-1834, Riedel 1955 (P); Mun. Barbosa, SP 425, $9 \mathrm{~km} \mathrm{~S}$ de río Tieté, 18-I-1978, Krapovickas et al. 33032 (CTES). PARAGUAY. Amambay: Colonia Santa Clara, Cerro Corá, 18-XII-1999, Ferrucci et al. 1690 (CTES). PERÚ. San Martín: Ricuricocha, Tarapoto, 860 m, II-1947, Woytkowski 15524 (CTES, USM).

Distribución geográfica: Vive en Perú, Bolivia, Paraguay y Brasil (BA, DF, GO, MG, SP, MS, MT), principalmente en campos cerrados y en el borde de caminos.

\section{Sida viarum A. St.-Hil.}

Sida viarum A. St.-Hil., Fl. Bras. mer. 1: 182. 1827. "Minas Geraes dictae Comarca do Rio das Mortes ad margines viarum haud infrequens". Typus: Brasil. "Comarca do Rio das Mortes, Januario-Martio", St. Hilaire s.n. (holotypus MPU!), (isotypus? S. João del Rey, St. Hilaire Catal. $D n^{\circ} 352$, P!).[São João del Rey está sobre el Rio das Mortes].

Iconografía: Monteiro, 1936, tab. II, fig. 2, Rodrigo, 1944, figs. 19 (4) y 20.

Hierba decumbente, ramificada, 0,40-1 m alt. Estípulas rígidas, lineares, 8-10 mm long., persistentes hasta después de la caída de las hojas. Pecíolo breve, 3-4 mm long. Lámina lanceolada, angosta, 15-40 mm long. $\times$ 5-8 $\mathrm{mm}$ lat., discolor, trinervada, margen ciliado, liso en la mitad inferior y en la superior con dientes poco profundos, haz con pelos simples espaciados, envés verde claro, con pelitos cenicientos muy compactos. Flores subsésiles, solitarias o en glomérulos axilares. Pedicelos 1,5-6 mm long. Cáliz 5-7 mm long. con 10 costillas basales, sobresalientes, ciliado. Pétalos 7-9 mm long. $\times 5 \mathrm{~mm}$ lat., blancos o crema con la base rojiza, uña ciliada. Ovario 5-carpelar. Mericarpos 2,5 mm long. $\times 2 \mathrm{~mm}$ lat., subglobosos, múticos o submúticos, reticulados, glabros. Semilla glabra. Cromosomas $2 \mathrm{n}=14$.

Material seleccionado estudiado: 
ARGentinA. Chaco: Dep. $1^{\circ}$ de Mayo, Colonia Benítez, 17-I-1954, Schulz 8629 (CTES). Corrientes: Dep. Concepción, Carambola, 10-III1982, Pedersen 13361 (C, CTES); Dep. General Paz, General Paz, 1-I-1966, Krapovickas \& Cristóbal 11835 (CTES); Dep. Ituzaingó, 12 km E de Ituzaingó, ruta 12, 15-I-1966, Krapovickas \& Cristóbal 12005 (CTES); Dep. Mburucuyá, Estancia Santa Teresa, 10-II-1968, Krapovickas \& Cristóbal 13788 (CTES); Dep. Saladas, Estancia "La Amistad", 9-II-1950, Schwarz 9633 (CTES, LIL); Dep. San Martín, Tres Cerros, Co. Pelón, 15-II-1979, Schinini et al. 17138 (CTES); Dep. San Miguel, 12 km NE de San Miguel, 4-III-1990, Vanni et al. 1712 CTES); Dep. Santo Tomé, Ruta 12 , camino a Colonia Liebig, $27^{\circ} 55^{\circ} 56^{\prime} \mathrm{W}, 22-\mathrm{XI}-$ 2002, Schinini 36251 (CTES). Misiones: Dep. Cainguás, Puerto Rico, 19-II-1948, Schwindt 598 (CTES, LIL). Dep. Candelaria, Loreto, $27^{\circ} 18^{\prime} \mathrm{S}$, 553'ㄴ, 128 m, 28-II-2011, Keller \& Paredes 9905 (CTES); Dep. Capital, ayo. Itaembé, ruta 12, 17-I-1966, Krapovickas \& Cristóbal 12100 (CTES); Dep. San Ignacio, San Ignacio, 120 m, 27ำ $16^{\prime} \mathrm{S}, 55^{\circ} 33^{\prime} \mathrm{W}, 18 \mathrm{III}-2002$, Múlgura de Romero et al. 3459 (CTES, SI). BOLIVIA. Beni: Prov. Ballivián, San Borja, 14²51'S, 66 $57^{\circ}$ W, 12IV-1979, Krapovickas \& Schinini 34891 (CTES). Santa Cruz: Prov. Chiquitos, $55,9 \mathrm{~km} \mathrm{~W}$ de Roboré, $382 \mathrm{~m}, 18^{\circ} 06^{\prime} \mathrm{S}, 60^{\circ}{ }^{\circ} 5^{\prime} \mathrm{W}, 8-\mathrm{II}-2005$, Solís Neffa et al. 1920 (CTES, LPB); Prov. Ñuflo de Chavez, $24 \mathrm{~km} \mathrm{~W}$ de Concepción, $600 \mathrm{~m}, 16^{\circ} 14$ 'S, 6214'W, 3-V-1977, Krapovickas \& Schinini 32180 (CTES); Prov. Sandoval, Santo Corazón, 460 m, 3-V-1997, Fuentes \& Cabrera 1889 (CTES; USZ); Prov. Velasco, Parque Nacional Noel Kempff M., 259 m, 14³6'S, 6051'W, 1-V1994, Gutiérrez et al. 647 (CTES, MO, USZ). BRASIL. Bahia: $5 \mathrm{~km}$ W of Cocos, $530 \mathrm{~m}, 17-\mathrm{III}-$ 1972, Anderson et al. 37105 (CTES, NY). Distrito Federal: Reserva Biológica do IBGE, 1556'S, 47053'W, 1100 m, 18-IV-1995, Aparecida da Silva 2549 (CTES, IBGE). Goiás: $3 \mathrm{~km} \mathrm{~S}$ of São João da Aliança, 850 m, 15-III-1971, Irwin et al. 31285 (CTES, NY). Mato Grosso do Sul: Mun. Porto Murtinho, Reserva Indigena Cadiéus, 13-III-2003, Hatschbach et al. 74679 (CTES, MBM). Minas Geraes: Mun. Formoso, Parque Nacional Grande Sertão Veredas, 710 m, $15^{\circ} 18^{\prime}$ S, 455'ㄱ' 18-II-1999, Mendonça 3856 (CTES, IBGE). Pará: Estreito-Marabá, km 1, 4-IV-1974, Pinheiro \& Carvalho 48 (CTES). Paraná: Mun.
Ponta Grossa, Parque V. Velha, Furnas, 25-II1967, Hatschbach 16075 (CTES, MBM). Piauí: Mun. Corrente, BR-135, $500 \mathrm{~m} \mathrm{~S}$ da ponte sobre o rio Corrente, $450 \mathrm{~m}, 10^{\circ} 27^{\prime} \mathrm{S}, 45^{\circ} 9^{\prime} \mathrm{W}$, 4-IV1083, Krapovickas et al. 38728 (CEN; CTES); Rio Grande do Sul, Tramandaí, 6-III-1950, Rambo 46121 (CTES, LIL); Santa Catarina, Cachoeira do Bom Jesus, 10 m, 19-XI-1969, Klein 8450 (CTES, FLOR, HBR); São Paulo: Itu, 7-I-1962, Grotta 279 (CTES, SPF). Tocantins: Mun. Conceição do Tocantins, Rod. TO-050, km 375, río Santa Isabel, $400 \mathrm{~m}, 11-\mathrm{V}-2000$, Hatschbach et al. 70891 (CTES, MBM). PARAGUAY. Amambay: 45 km S de Bella Vista, 26-II-1994, Krapovickas \& Cristóbal 45041 (CTES). Caaguazú: $15 \mathrm{~km}$ $\mathrm{N}$ de Caaguazú, 8-II-1966, Krapovickas et al. 12566 (CTES). Canendiyú: 13 km S de Ipé-Hú, 3-XII, 1997, Schinini \& Dematteis 33274 (CTES). Cordillera: cerros de Tobaty, Hassler 6392 (P). Guairá: Villarica, 28-V-1985, Bordas 4119 (CTES). Itapúa: $15 \mathrm{~km}$ SE de General Delgado, 15-XI-1978, Arbo et al. 2248 (CTES). Misiones: Ayolas, $27^{\circ} 25^{\prime} \mathrm{S}, 56^{\circ} 50^{\prime} \mathrm{W}, 2-\mathrm{II}-1988$, Schinini \& Vanni 25948 (CTES). Paraguarí: Valle Apu'a, Cía. Achotei, $25^{\circ} 59^{\prime} \mathrm{S}, 5^{\circ} 24^{\prime} \mathrm{W}, 7-\mathrm{XI}-2000$, Mereles et al. 8139 (CTES, FCQ); San Pedro, 36 km N de San Estanislao, 18-II-1968, Krapovickas et al. 13973 (CTES). VENEZUELA. Bolívar: 78 $\mathrm{km} \mathrm{SW}$ of Caicara del Orinoco, $7^{\circ} 10-15^{\prime} \mathrm{N}, 6^{\circ} 25$ 30’W, 80 m, 4-IX-1985, Steyermark et al. 131312$A$ (CTES, MO). Guárico: Calabozo, 12-XI-1988, Zypman 9 (CTES). Portuguesa: Guanare, $200 \mathrm{~m}$, 6-XI-1984, Aymar 3111 (CTES, PORT).

Distribución geográfica: Vive en Venezuela, Brasil, desde Pará a Rio Grande do Sul, Bolivia, en el Beni y en Santa Cruz, Paraguay Oriental y NE de Argentina, en Misiones, Chaco y Corrientes. También fue coleccionada en México (Fryxell, 1988). Por lo común prefiere borde de caminos, como su nombre lo sugiere. Llega a los 1100 m s.n.m. en Brasilia.

Obs.: Fryxell (1988: 377) ubica a Sida viarum en la sección Spinosae, por tener frutos con 5 carpelos, pero sus hojas con el margen dentado en la parte superior y el cáliz con 10 costillas sobresalientes en la base la hacen más parecida a las especies de la sección Sida. 


\section{Agradecimientos}

A la Lic. Sara G. Tressens por la lectura crítica del manuscrito y a Mirta Liliana Gómez por las ilustraciones de las especies, en especial por los detalles de las mismas.

\section{Bibliografía}

BAKER, E. G. 1892. Synopsis of Genera and Species of Malveae. XVII. Sida. J. Bot. 30: 138-142, 235-240, 290-296, 324-332.

BRITTON, N. L. \& A. BROWN.1913. An illustrated flora of the United States, Canada, etc. 2d. ed. 3 vols. New York: Charles Scribner's Sons.

BUENO, O. L. 1979. Duas novas citaçoes de Sida (Malvaceae) para o estado do Rio Grande do Sul. Anais sa Sociedade de Botánica do Brasil (XXX Congresso Nacional de Botánica, Campo Grande, MS- 21 a 27 de janeiro. Pp. 83-84.

CLEMENT, I. D. 1957. Studies in Sida (Malvaceae). Contr. Gray Herb. 180: 1-91.

FRYXELL, P. A. 1985. Sidus sidarum - V. The North and Central American species of Sida. Sida 11: $62-91$.

1988. Malvaceae of Mexico. Syst. Bot. Monogr. 25: $1-522$.

- 1992. Malvaceae. En G. Harling \& L. Andersson (eds.), Flora of Ecuador 44: 3-142.

—. 2001. Malvaceae. En V. C. Hollowell (ed), Flora de Nicaragua. Monogr. Syst. Bot. Missouri Bot. Gard. 85 (2): 1293-1322

— A. KRAPOVICKAS \& D. CREWZ. 1984. Sidus sidarum IV. A new record of Sida in North America, Sida santaremensis. Sida 10: 329-320.

FUERTES AGUILAR, F. J. 1995. Sida L. (Malvaceae). En S. Díaz Piedrahita \& al.(eds.), Flora de Colombia 17: 1-142.

HUTCHINSON, J. 1967. Family 119, Malvaceae: 536567 in The Genera of Flowering Plants. Vol. 2. Oxford University Press.
JARVIS, C. H, 2007. Order out of Chaos: Linnaean plant names and their types. 1 vol.: 847 . The Linnean Society of London and Natural History Museum: London. 1016 pp.

KEARNEY, T. H. 1954. A tentative key to the North American species of Sida L. Leafl. W. Bot. 7: 138-150. 1958. A. tentative key to the South American species of Sida L. Leafl. W Bot. 8: 249-270.

KRAPOVICKAS, A. 2007. Novedades en el género Sida (Malvaceae, tribu Malveae). Bonplandia 16: 193-208.

MARAIS, W. 1983. Notes on Mascarene Malvaceae. Kew Bull. 38: 38-41.

MONTEIRO FILHO, H. da C. 1936. Monographia das Malvaceas Brasileiras. Fasc. I. O genero Sida; Revisão das especies brasileiras. $1^{\mathrm{a}}$ Partes. Chave das especies sul americanas e novedades brasileiras. Rio de Janeiro: Ministério da Agricultura. Pp . 1-56.

- 1942. Sida sul-riograndenses. 1 parte. Chaves das espécies. Ministério da Agricultura. Escola Nacional de Agronomía. 10 pp.

_ _ 1949. As especies argentinas, brasileiras e uruguayas da secção Malvinda do genero Sida (Malvaceas). Lilloa 17: 501-522.

RODRIGO, A. del P. 1944. Las especies argentinas y uruguayas del género Sida (Malvaceae). Revista Mus. La Plata, Secc. Bot. 6: 81-212.

SCHUMANN, K. 1891. Malvaceae. En C. F. P. Martius, Flora bras. 12(3): 254-455.

SIVARAJAN, V. V. \& A. K. PRADEP. 1994. Taxonomy of the Sida rhombifolia (Malvaceae) complex in India. Sida 16: 63-78.

SIVARAJAN, V. V., A. K. PRADEP \& J. GEORGE. 1992. Mericarp morphology of Indian species of Sida L. (Malvaceae) in relation to taxonomy. J. Taiwan Mus. 45: 65-73.

UGBOROGHO, R. E. 1980. The taxonomy of Sida L. (Malvaceae) in Nigeria II. The S. rhombifolia complex. Bol. Soc. Brot., ser. 2, 54: 65-85.

VERDCOURT, B. 2004. The variation of Sida rhombifolia (Malvaceae) in East Africa. Kew Bull. 59: 233-239.

Original recibido el 1 de octubre de 2013; aceptado el 12 de noviembre de 2014. 


\section{Índice de Nombres}

Acuminitae 66

Acutae 66

Allosidastrum 66

Angustissimae 66

Bastardiopsis 66

Billieturnera 66

Cordifolia 66

Cordifoliae 66

Decumbentae 66

Dendrosida 66

Glutinosae 66

Krapovickasia 66

Malvaceae 65

Malvella 66

Meximalva 66

Oligandrae 66

Potentilloides 66

Rhombifoliae 66

Rhynchosida 66

Robinsonella 66

Rubifoliae 66

S. abadiana sp. nov. 65, 67, 68, 69

S. acrantha $66,67,71,79,81$

S. adrianopolitana sp. nov. $65,67,80,82,83$

S. albinervia sp. nov. $65,67,79, \mathbf{8 2}, 84$

S. alnifolia 65

S. ambatense sp. nov. $65,67,79, \mathbf{8 5}, 86$

S. arcuata sp. nov. $65,67, \mathbf{6 8}, 70,71,74$

S. Beckii 67, 79, 87

S. blepharoprion 67,71

S. bortolanensis sp. nov. $65,67,71,72$

S. Bradei 90

S. carandana sp. nov. $65,67,79, \mathbf{8 7}, 88,94,97$

S. collina 109

S. cruziana sp. nov. $65,67,71,73,74$

S. farroupilhensis sp.nov. 65, 67, 80, 87, 89

S. Glaziovii 67, 81, 90

S. Heringeri sp. nov. 65, 67, 80, 90, 91, 92

S. Honoriana 67, 80, 92, 99, 101, 108

S. hyssopifolia 109

S. ignaciana sp. nov. 65, 67, 80, 92, 93

S. incerta 97

S. Kelleri sp. nov. 65, 67, 79, 94, 95, 99

S. Kohautiana 108

S. Kranzii sp. nov. 65, 67, 81, 94, 96, 97

S. Leitaofilhoi 67, 79, 97

S. linearifolia $67,112,113$

S. linifolia 71

S. lonchitis 67, 81, 97

S. loretana sp. nov. 65, 67, 81, 97, 98, 99

S. magnifolia sp. nov. 65, 67, 80, 99, 100, 108

S. palustris $s p$. nov. $65,67,81, \mathbf{1 0 1}, 102$

S. piraporana sp. nov. $65,67,74,75$

S. Poeppigiana 67, 80, 92, 101, 103, 104

\section{S. Pohliana 108}

S. ramoniana sp. nov. $65,67,79,99, \mathbf{1 0 4}, 105$

S. rhombifolia 65, 66, 67, 79, 85, 99, 103, 104, 106

S. rhombifolia var. Poeppigiana 101

S. rhombifolia var. Pohliana 108

S. rhombifolia var. subtomentosa 106

S. rhombifolia var. surinamensis 108

S. rhombifolia var. surinamensis $f$. Sampaioi 92

S. Santosii sp. nov. 65, 67, 76, 77

S. santaremensis $67,81,90,99,106$

S. Saraviae sp. nov. 65, 67, 80, 106, 107, 108

S. setosa 67, 80, 82, 103, 108

S. silvaniana sp. nov. 65, 67, 80, 109, 110

S. subcuneata 81,82

S. subcuneata var. acrantha 81

S. surinamensis 108

S. tapiraguensis sp. nov. 65, 67, 76, 78

S. tuberculata 80, 87, 109, 111

S. tuberculata var. pseudo-rhombifolia 67, 80, 109, 111

S. tuberculata var. tuberculata 80,111

S. urosepala 81,82

S. viarum $67,68,112,113,114$

S. Weberbaueri 79, 112

sect. Abutilastrum 66

sect. Bastardiopsis 66

sect. Calyxhymenia 66

sect. Cordifoliae 66

sect. Disticophylla 66

sect. Ellipticifoliae 66

sect. Hookerianae 66

sect. Malachroideae 66

sect. Malvinda 66, 112

sect. Muticae 66

sect. Nelavaga 66

sect. Oligandrae 66

sect. Physalodes 66

sect. Pseudomalachra 66

sect. Pseudomalvastrum 66

sect. Pseudo-Napaeae 66

sect. Sida 65, 66, 71, 76, 87, 101, 104, 108, 109, 114

sect. Spinosae 66, 114

sect. Steninda 66

sect. Thirsinda 66

ser. Biapiculata 66,71

ser. Bifurcata 66, 67, 76

ser. Sida 66, 79, 112

ser. Viarum 71

ser. Viarumae ser. nov. 66, 112

Serratae 66

Sida 65, 66, 92, 112

Sidastrum 66

Spinosae 66

Subcuneatae 66

subsect. Distichaefolia, 66 
subsect. Oligandrae 66

subsect. Pentacocca 66

subsect. Polycocca 66

Urentae 66

Viarumae 66, 112

\section{Lista de coleccionistas}

Agostini, G. 677 (34b).

Ahumada, O. 676 (34b), 1885 (34b), 4183 (31), $5256(31)$.

Ahumada, O \& J.J. Agüero, 8580 (31).

Allart, A. 215 (34b).

Alston, A.H.G. 6428 (27).

Anderson, W.R. \& al. 37105 (37).

Aparecida da Silva, M. 2549 (37).

Araujo, A. et al. 233 (27).

Arbo, M.M. et al. 1805 (34b), 2248 (37), 4012 (22), 4015 (9), 7097 (34b).

Arbocz, G.F. et al. ESA 39173 (36).

Asplund, E. 8506 (27).

Aymard, G. \& F. Ortega 4242 (27), ( 4923 (27).

Baitello, J.B. 541 (18).

Balansa, B. 1617 (30).

Balcazar, J. \& P. Franco (31).

Barreto, K.D. et al. 2185 (18).

Beck, S.G. 2170 (27), 3655 (27), 3994 (27), 4774 (27), 5240 (34b), 8341 (27), 11308 (27), 26055 (31). 33051 (13).

Beck, S.G. \& R. Haase, 9903 (34a), 10043 (36).

Bernacci, L.C. et al. 1243 (18), 1434 (18).

Biurrum, P. et al. 4668 (31).

Bordas, E. 4119 (37).

Bourdy, G. 1662 (34b).

Brade, A.C. 5558 (9), 6864 (16), 7356 (16).

Breteler, F.J. 3984 (27).

Bueno, O. 676 (15), 1915 (15), 1090 (15), 2197 (34b), 4601 (15), 4673 (15).

Cabrera, A.L. 19052 (31), 21582 (12), 21612 (31), 28257 (34b).

Candia, D. 38 (11).

Cano, P. 1981 (34b).

Casas Opaza, M.O. 32 (31).

Cerón, C.E. \& J. Ayala 10028 (27).

Charpin, A. \& F. Jacquemoud 13328 (27).

Coehlho, C.T.F. 734 (9).

Cordeiro, M. dos R. 5 (34a).

Costa, B.M. da 49A (30).

Dodson, C.H. \& L.B. Thien 2088 (27).

Dombrowski, L.T.D. 3849 (34b), 7268 (34a).

Dubs, B. 1831 (36).

Emperaire, L. (35).

Esteves, G.L. 2367 (34b).

Ferrucci, M.S. et al. 894 (27), 1690 (36), 1841 (14),
1946 (27), 1947 (27), 2001 (27), 6385 (34b).

Fortunato, R.H. 1842 (27).

Fuentes, A. \& C. Cabrera 1889 (37).

Fryxell, P.A. \& G. Aymard 4242 (27).

Fryxell, O.A. \& C.L. Burandt 4382 (27).

Glantón, N. 045 (34b).

Gaudichaud, C. 938 (23), 1833 (23).

Glaziou, A. 14510 (16), 18138 (9).

Gottsberger, G.K. 11-6467 (34b), 21-7471 (34a), 24-7471 (34a), 125-13371 (34a).

Gregory, W.C. \& al. 8677 (34b). 10111 (36).

Grotta, A.S. 279 (37).

Gutiérrez, E. et al. 647 (37).

Haenke,T.P.X. s.n. (32).

Hashimoto, G. 616 (34a).

Hassler, E. 6392 (37).

Hatschbach, G. 16075 (37), 16151 (18), 20875 (23), 21042 (23), 21805, 31814 (18), 34404 (18), 43838 (25), 58557 (34b), 58739 (34b),63162 (1), 64620 (6), 70891 (37), 74670 (37).

Heringer, E.P. 5599 (18), 7636 (17), 8130 (18), 11088 (334a), 11108 (25). 16708 (36).

Herrera 221 (31).

Hilgert, N. 1982 (31).

Hoehne, W. 3450 (18), 11524 (9), 13449 (18), 13450 (18), 13451 (34a), 17338 (18).

Holm-Nielsen, L.B. \& S. Jeppesen 44 (27).

Hostmann. F.W. 1079 (32).

Hunziker, A.T. \& T.E. Di Fulvio 12101 (12), 21161 (12).

Imaguire, N. 486 (18), 749 (18).

Irwin, H.S. 10710 (23), 12990 (36), 13451 (34b), 13804 (34a), 14537 (34a), 16021 (34a), 21243 (36), 30607 (9), 31544 (36). 31825 (37).

Keller, H.A. 4030 (34b), 4101 (34b), 4641 (31).

Keller, H.A. \& al. 644 (20), 1604 (18), 2153 (18), 2856 (18), 10964 (20).

Keller, H.A. \& M Franco, 4919 (34b), 5850 (37).

Keller, H.A. \& C.J.Keller. 9700 (20), 10817 (19).

Keller, H,A, \& N.G. Paredes, 8365 (24), 8623 (19), 9809 (28), 9905 (37), 10825 (28).

Kiesling, R. et al. 9755 (34b).

Kirizawa, M. et al. 3062 (18).

Klein, R.M. 9450 (37).

Kohaut, F. s.n. (32).

Kranz, W. 453 (21), 491 (21), 495 (21).

Krapovickas, A. 4796 (31), 10023 (34b), 12640 (34a), 34642 (14), 38146 (34b), 46762 (27).

Krapovickas, A. et al. 12168 (34b), 12428 (34b), 12451 (34b), 12566 (37), 13918 (8), 13973 (37), 14186 (20), 15130 (34b), 18855 (12), 18858 (12), 19065 (34a), 23243 (23), 27925 (31), 27942 (12), 28261 (31), 33032 (CTES), 33266 (CTES), 40159 (34b), 40264 (36).

Krapovickas, A. \& C.L. Cristóbal, 11298 (34b), 11417 (34b), 11452 (34b), 12005 (37), 12100 
(37), 14945 (34b), 15338 (31), 13788 (37), 35329 (23), 35344 (34a), 35345 (34b), 35364 (4), 33440 (22), 35400 (23), 35500 (18), 37108 (31), 38166 (27), 38168 (27), 38444 (23), 38728 (37), 42762 (2), 43124 (34b), 44174 (34b), 45041 (37).

Krapovickas, A. \& R.H. Fortunato, 43928 (14), 43944 (31).

Krapovickas, A. \& A. Schinini, 30711 (31), 31999 (36), 32036 (34b), 32038 (14), 32180 (37), 32266 (5), 34891 (37), 35136 (34b), 36248 (36) 38219 (15).

Krapovickas, A \& R.A.Vanni, 39505 (31).

Leitão Filoho, H.de F. et al. 9649 (22).

Lewis, M. 35133 (31).

Linnaeus, C. 866.3 (29).

Lorentz, P.G. 278 (31).

Martius, C.F.P. von, s.n. (32).

Mendonça, R.C. \& al. 3856 (37).

Mereles, F. \& al. 8139 (37).

Monteiro, H. 711 (34b).

Montes, J.E. 14938 (34b), 27503 (34b), 27624 (34b).

Moraes, M. et al. 1624 (34a).

Múlgura de Romero, M.E. et al. 3459 (37).

Muñoz, J.D. (34b).

Nunes, E \& P. Martins, 8573 (34b).

Oliveira, A.M. 73 (22).

Occhioni, P. 808 (9), 849 (23), 5421 (23), 10433 (34b).

Pedersen, T.M. 5046 (34b), 7729 (34b), 13361 (37), 15644 (34b).

Pereira da Silva, G. 7706 (33).

Pickel, B.J. 2770 (34b), 5259 (18).

Pinheiro, G.S. \& J.F. Carvalho 48 (37).

Pinto, G.C.P. 278/81 (9).

Pittier, H.F. 10766 (34b), 12497 (34b).

Poeppig, E.F. 45 (27).

Rambo, B. 46121 (37).

Ramella, L. 2731 (34b).

Ramírez, N. 017 (34b).

Ramos, J.E. \& L.H. Ramos, 4533 (27), 4732 (27).

Ramos, J.E. \& C. Reina 3531 (27).

Rapini, A. et al. 85 (18).

Regnell, A.F. III, 165 (34a).

Reitz, P.R. \& R.M. Klein, 6248 (23), 12263 (23).

Ribas, O.S. et al. 5126 (18).

Riedel, L. 1955 (36).
Risso, J. 522 (12).

Rizzo, J.A. 9542 (36).

Rojas, T. 10407 (34b).

Sagastegui, A. et al. 8037 (31).

Saint Hilaire, A. de. s.n. foto F 35544 (9).

Saldías, M \& F. Claros 4478 (27).

Sampaio, A. J. de 1965 (18).

Sánchez V., I. 1562 (31).

Santos, T.S. 1937 (7).

Saravia Toledo, C. et al. 12205 (31), 13128 (12), 13387 (12), 13968 (31).

Savassi, A.P. et al. 268 (18).

Schinini, A. 36241 (37).

Schinini, A. et al. 177138 (37), 17433 (34b), 24301 (26), 27644 (34b), 36163 (34b).

Schinini, A. \& E. Bordas 20451 (34b).

Schinini, A. \& G. Caballero Marmori 27335 (34b).

Schinini, S. \& M. Dematteis 333274 (37).

Schinini, A. \& C.Saravia Toledo \& R.Neumann 34766 (31).

Schinini, A. \& R. Vanni 25948 (37).

Schmit, J.P. 118 (27).

Schulz, A.G. 8629 (37).

Schwartz, G.J. 9633 (37), 10051 (34b).

Schwindt, E. 598 (37).

Seidel, R. \& I. Hinojosa 1281 (34a).

Seijo, J.G. et al. 2399 (34b).

Sello, F. s.n. foto F 9367 (9).

Silva, J.S. 265 (34a).

Silva, M.A. da, 4116 (34a).

Silva, J.M. \& L. M. Abe 4168 (10).

Silverstone-Sopkin, P.A. \& R. Clavijo 8239 (27).

Silverstone-Sopkin, P.A. \& N. Paz, 6755 (27).

Solís Neffa, V. et al. 1587 (34a), 1748 (36), 1620 (34a), 1920 (37).

Solomon, J.C. et al. 10076 (31), 11921 (27), 17821 (27).

Sota, E.R. de la 4343 (31).

Steinbach, R.F. $51 b$ (31), 828 (34a).

Stergios, B.G. \& R. Caracas 19016 (27).

Steyermark J.A. et al. 131312-A (37).

Stuessy, T.F. 5821 (27).

Tameirāo Neto, 246 (9).

Vanni, R. 1712 (37).

Viegas, A.P. 3952 (9).

Woytkowski, F. 15524 (36).

Zak, V. \& J. Jaramillo 3469 (27).

Zypman, S. 9 (37). 